University of San Diego

Digital USD

1999-05-01

\title{
The Relationship of Principal Leadership Styles and School-Site Conditions to Stress Levels of Elementary School Teachers
}

Mark Nicholas Remy EdD

University of San Diego

Follow this and additional works at: https://digital.sandiego.edu/dissertations

Part of the Leadership Studies Commons

\section{Digital USD Citation}

Remy, Mark Nicholas EdD, "The Relationship of Principal Leadership Styles and School-Site Conditions to Stress Levels of Elementary School Teachers" (1999). Dissertations. 657.

https://digital.sandiego.edu/dissertations/657

This Dissertation: Open Access is brought to you for free and open access by the Theses and Dissertations at Digital USD. It has been accepted for inclusion in Dissertations by an authorized administrator of Digital USD. For more information, please contact digital@sandiego.edu. 


\title{
UNIVERSITY OF SAN DIEGO \\ SCHOOL OF EDUCATION
}

\section{THE RELATIONSHIP OF PRINCIPAL LEADERSHIP STYLES AND \\ SCHOOLSITE CONDITIONS TO STRESS LEVELS OF \\ ELEMENTARY SCHOOL TEACHERS}

\begin{abstract}
A dissertation submitted in partial fulfilment of the requirements for the degree of Doctor of Education
\end{abstract}

by

Mark Nicholas Remy

Dissertation Committee

Ronn Johnson, Ph. D., Chair

Robert Bacalski, Ph. D.

William Howe II, Ph. D.

Mariam True, Ed. D.

May, 1999 


\begin{abstract}
The purpose of this study was to determine if principal leadership styles and school-site conditions were associated with elementary teachers' stress levels. The study focused on the relationship between the independent variables of principal leadership styles and school-site conditions and the dependent variables of teacher stress levels. A survey composed of the Leader Behavior Description Questionnaire (LBDQ), Teacher Stress Inventory (TSI) and a demographic information sheet was administered to 585 teachers from 28 elementary schools. This study was conducted in the San Diego Unified School
\end{abstract} District during the 1998-1999 school year.

The LBDQ measured two dimensions of leadership: Consideration and Initiating Structure. Additionally, these two dimensions were investigated in tandem: HighConsideration, High-Initiating Structure (HC-HIS); High-Consideration, Low-Initiating Structure (HC-LIS); Low-Consideration, High-Initiating Structure (LC-HIS); and LowConsideration, Low-Initiating Structure (LC-LIS). The level of teacher stress was determined by scores on the TSI in terms of sources of stress (Time Management, WorkRelated Stressors, Professional Distress, Student Discipline \& Motivation, and Professional Investment) and manifestations of occupational stress (Emotional, Fatigue, Cardiovascular, Gastronomic, and Behavioral Manifestations). The TSI rendered ten subscale scores (as listed above in parentheses) and one Total Stress Score. Furthermore, school-site conditions were defined in terms of organizational factors that were common 
to all schools participating in the study and that could possibly have a relationship with teacher stress levels.

The data were analyzed using a cross-sectional, correlation study design. Descriptive statistics, correlation coefficients and stepwise multiple regression were calculated by using SPSS. Stepwise multiple regression revealed that Consideration (Relationship-Oriented Leadership) was a stronger predictor of teacher stress levels than Initiating Structure (Task-Oriented Leadership). More specifically, Relationship-Oriented Leadership explained more of the variance in teacher stress levels from the sources of Professional Investment and Professional Distress, both of which treated the area of job satisfaction. Furthermore, several school-site conditions were strong predictors of teacher stress levels from the sources of Student Discipline \& Motivation, Time Management and Work-Related Stressors. All together, this study sought to offer additional insight into principal leadership styles, school-site conditions, and the relationship of both to teacher stress levels in a large urban school district. 


\section{Copyright $\mathbb{C} 1999$}

by

Mark Nicholas Remy

All rights reserved 


\section{DEDICATION}

To all the principals who allowed me to conduct research at their schools and especially to all the elementary school teachers in San Diego Unified School District who took time out of their busy schedules to participate in my study. 


\section{ACKNOWLEDGMENTS}

First, I would like to express my sincere gratitude and thanks to my committee members, Ronn Johnson, Ph. D, Robert Bacalski, Ph. D., and William Howe, III, Ph. D. for their never-ending support, assistance, and patience during the entire process. They were more than just members of my committee; they were part of a team whose continual collaborative effort made this extensive study possible.

Next, I would like to thank Mariam True, Ed. D for endorsing and sponsoring my research in the San Diego Unified School District. Her good name in the district opened many doors that might have remained closed. Additionally, her level of assistance and support were far above and beyond that which was required of her duties and responsibilities as my District Research Sponsor. I also thank her secretary, Nancy Brant, for her constant assistance getting all those little things that made a big difference. Lastly, I extend a great deal of gratitude to Karina Reyes for her many years as my Educational Mentor. She never stopped helping me be a better teacher and even introduced me to Mariam which I consider nothing short of giving me manna from heaven.

I would like to thank all the principals who listened to my research proposal and found time for me during staff meetings. As for all the teachers who participated, I cannot thank you enough. Being a teacher in San Diego Unified, I understand all too well the demands placed upon classroom teachers. Their willingness to participate and enthusiasm were truly awe inspiring. 
I would like to thank Carmen López de la Manzanara Moreno for not only her love, support, and patience, but also her endless hours working as my Research Assistant during the administration of my surveys at the schools and also as a data entry clerk.

Without her help I would never have been able to make such amazing progress during the data collection phase of this study.

I would like to express my appreciation to my family for their support, encouragement and unconditional love. From the time I was a small child they always told me that I would go to college and graduate school. As the years have passed, those words from childhood have sustained me a great deal more than I ever imagined. Thank you -- I love you very much.

Finally, I give a great deal of thanks to God. Without His presence in my life I would never have been able to complete this doctoral degree. 


\section{THE PROBLEM}

Statement of the Problem 1

Background ___ 2

Significance of the Study___ 7

Purpose of the Study ___ 8

Operational Definitions _ـ 10

Definition of Terms ___ 12

\section{REVIEW OF THE LITERATURE}

Introduction 14

Leadership 15

Conceptualizations of Leadership 16

Leadership Styles Studies ___ 20

Stress _ـ 26

Definitions of Teacher Stress __ 29

Teacher Stress Research _ 30

Role Demands/Conflicts and Environmental Demands __ 31

Principal Support and Leadership __ 40

Principal Leadership Styles and Teacher Stress ___ 42

ix 


\section{METHODOLOGY}

Study Design 46

Research Questions 48

Null Hypothesis to be Tested 49

Variables Evaluated in This Study 50

Dependent Variables 50

Independent Variables 50

Population Description and Sampling Procedure 51

Survey Administration 54

Data Collection and Instrumentation 54

Data Analysis 57

Preliminary Analysis 58

Primary Analysis 58

Protection of Human Subjects 59

Potential Risks 59

Risk Management Procedures 59

Summary 60

\section{RESULTS}

Introduction 61

Participants 62 


\section{RESULTS (Continued)}

Principal Demographic Information

School-Site Demographic Information

Principal Leadership Styles as Measured by the Leader Behavior

Description Questionnaire for the Overall Sample 76

Principal Leadership Styles as Measured by the Leader Behavior Description Questionnaire for Stratum I

Principal Leadership Styles as Measured by the Leader Behavior

Description Questionnaire for Stratum II 82

Principal Leadership Styles as Measured by the Leader Behavior Description Questionnaire for Stratum III 85

Teacher Stress Levels as Measured by the Teacher Stress Inventory 87

Teacher Stress Levels as Measured by the Teacher Stress Inventory : Overall Sample 88

Teacher Stress Levels as Measured by the Teacher Stress Inventory: Stratum I 91

Teacher Stress Levels as Measured by the Teacher Stress Inventory: Stratum II 93

Teacher Stress Levels as Measured by the Teacher Stress Inventory: Stratum III 95

Reliability Coefficients: Alpha, Guttman Split-half and Spearman-Brown _ 97

Pearson's Product-Moment Correlation Coefficients 97

Correlations Between LBDQ and the TSI 98

Correlations Between School-Site Conditions and the TSI 102

Stepwise Multiple Regression Analyses 107 


\section{RESULTS (Continued)}

Stepwise Multiple Regression Analyses: Overall Sample 107

Results by Null Hypotheses for the Overall Sample 112

Stepwise Multiple Regression Analyses: Stratum I 114

Results by Null Hypotheses for Stratum I 120

Stepwise Multiple Regression Analyses: Stratum II 122

Results by Null Hypotheses for Stratum II 129

Stepwise Multiple Regression Analyses: Stratum III 131

Results by Null Hypotheses for Stratum III 136

Summary 139

\section{DISCUSSION}

Introduction 143

The San Diego Unified School District During the 1998-1999 School Year 144

Discussion of Results 147

Teacher Stress as a Function of Principal Leadership Styles 148

Professional Distress Definition and Subscale Items from TSI 149 Professional Investment Definition and Subscale Items from TSI 149

Teacher Stress as a Function of School-Site Conditions 151 


\section{DISCUSSION (Continued)}

Student Discipline \& Motivation Definition and Subscale Items from TSI 152

Time Management Definition and Subscale Items from TSI 152

Work-Related Stressors Definition and Subscale Items from TSI _ 153

Teacher Stress as a Function of School-Site Conditions: Overall Sample _ 153

Teacher Stress as a Function of School-Site Conditions: Stratum I 154

Teacher Stress as a Function of School-Site Conditions: Stratum II 156

Teacher Stress as a Function of School-Site Conditions: Stratum III 159

Policy and Leadership Implications 163

Study Limitations 171

Recommendations for Future Research 173

\section{APPENDICES} 186

A. Leader Behavior Description Questionnaire 187

B. Teacher Concerns Inventory A/K/A Teacher Stress Inventory 190

C. Demographic Information Sheet 196

D. Principal Informed Consent Form 199

E. Informed Consent Form for Teachers 201

F. Letter from the Ohio State University: Permission to Use the Leader Behavior Description Questionnaire 


\section{APPENDICES (Continued)}

G. Letter from Dr. Michael J. Fimian: Permission to Use the Teacher Stress Inventory

H. Letter from Dr. Mariam L. True: Endorsement and Sponsorship from SDUSD's Institute for Learning - Teacher Development and Induction 205

I. Letter from Dr. Peter D. Bell, Director SDUSD's Department of Research and Reporting Unit: Permission to Conduct Research in SDUSD

J. Script to Administer the Survey to Teachers at Participating School-sites

K. Subscales Scores of Teacher Stress Inventory and Leader Behavior Description Questionnaire in Tabular Form for Overall Sample of 28 Schools, Stratum I, Stratum II, Stratum III and Individual Schools 211 


\section{LIST OF TABLES}

TABLE

PAGE

TABLE 1: $\quad$ Experienced Teachers' Reported Sources of Stress 32

TABLE 2: Swick Report: Findings On Causes of Teacher Stress From Time and Scheduling 37

TABLE 3: $\quad$ Swick Report: Findings On Causes of Teacher Stress From Interruptions During Lessons 38

TABLE 4: Swick Report: Findings On Causes of Teacher Stress From

Excessive and Diverse Paperwork Demands 38

TABLE 5: Swick Report: Findings On Causes of Teacher Stress From

Compliance with Federal Programs 39

TABLE 6: Swick Report: Findings On Causes of Teacher Stress From Increased Curriculum Demands 39

TABLE 7: Teacher Demographic Information 63

TABLE 8: Principal Demographic Information: Overall Sample, Strata I, II, and III 72

TABLE 9: School-site Demographic Information: Overall Sample,

Strata I, I, and III 74

TABLE 10: Leader Behavior Description Questionnaire: Means and Standard Deviations from LBDQ Manual, Overall Sample, Strata I, II, and III 78

TABLE 11: Four Different Principal Leadership Styles for Overall Sample 79

TABLE 12: Leader Behavior Description Questionnaire: Means for Stratum I - 12 Schools All Schools Listed Individually by Randomly Assigned Identification Numbers 80

TABLE 13: Four Different Principal Leadership Styles for Stratum I 82 
TABLE 14: Leader Behavior Description Questionnaire: Means for Stratum II - 9 Schools All Schools Listed Individually by Randomly Assigned Identification Numbers 83

TABLE 15: Four Different Principal Leadership Styles for Stratum II 84

TABLE 16: Leader Behavior Description Questionnaire: Means for Stratum III - 7 Schools All Schools Listed Individually by Randomly Assigned Identification Numbers 85

TABLE 17: Four Different Principal Leadership Styles for Stratum III 87

TABLE 18: Teacher Stress Inventory: Overall Subscale Means from Least Stress Producing Subscale to Greatest Stress Producing Subscale for the Overall Sample of 28 Schools with LBDQ Scores for Comparison 90

TABLE 19: Teacher Stress Inventory: Overall Subscale Means from Least Stress Producing Subscale to Greatest Stress Producing Subscale for the 12 Schools in Stratum I ( $n=156)$ with LBDQ Scores for Comparison

TABLE 20: Teacher Stress Inventory: Overall Subscale Means from Least Stress Producing Subscale to Greatest Stress Producing Subscale for the 9 Schools in Stratum II ( $n=212)$ with LBDQ Scores for Comparison 94

TABLE 21: Teacher Stress Inventory: Overall Subscale Means from Least Stress Producing Subscale to Greatest Stress Producing Subscale for the 7 Schools in Stratum III $(n=217)$ with LBDQ Scores for Comparison 96

TABLE 22: Reliability Coefficients: Alpha, Guttman Split-half and Spearman-Brown 97

TABLE 23: Pearson Correlation Coefficients Between LBDQ and TSI Variables 100

TABLE 24: Pearson Correlation Coefficients Between School-Site Conditions and TSI Variables for the Overall Sample 103

TABLE 25: Pearson Correlation Coefficients Between School-Site Conditions and TSI Variables for Stratum I 104 
TABLE

PAGE

TABLE 26: Pearson Correlation Coefficients Between School-Site Conditions and TSI Variables for Stratum II 105

TABLE 27: Pearson Correlation Coefficients Between School-Site Conditions and TSI Variables for Stratum III 106

TABLE 28: Stepwise Multiple Regressions Depicted by Step(s) for the Overall Sample Equation Number 1: Dependent Variable Professional Investment 108

TABLE 29: Stepwise Multiple Regressions Depicted by Step(s) for the Overall Sample Equation Number 2: Dependent Variable Professional Investment 109

TABLE 30: Stepwise Multiple Regressions Depicted by Step(s) for the Overall Sample_Equation Number 3: Dependent Variable Professional Distress 110

TABLE 31: Stepwise Multiple Regressions Depicted by Step(s) for Stratum I Equation Number 1: Dependent Variable Professional Distress 115

TABLE 32: Stepwise Multiple Regressions Depicted by Step(s) for Stratum I Equation Number 2: Dependent Variable Professional Distress 115

TABLE 33: Stepwise Multiple Regressions Depicted by Step(s) for Stratum I Equation Number 3: Dependent Variable Professional Investment 117

TABLE 34: Stepwise Multiple Regressions Depicted by Step(s) for Stratum I Equation Number 4: Dependent Variable Professional Investment 117

TABLE 35: Stepwise Multiple Regressions Depicted by Step(s) for Stratum I Equation Number 5: Dependent Variable Time Management 118

TABLE 36: Stepwise Multiple Regressions Depicted by Step(s) for Stratum II Equation Number 1: Dependent Variable Professional Investment 123

xvii 
TABLE

PAGE

TABLE 37: Stepwise Multiple Regressions Depicted by Step(s) for Stratum II Equation Number 2: Dependent Variable Professional Investment 124

TABLE 38: Stepwise Multiple Regressions Depicted by Step(s) for Stratum II Equation Number 3: Dependent Variable Work-Related Stressors

TABLE 39: Stepwise Multiple Regressions Depicted by Step(s) for Stratum II Equation Number 4: Dependent Variable Discipline and Motivation of Students

TABLE 40: Stepwise Multiple Regressions Depicted by Step(s) for Stratum III Equation Number 1: Dependent Variable Professional Investment 132

TABLE 41: Stepwise Multiple Regressions Depicted by Step(s) for Stratum III Equation Number 2: Dependent Variable Professional Investment 133

TABLE 42: Stepwise Multiple Regressions Depicted by Step(s) for Stratum III Equation Number 3: Dependent Variable Total Stress Score 134

TABLE 43: Stepwise Multiple Regressions Depicted by Step(s) for Stratum III Equation Number 4: Dependent Variable Work-Related Stressors 135

TABLE 44: Tabular Summary of Failed to Reject and Rejected Null Hypotheses for the Overall Sample and Strata I, II, and III 142

xviii 


\section{LIST OF FIGURES}

FIGURE

PAGE

FIGURE 1: Graphic Representation of Initiating Structure and

Consideration Mean Scores as Measured by the LBDQ for the

Overall Sample and Strata I, II, and III with the Means from the

LBDQ Manual for Comparison Depicted by the Diamond and

Square Lines

FIGURE 2: Graphic Representation of Initiating Structure and Consideration

Mean Scores as Measured by the LBDQ for All 12 Schools in

Stratum I with the Means from the LBDQ Manual for Comparison

Depicted by the Diamond and Square Lines

FIGURE 3: Graphic Representation of Initiating Structure and Consideration

Mean Scores as Measured by the LBDQ for All 9 Schools in

Stratum II with the Means from the LBDQ Manual for Comparison

Depicted by the Diamond and Square Lines

FIGURE 4: Graphic Representation of Initiating Structure and Consideration

Mean Scores as Measured by the LBDQ for All 7 Schools in

Stratum III with the Means from the LBDQ Manual for Comparison

Depicted by the Diamond and Square Lines

FIGURE 5: Graphic Representation of High-Low Cut-Off Points for the

TSI Subscale and Subscale Mean Scores

FIGURE 6: Graphic Representation of High-Low Cut-Off Points for the TSI Subscale and Subscale Mean Scores Compared to the Subscale Mean Scores of all 28 participating Elementary Schools in the San Diego Unified School District

FIGURE 7: Graphic Representation of High-Low Cut-Off Points for the TSI Subscale and Subscale Mean Scores Compared to the Subscale Mean Scores of Stratum I

FIGURE 8: Graphic Representation of High-Low Cut-Off Points for the TSI Subscale and Subscale Mean Scores Compared to the Subscale Mean Scores of Stratum II 94

FIGURE 9: Graphic Representation of High-Low Cut-Off Points for the TSI Subscale and Subscale Mean Scores Compared to the Subscale Mean Scores of Stratum III 


\section{CHAPTER I}

\section{THE PROBLEM}

\section{Statement of the Problem}

The topic of teacher stress has received a great deal of attention and research over the last three decades. Results rendered from studies have not only enriched the literature on teacher stress but have also been cause for alarm. As a result of stress many teachers experience emotional, psychosomatic and physical symptoms which have been compared to those of soldiers in combat and connected to mental health illnesses, substance abuse, absenteeism, sick leave, lost productivity, and attrition rates (Carnegie Forum on Education, 1986; Coates \& Thoresen, 1976; Dworkin, 1987; Maslach \& Leiter, 1997; NEA, 1979; U.S. Department of Education, 1997).

The National Education Association (NEA) corducted several studies since the 1960s to investigate not only the causes of teacher stress but also the impact. Their 1979 study of 2,165 teachers revealed that due to stress $9 \%$ planned to leave the classroom as soon as possible. The Carnegie Forum on Education (1986) concluded that $50 \%$ of all teachers leave the profession during the first seven years. The U.S. Department of Education, National Center for Education Statistics, (1997) concurred with the NEA's and Carnegie Forum on Education's findings. Additionally, they reported that the number 
one factor attributed to dissatisfaction within the teaching profession and leading to higher teacher attrition rates was a lack of recognition and support from administrators.

Studies repeatedly indicate that one of the underlying causes of stress was due in large part to role demands/conflicts, environmental demands, and principal leadership and support. Some of the literature on teacher stress has identified school principals as the leading source of occupational stress for their teaching staff. Blase (1984), Brightwell (1985), and Chen \& Miller (1997) concluded that when a principal failed to support teaching staff, stress levels increased and teachers' ability to accomplish job responsibilities decreased. Barnette (1990), Klanderman (1985), and Paré (1995) found that management tensions or poor relationships with principals increased teacher stress levels and decreased job satisfaction. Recent findings by the Department of Education, National Center for Education Statistics, (1997) looked at the impact of a non-supportive principal and revealed that $32 \%$ of all dissatisfied teachers departing the profession leave because of a lack of recognition and support from administrators. In conclusion, strong supportive relationships between teachers and principals lowered job-related stress. The purpose of this study is to determine if principal leadership styles and school-site conditions were associated with elementary teachers' stress levels in twenty-eight randomly selected elementary schools within the San Diego Unified School District.

\section{Background}

Although occupational stress for teachers is a topic that has recently received much attention from theorists and researchers, the first studies in the field can be found as 
early as the 1930s. In 1933, 600 classroom teachers participated in a study on teacher stress, anxiety, and mental health (Hicks, 1933). Hick's research "found that $17 \%$ of the participants were 'unusuaily nervous,' and another $11 \%$ suffered from 'nervous breakdown' " (Coates \& Thoresen, 1976, p. 160). Another study of 110 female teachers, conducted in the same year, revealed that $33 \%$ suffered from symptoms of nervousness and anxiety (Peck, 1933). Additional studies throughout the decades leading up to the 1970s revealed many of the same findings but with a growing increase in the levels of stress experienced by teachers which in turn lead to lower job satisfaction and higher teacher attrition rates (Gold \& Roth, 1993).

In 1967, the NEA's research on levels of teacher stress revealed that teachers experiencing moderate or considerable levels of stress had reached $78 \%$. In the late 1970's the Chicago teachers' union polled members about stress-related illness. Of the 5,500 participants, $56 \%$ stated that they suffered from job-related physical and/or mental illness (Walsh, 1979). During the 1977 annual convention of American Association of School Administrators, teaching was acknowledged as one of the top three most stressful professions (Hunter, 1977). With growing concern about teacher stress in public schools throughout the United States, the NEA conducted a nationwide survey in 1979. The survey of 2,165 public school teachers found that $43 \%$ had decided to continue teaching until retirement while $9 \%$ of 1,738 participants were considering leaving the classroom as soon as possible. The most disheartening finding from the survey revealed that $41 \%$ of the respondents claimed that they would have chosen another career path, outside of education, if they could do it all over again (NEA, 1979). 
In acknowledgment to mounting findings about stress' detrimental impact upon teachers, the teachers' union in Tacoma, Washington successfully negotiated stress insurance for its members. This policy enabled members to receive medical and psychological services to better manage and cope with occupational stress. The NEA followed by adopting Resolution E-42 which not only recognized increases in stressrelated incidences, but also strongly urged teacher unions and associations to create and promote programs targeted at helping teachers cope with occupational stress. In 1980, the U.S. House of Representatives' Sub-Committee on Elementary, Secondary and Vocational Education listened to teachers describe the causes and effects of stress upon educators. Compelling testimony not only encouraged Congress to acknowledge teacher stress as a severe problem in public schools, but also to promote the need for readily available professional help for teachers.

As teacher stress levels grew and attrition rates increased throughout public schools in the United States more effort was placed upon not only identifying the causes of job-related stress but also finding effective strategies for successful interventions. A review of the literature suggested that principal leadership and support was a leading cause of job-related stress (Chen \& Miller, 1997; Swick \& Hanely, 1985). Additionally, several studies began to focus specifically on the relationship of principal leadership styles to teacher stress levels.

Landsman (1978) reviewed 9,000 survey responses from teachers. In his article, entitled Principals may be hazardous to their teachers ' health, principals were perceived as the primary change agent on a school-site. Depending on his/her leadership, teacher 
stress levels would increase or decrease. Sparks (1981) reaffirmed the connection between teacher stress and principal leadership. Teachers with higher stress levels were associated with principals with whom they had a poor working relationship. Ginsberg (1981) surveyed 2,590 teachers using the Teaching Events Stress Inventory (TESI).

Findings revealed that a lack of administrative support or disputes with principals increased stress levels and reduced job satisfaction. Hoover-Dempsey and Kendall (1982) identified principals who were perceived as having poor leadership skills as a significant source of stress and job dissatisfaction. They also identified "lack of administrative support, poor principal-teacher relations, poor communication, poor or inappropriate supervision, and failure of the principal to create a sense of community within the school as other critical elements tied to stress on the job and in turn, job dissatisfaction" (p. 22). Brightwell (1985) concluded that a teacher's ability to perform his/her job was greatly diminished by stressful conditions. Furthermore, he felt that a principal was responsible for reducing job-related stressors and increasing a teacher's ability to accomplish job responsibilities. When the principal and teacher supported each other, the teacher's stress levels decreased. Klanderman (1985) concluded that management tensions or poor relationships with principals increased teacher stress levels. Barnette's (1990) and Paré's (1995) findings concurred with Klanderman's. A strong supportive relationship between teacher and principal lowered job-related stress. Recent findings by the Department of Education, National Center for Education Statistics, (1997) looked at the impact of a non-supportive principal and revealed that $32 \%$ of all dissatisfied teachers 
departing the profession leave because of a lack of recognition and support from administrators.

By the late 1980s, it had become very clear that the stakes were high. The Carnegie Forum on Education (1986) concluded that $50 \%$ of all teachers left the profession during the first seven years and attrition rates for classroom teachers in public schools ranged from $6 \%$ to $8 \%$ per year (Louis Harris \& Associates, 1988). Schlechty \& Vance, (1983) and Olson \& Rodman (1988) found similar results; $40 \%$ to $50 \%$ of all new teachers departed the profession due to stressful conditions within the first five years. Furthermore, the NEA projected that by 1990 one million teachers would be needed to replace those leaving public education and meet the demands of a burgeoning student population (Hanchey \& Brown, 1989). In 1997, The U.S. Department of Education, National Center for Education Statistics reported that $7 \%$ of the nationwide teaching force in public schools had left the classroom. Furthermore, from those that left the classroom $19 \%$ were still in education but in a non-teaching position, while another $23 \%$ had changed to a profession outside of education. Clearly, one out of four teachers departing the profession, due to job dissatisfaction (with stress as the underlying cause) was a statistic of great concern. In conclusion, the cost of stress to public school districts across the nation due to illness, substance abuse, absenteeism, sick leave, lost productivity, and attrition rates continues to deprive school districts of qualified teaching staff and to drain precious financial resources well into the millions of dollars each year. (Cedoline, 1982; Dworkin, 1987; Farber, 1991; Maslach \& Leiter, 1997). 


\section{Significance of the Study}

To date, a large body of literature has examined teacher stress. During the 1970s and 1980s researchers conducted hundreds of studies about the causes and consequences of teacher stress. Research continued in the 1990s but with less frequency. Three decades of literature on teacher stress did identify school principals as a leading source of occupational stress for their teaching staff. However, there have only been a limited number of studies that evaluate the role principal leadership styles may play in understanding stress levels in elementary teachers. Furthermore, most of those studies were conducted in the 1980s. This investigation helped fill that gap in the current literature with more recent findings.

Additionally, among the studies that had investigated that relationship, none had measured stress and leadership nor analyzed the relationship between the two as did this study. More specifically, none had focused solely on elementary schools in a large urban school district, used a stratified random sample, or been compared to school accountability report card data. Nor had instruments been administered like the Leader Behavior Description Questionnaire (LBDQ) and Teacher Stress Inventory (TSI) in tandem. The instruments used for data collection in the present study have been developed, tested, and standardized in public schools throughout the United States. As stated in the hypotheses, this study expected to find that the leadership dimension of consideration would result in less job-related stress on the part of followers. In the more specific context of schools, a principal who was described as high on the leadership dimension of consideration would have teachers with lower levels of stress. 


\section{Purpose of the Study}

The purpose of this study was to determine if the principals' leadership styles and school-site conditions were related to elementary teachers' stress levels. The study focused on the relationship between the independent variables of principal leadership styles and school-site conditions and the dependent variable of teacher stress. A survey composed of the Leader Behavior Description Questionnaire (LBDQ), Teacher Stress Inventory (TSI) and a demographic information sheet was administered to 585 teachers from 28 elementary schools. This study was conducted in the San Diego Unified School District during the 1998-1999 school year.

The LBDQ was developed by the Ohio State University and measured two dimensions of leadership: consideration and initiating structure. Additionally, these two dimensions were investigated in tandem: High-Consideration, High-Initiating Structure (HC-HIS); High-Consideration, Low-Initiating Structure (HC-LIS); Low-Consideration, High-Initiating Structure (LC-HIS); and Low-Consideration, Low-Initiating Structure (LC-LIS). The TSI was developed by Dr. Michael J. Fimian and measured teacher stress levels. The level of teacher stress was determined by scores on the TSI in terms of sources of stress (time management, work-related stressors, professional distress, student discipline \& motivation, and professional investment) and manifestations of occupational stress (emotional, fatigue, cardiovascular, gastronomic, and behavioral manifestations). The TSI rendered ten subscale scores (as listed above in parentheses) and one Total Stress Score for each participant. Furthermore, school-site conditions were defined in terms of organizational factors that were common to all schools participating in the study and that 
could possibly have a relationship with teacher stress levels. These data were provided by the San Diego Unified School District's School Accountability Report Cards, by the teacher demographic section of the survey, and by the principal at each site. School-site conditions included: school year calendar, staff size, dollars spent per pupil, unexcused student absences, student suspensions, instructional minutes per year, student ethnicity, Stanford Achievement Test (SAT-9) scores, Coordinated Compliance Review requirements (a form of program quality review required by the State of California), number of vice principals on site, and demographic information about the principals and teachers.

This study was endorsed and sponsored by San Diego Unified School District's Teacher Induction and Development Department. The findings from this investigation may be used for in-service leadership training for principals and provide a framework designed to teach principals effective methods to adapt leadership styles to reduce teacher stress levels. Additionally, findings will also aid the district in its development of stress management/coping workshops for teachers. This in turn could help instruct teachers on how to better manage and cope with stress, thus increasing job satisfaction and performance. Lastly, results may reveal some potential avenues for further research in the field of occupational stress and situational leadership theory. 


\section{Operational Definitions}

For the purpose of this research, the following operational terms have been defined:

1. Consideration: the perception of friendship, mutual trust, respect, and warmth in the relationship between principal and teachers as measured by the LBDQ (Stogdill, 1957). Scores range from 0 to 60 . Zero would translate to a principal low on the leadership style (dimension) of Consideration and sixty would translate to a principal high on Consideration.

2. Initiating Structure: the establishment of well-defined patterns of organization, avenues of communication and procedural methods as measured by the LBDQ (Stogdill, 1957). Scores range from 0 to 60 . Zero would translate to a principal low on the leadership style (dimension) of Initiating Structure and sixty would translate to a principal high on Initiating Structure.

3. Time Management: job-related commitments or responsibilities which require managing or coping with limited time resources, time constraints or insufficient time to complete a task or group of tasks.

4. Work-Related Stressors: Duties, responsibilities and tasks which compose a teachers workload and consume the hours of a workday at the school-site.

5. Professional Distress: job dissatisfaction or distress from lack of promotion or advancement opportunities, status and respect on the job, and inadequate salary and recognition. 
6. Student Discipline \& Motivation: frustration resulting from student discipline problems, monitoring pupil behavior, poorly motivated students, inadequate or poorly defined discipline problems or policies, and rejected authority by both students and administration.

7. Professional Investment: lack of control over decisions made about the classroom and school matters, lack of opportunities to be intellectually stimulated on the job or improve professionally, and inability to express opinions openly and honestly.

8. Emotional Manifestations: responses to stress by feeling insecure, vulnerable, unable to cope, depressed and anxious.

9. Fatigue Manifestations: responses to stress by sleeping more than usual, procrastinating, becoming tired in a very short time, physical exhaustion, and physical weakness.

10. Cardiovascular Manifestations: responses to stress with feelings of increased blood pressure, feelings of heart pounding or racing and with rapid and/or shallow breath.

11. Gastronomical Manifestations: responses to stress with stomach pain of extended duration, with stomach cramps and with stomach acid.

12. Behavioral Manifestations: responses to stress by using over-the-counter drugs, prescription drugs, alcohol and by calling in sick.

13. Elementary teacher: a person credentialed by the California Commission on Teacher Credentialing and hired to teach kindergarten through 6 th grade.

14. Principal: a person credentialed by the California Commission on Teacher Credentialing and hired to be the chief administrator of a public school. 
15. School-Site Conditions: were defined in terms of organizational factors common to all schools participating in the study and that could possibly have a relationship with teacher stress levels. These data were provided by the San Diego Unified School District's School Accountability Report Cards, by the teacher demographic section of the survey, and by the principal at each site. School-site conditions included: school year calendar, staff size, dollars spent per pupil, unexcused student absences, student suspensions, instructional minutes per year, student ethnicity, Stanford Achievement Test (SAT-9) scores, Coordinated Compliance Review requirements (a form of program quality review required by the State of California), number of vice principals on-site, and demographic information about the principals and teachers.

\section{Definition of Terms}

1. Leadership Style: a measure of Consideration (relationship-oriented leadership) and Initiating Structure (task-oriented leadership). "These patterns emerge in people as they begin to respond in the same fashion under similar conditions; they develop habits of action that become somewhat predictable to those who work with them" (Hersey \& Blanchard, 1981, p. 126).

2. Stress: a situation which causes an individual to mobilize mechanisms to adapt (McGrath, 1976). 
3. Stressor: " ... the particular relationship between the person and the environment that is appraised by the person as taxing or exceeding his or her resources and endangering his or her well-being" (Lazarus \& Folkman, 1984, p. 19).

4. Teacher Stress: "a response syndrome of negative effects (such as anger or depression) by a teacher usually accompanied by potentially pathogenic physiological changes (such as increased heart rate) resulting from aspects of the teacher's job and mediated by the perception that the demands made upon the teacher constitute a threat to his self-esteem or well-being and by coping mechanisms activated to reduce the perceived threat" (Kyriacou and Sutcliffe, 1978, p. 2). 


\section{CHAPTER II}

\section{REVIEW OF THE LITERATURE}

\section{Introduction}

The purpose of this chapter is to examine the literatures on leadership, stress, and leadership/stress interactions. The first three sections will critically evaluate and examine the literature that treats the dynamic of leadership between leaders and followers. Are leaders supposed to give orders to which foliowers submit without ever having been part of the mission or vision, or are leaders and followers supposed to be engaged together to accomplish a mission or vision which is held in common? Conceptualizations of leadership attempt to answer that question by summarizing the development, evolution, and nature of leadership during the twentieth century. As the conceptualizations reach more contemporary times, a major strand of research focuses on the study of leadership styles. By looking at the two leadership styles (or dimensions) of initiating structure and consideration, the field of leadership began to understand not only the importance of taskoriented leadership and relationship-oriented leadership, but also how the leadership process varied from situation to situation and was affected by both leaders and followers. 
The last three sections will critically evaluate and examine stress, its relationship to teachers, and the dynamic interaction between principai leadership and teacher stress levels. In order to better understand the condition known as stress, definitions from leading authorities explain how it affects everyone. Definitions for teacher stress define the condition more specifically toward the teaching profession. Their terminology brings to focus a clearer picture of the causes of teacher stress, the physiological and psychological reactions and, ultimately, the coping mechanisms teachers use to protect themselves. The final section delves into research on teacher stress with an emphasis on how role demands/conflicts, environmental demands, and principal support and leadership can be factors for increasing or decreasing stress levels. The review concludes that no grand theory of leadership or understanding of stress has been discovered to better prepare principals to lead and teachers to lowir stress levels.

\section{Leadership}

All leadership theories can be broken down into two general approaches. The first approach sees the leader as a single unitary actor who dispenses/gives direction or guidance to followers. From him or her all leadership activity flows, and, hence, the focus of discussion and research is on the leader alone. Followers are generally passive and exist primarily to carry out the wishes, missions or vision of the leader. The second approach tries to answer the question: What is the involvement of the followers in the leadership dynamic? This approach sees the followers as absolutely essential to the leadership dynamic. From this perspective leadership is a process that is accomplished when the 
leader and followers are engaged together to accomplish a common mission or vision. A collaborative relationship exists between "leader(s)" and "followers" or "collaborators."

Such an approach addresses the fact that people and organizations today are inherently complex and ambiguous, and cannot be led by one person. In order to respond to the needs of a global, complex society the talents and energies of a group of people who possess a myriad of talents is vitally important.

\section{Conceptualizations of Leadership}

To better understand not only the development and evolution of leadership but also its nature, it is important to begin with a detailed look at how it has been conceptualized. In the twentieth century academicians, leaders of industry, the military, social movements, religious organizations, and political institutions have attempted to define, theorize, and execute leadership practices. Hundreds of books and journal articles on leadership have been published, but more than half of them lack a definition of leadership (Rost, 1993). In response, Bass (1990) and Rost (1993) not only reviewed the history of leadership but also examined hundreds of existing definitions. They clearly depict leadership theory, research, and practice over the greater part of the twentieth century as an evolution from an emphasis on the individual leader to more collaborative, relationship-oriented leadership. The following paragraphs constitute a synopsis of this evolution from Bass' (1990) and Rost's (1993) thorough exploration of leadership.

Toward the end of the nineteenth century, leadership was viewed from the perspective of the Great Man Theories. Leadership involved the survival of the fittest, 
was the result of inheritance, or was engendered by a unique quality. This view helped develop and support Trait Theories of leadership as evidenced in studies by Bernard (1926), Bingham (1927), Bogardus (1934), Tead (1929), Page (1935), and Kilbourne (1935). Leaders were believed to possess superior attributes which differentiated them from followers. Bogardus (1934) argued, 'Leadership is personality in action under group conditions. . . It is interaction between specific traits of one person and other traits of the many, in such a way that the course of action of the many is changed by the one" (p.3). These theories continued to hold relevance well into the $1930 \mathrm{~s}$, though they were gradually adapted and modified by Situational Theories and Personal-Situational Theories.

During the period of the Great Man and Trait Theories, Frederick Taylor began to develop and implement Scientific Management, an orientation that borrowed from the works of Frederick of Prussia (1750/1981) in the area of military hierarchy and Adam Smith $(1776 / 1985)$ in division of labor, and redefined the role of the worker down to his or her every moment. Ironically, Taylor was investigated by a Congressional hearing in 1916; many felt he was the enemy of the working person. Nevertheless, much of what he initiated almost one hundred years ago still pervades the workplace in the United States and other developing countries. In the 1920s Max Weber (1924) took much of his intellectual predecessor's work and introduced the concept of bureaucracy. It called for centralized control of all functions of an organization, with each member selected to fill a particular position in the organization. 
Toward the end of the 1920s and well into the 1930s, Situational Theories and Personal-Situational Theories of leadership began to gain acceptance. Spiller (1929), Schneider (1937), and Murphy (1941) postulated that leadership was a function of the situation and did not hinge on a single individual. Leaders were instruments through which a solution materialized. Building upon Situational Theories, and earlier Trait Theories theorists began to explore the concept of Personal-Situational Theories. Case (1933), a leading figure in this movement, felt leadership was dependent upon three elements: (a) personality trait of the leader; (b) the composition of the group members (the employees); and (c) the problem which the group must confront and resolve (i. e., the situation). Additionally, by the 1950s Humanistic Theories as articulated by Argyris (1957), Likert (1947), Mayo \& Lombard (1944), and McGregor (1944) suggested that human beings were motivated to accomplish goals and that the organization must provide the structure. Motivated people, they argued, must be allocated a certain amount of freedom in order to fulfill their potential while at the same time accomplishing organizational goals and visions. Development of Scientific Management, situational leadership theory, and humanistic theory would bear more fruit in the late 1940s and 1950s with the advent of the Ohio State Leadership Studies.

In the late 1940s the Contingency Theory of leadership, with contributions by Fiedler (1958), Halpin (1953), Hemphill (1949), Shartle (1951), and Stogdill (1948) began to take the foreground in leadership studies throughout the country. In the 1950s Stogdill conducted extensive research at the Ohio State University in the area of consideration (relationship-oriented) and initiating structure (task-oriented) leadership behavior styles. 
Consideration represented the human interaction element of administration and initiating structure represented the function of bureaucracy to accomplish tasks. These two dimensions were identified by the Ohio State Leadership Studies as the two most significant variables of leadership behavior styles. In essence, Contingency Theory argued that the effectiveness of a specific leadership behavior, task-oriented and/or relationshiporiented, was based upon the situation at that moment.

Contingency theory has continued to be acknowledged in the field of leadership studies. However, scholars have begun to expand upon its original premises. Maslow (1954) introduced a new approach based on the belief that if the welfare of the employees was promoted, they would produce more and better products. Maslow's hierarchy was the first attempt to look out for the needs of the employees starting from basics (housing, food, clothing) and culminating in self-actualization. This was the beginning of looking deeper into the psychological benefits within the workplace. Transformational Leadership Theory, as developed initially by Burns (1978), argued that the purpose of leadership is to elevate followers' end values such as liberty, justice, and equality. "The transformational leader asks followers to transcend their own self-interests for the good of the group, organization or society; to consider their long-term needs to develop themselves, rather than their needs of the moment; and to become more aware of what is really important. Hence, followers are converted into leaders" (Bass, 1990, p. 53). By the 1970s and 1980s (and especially after the OPEC petroleum crisis), the United States began to see the need for changes within organizational structure. New theories like 
Maslow's and Burns' gained more acceptance, as did such approaches as TQM, and Chaos and Complexity Theory.

In the 1990 s organizations began to tackle problems, re-invent themselves, and evolve with the times in a far more collaborative manner. Scholars such as Senge (1990) and Weisbord (1992) looked toward what they called "learning organizations." Heifetz (1994) demonstrated the benefits of Adaptive Leadership as a way to include all in the collaborative leadership process. Rost (1993) advocated leadership as "an influence relationship among leaders and followers who intend real changes that reflect their mutual

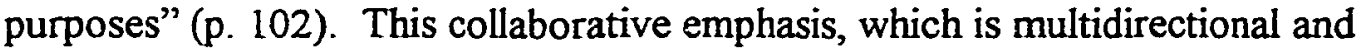
noncoercive, allows all to take part in meaningful interaction.

The next section treats the development and evolution of leadership styles studies. It explores the dynamic of how leaders, through differing leadership styles, can facilitate more collaborative leadership interaction between leaders and followers and promote more effectively run organizations.

\section{Leadership Styles Studies}

For much of the first half of the twentieth century, leadership was considered a personality trait. However, fifty years of research failed to clearly define a personality trait that could be used to separate leaders from nonleaders/followers (Stogdill, 1948). After this inconclusive research, the Ohio State University and the University of Michigan began investigating leadership studies and shifting the focus from traits to leadership styles. The two styles which these studies explicitly identified as most pertinent to leadership behavior 
were initiating structure and consideration. Additionally, in the 1960s Blake and Mouton delved deeper into leadership styles by examining how managers used task and relationship leadership behavior within organizations, two dimensions that obviously bear close conceptual links with Initiating Structure and Consideration. Furthermore, empirical studies suggested that leadership was a process which varied from situation to situation and was affected by both leaders and followers. Hersey and Blanchard (1977) defined situational leadership as "the process of influencing the activities of an individual or a group in efforts toward goal achievement in a given situation" (p. 84). Clearly, given that definition, a leader had to accomplish goals with and through people and thus be cognizant of both initiating structure (task-oriented) and consideration (relationship or human relations-oriented) leadership behavior styles. These two leadership styles, it should be noted, have their roots in Taylor's Scientific Management Movement and the subsequent Human Relations Movement, suggesting that there has been considerable continuity in the evolution of leadership studies.

Initiating Structure was implicit in Taylor's Scientific Management from the early 1900s. Taylor (1911) studied how to make labor more effective and efficient along with methods to increase output and/or productivity. By employing science to examine a task, managers could determine the most efficient way to accomplish that task. Unfortunately, Taylor saw workers as little more than machines at the disposal of their leaders. Workers were to adapt to the leaders, and the leaders main objective was to meet the needs of the organization. In Taylorism, as Hansen (1979) has argued, 'Management was to be 
divorced from human affairs and emotions" (p. 90). Management did not concern itself with the human relations side of the organization.

Consideration was implicit in Mayo's Human Relations movement in the 1930s. Mayo believed that scientific technology in the workplace alone was not the only method to improve labor's efficiency, effectiveness, output, and productivity. Workers had needs which could be met by taking into consideration their feelings and attitudes. The leader was still seen as accomplishing goals, but he was also expected to provide for the wellbeing of the worker. The leader's focus had shifted from the organization's needs to the workers' needs. In essence, human relations theorists believed that the most satisfying organizations would also be the most efficient.

Additionally, "human relations methodology emphasized that practicing democratic principles in management, advocating participation with employees, and establishing open channels of communication would resolve superordinate-subordinate differences in a spirit of goodwill and cooperation" (Roberts, 1983, p. 22). Argyris (1964) considered bureaucracy to be the cause of many organizational ills such as poor, shallow, and mistrustful relationships between management and labor. Democratic values, he suggested, promoted and reinforced sincere and authentic relationships, which in turn increased an organization's effectiveness and responsiveness to human needs. Knezevich (1975), Likert (1967), and McGregor (1966) all concurred with Argyris. The human resource was indispensable and organizations would not reach their full potential without it.

The first study to be conducted in the area of leadership styles, or more specifically style approach, was in the late 1940s at the Ohio State University (OSU). This research 
was based on Stogdill's (1948) conclusion that leadership was more than just a leader's traits. Researchers at Ohio State examined how individuals lead a group or organization. This examination was conducted by asking followers/subordinates to complete a survey which measured their perceptions about how often their leaders engaged in certain leadership behaviors. This research facilitated the development of the Leader Behavior Description Questionnaire (LBDQ). The original LBDQ was composed of 150 questions drawn from a pool of more than 1,800 items describing different elements of leadership. By the early 1960 s, it had been shortened to forty items. The LBDQ was administered to people in education, the military, and industry. Responses to the questionnaire clustered around two leadership dimensions: Initiating Structure and Consideration (Stogdill, 1974). Initiating structure behaviors were essentially task behaviors, including such acts as organizing work, giving structure to the work context, defining role responsibilities, and scheduling work activities. Consideration behaviors were essentially relationship behaviors and included building camaraderie, respect, trust, and liking between leaders and followers (Northouse, 1997, p. 34).

The two leadership dimensions of Initiating Structure and Consideration were perceived as distinct and independent, though it became clear that a leader did not have just one or the other. For instance, one leader may be high in Initiating Structure and high or low in Consideration, along with the inverse. "The degree to which a leader exhibited one behavior was not related to the degree to which she or he exhibited the other behavior" (p. 34). Furthermore, no single style is considered more effective than another; effectiveness is based on the situation. 
During the same time period, the University of Michigan (UM) was also conducting research in the area of leadership styles, but with a focus on the leader's impact on the performance of small groups (Cartwright \& Zander, 1960; Katz \& Kahn, 1951; Likert, 1961, 1967). UM researchers investigated two dimensions of leadership that paralleled OSU's: employee orientation and production orientation. Employee Orientation parallels Consideration and Production Orientation parallels Initiating Structure. Initial studies at UM conceptualized these two dimensions on a single continuum - - a leader was one or the other and not a combination of both. However, as more research was conducted, the two dimensions were re-evaluated and conceptualized like the OSU studies (Kahn, 1956) -- that is, a leader could exhibit both orientations at the same time, though behavior on one orientation might be stronger than behavior on the other.

OSU and UM both conducted extensive studies in the area of leadership styles during the 1950s and 1960s. Researchers wanted to find a universal theory of leadership capable of explaining leadership effectiveness in every situation. Unfortunately, findings were contradictory and unclear. However, some studies did validate the value of a leader who was perceived as high on both dimensions -- Initiating Structure and Consideration (Argyris, 1964; Halpin, 1953; Misumi, 1985). Out of these studies and their findings, Blake and Mouton, in the early 1960s, began analyzing twenty years of leadership style data. They synthesized ideas and concepts into broad theories based upon OSU and UM research. The result was the development of the Managerial (Leadership) Grid ${ }^{\infty}$ which was designed to measure two dimensions of leadership: concern for production and concern for people (Blake \& McCanse, 1991; Blake \& Mouton, 1964, 1978, 1985). 
Concern for Production focuses on task-oriented leadership and parallels Initiating Structure. Concern for people focuses on relationship-oriented leadership and parallels Consideration.

The Managerial (Leadership) Grid joins Concern for Production and Concern for People in a model that has two intersecting axes. The horizontal axis represents the leader's Concern for Production and the vertical axis represents the leader's Concern for People. Each of the axes is drawn as a 9-point scale on which a score of 1 represents minimum concern and 9 represents maximum concern. By plotting scores from each of the axes, various leadership styles can be illustrated. The Leadership Grid portrays five major leadership styles: AuthorityCompliance $(9,1)$, Country Club Management $(1,9)$, Impoverished Management $(1,1)$, Middleof-the-Road Management (5,5), and Team Management $(9,9)$ (Northouse, 1997, p. 36).

Authority-Compliance style is indicative of High-Initiating Structure; Country Club Management style of High-Consideration; Impoverished Management style of LowInitiating Structure and Low-Consideration; Middle-of-the-Road Management style of a balance between Initiating Structure and Consideration; and Team Management style of High-Initiating Structure and High-Consideration.

In sum, the study of leadership styles did not produce a grand theory of effective leadership behavior. Nevertheless, the leadership styles approach provides a framework for evaluating task-oriented and relationship-oriented dimensions. Leaders are not told how to behave; instead they are given a description of their leadership behavior. This leadership style approach enables leaders to be constantly cognizant of their leadership styles, to adjust them to a given situation, and to respond according to the needs of others 
and/or the organization. The next several sections review the literature on stress and explore research which addresses how principal leadership styles are associated to teacher stress levels.

\section{$\underline{\text { Stress }}$}

Stress is not a condition experienced only by teachers or other professionals in the field of education. Everyone is subjected to some degree of stress. As research on stress has increased, its definitions have grown in number. Furthermore, positive and negative aspects of stress have been investigated, and the term stress itself has often been utilized interchangeably with or in conjunction with words such as anxiety, burnout, or distress.

In the Penguin Dictionary of Psychology, stress is generically defined as "any force that when applied to a system causes some significant modification of its form, usually with the connotation that the modification is a deformation or a distortion. The term is used with respect to physical, psychological, and social forces and pressures. A state of psychological tension produced by the kinds of forces and pressures alluded to above" (Reber, 1985, 736-737).

Selye, considered the premiere leading authority in stress research, was one of the first to provide a formal definition of stress: "the nonspecific response of the body to any demand made upon it [and] it is immaterial whether the agent or situation we face is pleasant or unpleasant; all that counts is the intensity of the demand for readjustment or adaptation" (Selye, 1974, pp. 27-29). Lenci, in General Electric's Good vs. bad stress (1978), concurs, but also states: "Stress is the state you are in, not the agent which 
produces it" ( p. 38). Burchfield (1979) defined stress "as anything which causes an alteration of psychological homeostatic processes" (p. 662). Albrecht (1979) defined stress as a chemical process within the body as it adapts to changes in demands which were caused by either a physical or psychological stressor. Fimian defined stress as "a hypothetical construct that represents an equilibrium state that exists between the individual responding to environmental demands and the environment. Disequilibrium may have actual causes, perceived causes, or, frequently, a combination of both actual and perceived causes" (1982, p. 101). Kaiser and Polcyznski (1982) defined stress as a biochemical reaction which can be positive or negative; it is the body's reaction to pressure, in excessive amounts, that may be harmful.

Selye's research, dating from the mid 1930's, examined the operation of the body when subjected to long term periods of stress. The result was the development of the General Adaptation Syndrome (GAS). It was comprised of three stages: a) the alarm reaction; b) stage of resistance; and c) stage of exhaustion. The stages were defined as follows:

1. Alarm reaction. The body shows the changes characteristic of the first exposure to a stressor. At the same time, its resistance is diminished and, if the stressor is sufficiently strong (severe burns, extreme temperature), death may result.

2. Stage of resistance. Resistance endures if continued exposure to the stressor is compatible with adaptation. The bodily signs characteristic of the alarm reaction have virtually disappeared, and resistance rises above normal. 
3. Stage of exhaustion. Following long-continued exposure to the same stressor, to which the body has become adjusted, eventually adaptation reaction reappears, but now they are irreversible, and the individual dies (Selye, 1974, p. 38).

Additionally, stress has been delineated by distress (unpleasant stress) and eustress (pleasant stress) (Gmelch 1982a, 1982b). The two work in tandem to propel humans forward or backward or to maintain them at a standstill during daily activities. Balanced levels of stress (i.e., distress and eustress) can energize people to greater productivity and to enhanced enjoyment of what they do and create (Cox \& Harquail, 1991; Gattiker \& Larwood, 1990; Tharenou, Latimer \& Conway, 1984). Additionally, Sparks and Hammond (1981) recognized in their research that a stressful event may be distress on one occasion and eustress on another.

However, "stress becomes a problem when it ceases to be a healthy stimulus, but instead creates a burden the individual cannot handle without harmful effects ... events do not in themselves produce distress reactions . . . it is one's perception of events that makes them distressful"' (Cedoline, 1982, p. 2). Research conducted by Dunham (1984) confirmed and supported Cedoline's studies. Furthermore, he and other researchers noted that in work environments, as stress surpassed balanced levels and became distress, a person's job satisfaction declined, thus compromising job performance, morale and commitment to the organization (Assoulini \& Meir, 1987; Fried \& Tiegs, 1995; Judge, Boudreau \& Bretz, 1994; Kahn \& Byosiere, 1992; Sutherland \& Cooper, 1988; Schwab, Jackson \& Schuler, 1986). Thus, stress in general can aid and support human beings' every activity if there is a balance between distress and eustress. 
The next section discusses stress in relation to teacher stress and will commence with comprehensive definitions of that condition.

\section{Definitions of Teacher Stress}

Stress has also been more specifically defined for the teaching profession. Swick and Hanley (1985) defined teacher stress as "the occurrence of perceived negative situations that result in adverse teacher responses or behaviors" (p. 25). Needle et al. (1980) defined teacher stress as discrepancies between needs, values and expectations, professional rewards or role demands, and the ability of the teacher to meet these requirements. Moracco and $\mathrm{McFadden}$ defined teacher stress as:

an alteration of psychological homeostasis usually accompanied by physiological changes resulting from aspects of the teacher's job and mediated by the perception that the demands upon the teacher are threats to self-esteem or well-being, and by psychological coping mechanisms employed to maintain homeostasis (1980, p. 5). Kyriacou and Sutcliffe offered a similar definition:

a response syndrome to negative effects (such as anger or depression) by a teacher usually accompanied by potentially pathogenic physiological changes (such as increased heart rate) resulting from aspects of the teacher's job and mediated by the perception that the demands made upon the teacher constitute a threat to his self-esteem or well-being and by coping mechanisms activated to reduce the perceived threat $(1978$, p. 2$)$. 
For the purpose of this study, Kyriacou and Sutcliffe's definition of stress will be utilized to describe teacher stress. In the following sections teacher stress research and findings, from the 1930 s to the present, are critically reviewed.

\section{Teacher Stress Research}

"The incidence of various types of emotional maladjustment, particularly anxiety, among teachers has received considerable attention since early in this century" (Coates \& Thoresen, 1976, p. 160). In 1933, 600 classroom teachers participated in a study on teacher stress, anxiety, and mental health (Hicks, 1933). Hick's research discovered that $17 \%$ of the participants were "unusually nervous," and that another $11 \%$ suffered a nervous breakdown. Another study of 110 female teachers, conducted in the same year, revealed that $33 \%$ suffered from symptoms of nervousness and anxiety (Peck, 1933). In 1938 , the NEA, from a nationwide sample of 5,150 teachers, reported that $37.5 \%$ were seriously worried and nervous, and in 1950, 43\% of 2,200 teachers indicated that they were working under considerable strain and tension (NEA, 1938, 1951). Another early study examined the relationship between absenteeism and nervous conditions (Randall, 1951). Randall discovered that $10 \%$ of teacher absences were due to fatigue, prolonged menstrual disorders and situational reactions -- all of which had been brought on and exacerbated by stressful conditions.

In 1967 , the NEA again conducted research which revealed that $78 \%$ of the teachers in the study experienced moderate or considerable levels of stress (NEA, 1967). In the late 1970s, the Chicago teachers' union polled members about stress-related illness. 
Of the 5,500 participants, $56 \%$ stated that they suffered from job-related physical and/or mental illness (Walsh, 1979). During the 1977 annual convention of American Association of School Administrators, teaching was acknowledged as one of the top three most stressful professions (Hunter, 1977). The National Education Association surveyed 2,165 public school teachers in the United States with the following findings: $9 \%$ planned on leaving the profession as soon as possible; and $41 \%$ claimed they would choose a different profession if they had to do it all over again (NEA, 1979).

Studies such as these began to promote more research about the association of environmental characteristics to teacher stress levels. D'Arienzo et al. (1982) defined environmental stressors as "those ingredients within the teaching profession which, when mixed together, produce a situation best characterized as responsibility without control" (p. 24). Furthermore, varying levels of teacher stress were seen as a primary factor in promoting job satisfaction or dissatisfaction. Researchers investigated, analyzed and synthesized forty years of research, data and findings. The three key areas, all of which have relevance to the present study, include role demands/conflicts, environmental demands, and principal support and leadership.

\section{$\underline{\text { Role Demands/Conflicts and Environmental Demands }}$}

Many of the studies described above link role demands/conflict and environmental demands to teacher stress levels. Coates and Thoresen (1976) reviewed studies from 1939 to 1974 on teacher anxiety and its causes, while carefully investigating role demands/conflicts and environmental demands. Thirty-five years of literature on teacher 
stress (or anxiety) revealed common sources of reported anxiety: pupil discipline, class size, lack of supplies, inadequate salary and benefits, and especially time demands. In the following table, Coates and Thoresen arranged 35 years of research and findings on sources of anxiety for experienced teachers.

Table 1

Experienced Teachers' Reported Sources of Anxiety

\begin{tabular}{cc}
\hline Study & Reported Sources of Anxiety \\
\hline 1. National Education Association (1939) & class interruptions: bulletins, announcements, \\
& errands, and special events \\
adapting class program to individual & differences in ability, interest, need \\
& adapting promotion standards \\
& to meet a "no failure" ideal without \\
& neglecting "minimum essentials" \\
& expected by the school or without \\
endangering future school adjustment & and progress of pupils \\
clerical activities-mimeographing class \\
materials, work sheets, transcribing \\
records, test results for central files \\
total number of pupils assigned \\
size of individual class
\end{tabular}


Table 1 (cont.)

Experienced Teachers' Reported Sources of Anxiety

\begin{tabular}{ll}
\hline Study & Reported Sources of Anxiety \\
\hline 2. NEA (1951) & number or type of pupils \\
& inadequacy of school facilities \\
& extracurricular responsibilities \\
& clerical and administrative work \\
& instructional planning
\end{tabular}

3. NEA (1967)

insufficient time for rest and preparation in school day

large class size, inadequate salary inadequate fringe benefits

insufficient clerical help

4. Susskind et al. (1969) incompatible relationships with supervisor his petty demands, inability to communicate with him, his anger when things are not done his way assignment of paraprofessional duties recess and lunch duty 


\title{
Table 1 (cont.)
}

\section{Experienced Teachers' Reported Sources of Anxiety}

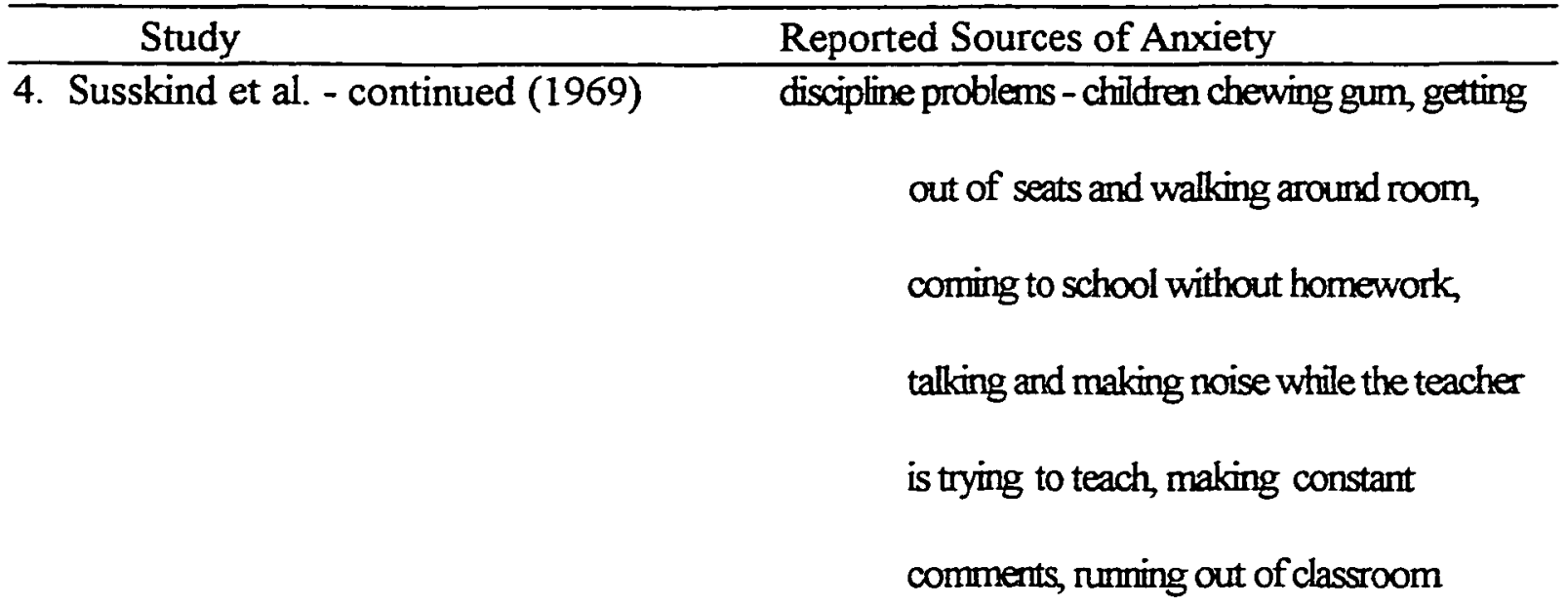

5. Olander \& Farrell (1970)

\author{
finding time for individual and remedial work \\ working without benefit of a daily preparation \\ period \\ obtaining funds for the purchase of extra \\ classroom aids \\ finding time for creative teaching \\ planning lessons, grading papers, \\ completing report cards
}

6. Fuller (1969); Parsons \& Fuller (1972) concerns with pupils - ability to understand pupils' capacities, to specify objectives for them, to assess their gain, 
Table 1 (cont.)

Experienced Teachers' Reported Sources of Anxiety

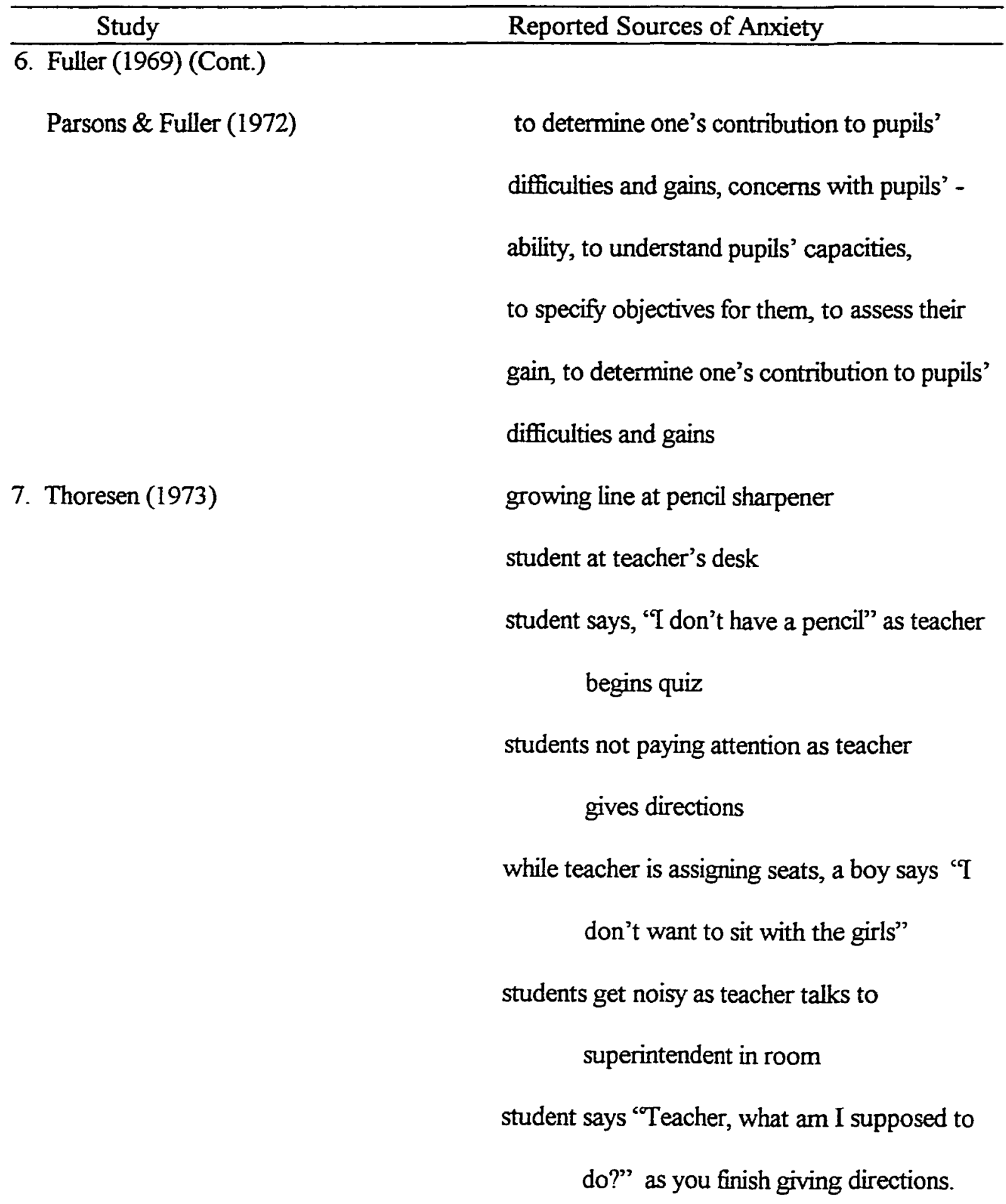


Table 1(cont.)

Experienced Teachers' Reported Sources of Anxiety

\begin{tabular}{lc}
\hline Study & Reported Sources of Anxiety \\
\hline 7. Thoresen et al. - continued (1973) & student becomes belligerent when teacher \\
corrects him & one boy says, 'I won't do it" when teacher \\
gives students instructions \\
principal says, 'We don't have enough money" \\
when teacher makes suggestions that \\
would help him do a better job of teaching
\end{tabular}

1. From "Teacher anxiety: A review with recommendations," by T. J. Coates and C. E. Thoresen, 1976, Review of Educational Research, 46(2), p. 162-167. Copyrighted 1976 by the American Educational Research Association; reproduced with permission from the publisher.

In a similar investigation of previous studies, Turk, Meeks and Turk (1982) reviewed 40 years of research about teacher stress. They concurred with Coates and Thoresen's conclusions on role demands/conflicts and environmental demands. More specifically, there was insufficient time to fulfill the requirements of their position due to large work loads, extracurricular activities, excessive paperwork and clerical duties, supervision duties (e. g., bus monitor, recess and lunch duty), no lesson preparation time, and few or no breaks (NEA, 1939, 1951; Rudd \& Wiseman, 1962; Susskind et al., 1969; Olander \& Farrell, 1970; Kryiacou \& Sutcliffe, 1978; Landsman, 1978; Meeks, 1979). They also postulated that inadequate teacher training contributed to teacher stress by 
exacerbating problems in the areas of sustaining pupils' attention and interest, inadequate preparation, effectively responding to individual and group differences, preparing and executing student activities, and dealing with a diverse range of student personalities and behavior patterns (Rudd \& Wiseman, 1962; Study Commission on Undergraduate Education and the Education of Teachers, 1976; Gaede, 1978; Cook, 1979).

Swick and Hanley (1985) also investigated role demands/conflicts and environmental demands in the areas of time and scheduling pressures, internuptions during lessons, excessive and diverse paperwork demands, compliance with federal programs and increased curriculum development. Their analyses of past studies on teacher stress research revealed several findings: stressors limited break time and/or time to relax; teachers frequently departed work physically and emotionally exhausted, and/or felt angry and frustrated; and stress levels could be even higher if stress originated from two or more of the above areas. The following tables categorize specific environmental stressors revealed during their investigations.

Table 2

Swick Report Findings on Causes of Teacher Stress from Time and Scheduling Pressures

\begin{tabular}{ll}
\hline Contributing Researchers & Specific Stressor \\
\hline Coates \& Thoresen, 1976; & taking roll, \\
Kyriacou \& Sutcliffe, 1978; & collecting various items from students \\
Landsman, 1978; & (money, permission slips, homework, etc.), \\
Olander \& Farrell, 1970; & correspondence with parents,
\end{tabular}


Table 2 (cont.)

Swick Report Findings on Causes of Teacher Stress from Time and Scheduling Pressures

\begin{tabular}{ll}
\hline Contributing Researchers & Specific Stressor \\
\hline Leffingwell, 1979. & parent teacher conferences/meetings, \\
& reports cards, \\
& planning and preparing lessons, \\
& grading papers, \\
& supervisory duties and \\
meeting the needs of individual students.
\end{tabular}

Table 3

Swick Report Findings on Causes of Teacher Stress from Interruptions During Lessons

\begin{tabular}{ll}
\hline Contributing Researchers & Specific Stressor \\
\hline Hamburg, 1977; & announcements, \\
Hodge \& Marker, 1978; & special assemblies, \\
Styles \& Cavanaugh, 1977 & fundraising events, athletics, sick children, \\
& pull-out programs and visiting parents.
\end{tabular}

Table 4

Swick Report: Causes of Teacher Stress from Excessive \& Diverse Paperwork Demands

\begin{tabular}{ll}
\hline Contributing Researchers & Specific Stressor \\
\hline Kyriacou \& Sutcliffe, 1978; & completing forms, reports \\
Ingram, 1979; Walsh, 1979. & assessments, notices and \\
& developing and writing curricular materials.
\end{tabular}


Table 5

Swick Report: Causes of Teacher Stress from Compliance with Federal Programs

\begin{tabular}{ll}
\hline Contributing Researchers & Specific Stressor \\
Harlin, 1978; & Special Education Programs, \\
Bensky et al, 1979. & needs of Special Education students, \\
inadequate teacher preparation and training & to meet the goals and objectives of \\
Federal Programs and compliance & issues, \\
insufficient funding of federally mandated \\
programs, \\
limited school facilities or educational \\
environment to implement program(s), \\
and physical and emotional burden to implement \\
and manage the program.
\end{tabular}

Table 6

Swick Report Findings on Causes of Teacher Stress from Increased Curriculum Demands

Contributing Researchers $\quad$ Specific Stressor

Dillon, 1978; Hodge \& Marker, 1978; development and preparation of new

Needle, Griffen, Svendsen, \& Berney, 1980; $\quad$ curriculum, insufficient instructional

Olander \& Farrell, $1970 . \quad$ materials and other related teaching

resources. 
Additionally, Billingsley (1993), Chen \& Miller (1997), Gold and Roth (1993), and Wisniewski and Gargiulo (1997), reviewed research on teacher stress dating from the 1940s. Findings from the 1970 s to the present paralleled each other in many studies that is factors which had caused stress back in the 1970s and 1980s were still causing stress in the 1990s. Teacher stress levels were still a factor of role demands/conflicts and environmental demands. However, the intensity of stress experienced by teachers continued to increase. A striking example of increased demands on teachers and exacerbated stress levels was adeptly portrayed in a comparison of 1940s' and 1980s' problems encountered in schools (Metropolitan Milwaukee Chamber of Commerce, 1990). In the 1940 s, specific contributing factors toward teacher stress included talking out of turn, chewing gum, making noises, running in the halls, cutting in line, violating the dress code and littering. In the 1980s, specific contributing factors had evolved into drug abuse, alcohol abuse, pregnancy, suicide, rape, robbery and assault. The contrast and degree of change between the 1940s and 1980s of student behavior represents only one source of stress within role demands/conflicts and environmental demands. However, it is a poignant example of how pressure on teachers continued to increase stress levels. In the next section, a critical review of the literature on principal support and leadership will expose another primary source of teacher stress.

\section{Principal Support and Leadership}

The Turk report revealed that differing opinions on educational policy and use of resources (Reitman, 1971; Gesten, et al., 1978; Youngs, 1978; Meeks, 1979), too many 
poor administrators or disliked administrators ("Professional Satisfaction", 1975), principal's leadership style such as ability to tolerate/permit staff freedom and/or administrate (Schroder, 1978), and lack of principal concern and appreciation for staff (Cook, 1979) all caused increased teacher stress levels. Swick and Hanley (1985) discovered similar findings during their review of the literature on principal support and leadership as a source of teacher stress. Additionally, principals were perceived as creating threatening situations for teachers which arose from ineffective communication between staff and principal in the areas of evaluations, job expectations, school/district policies and staff changes (Gmelch, 1982a, Hodges, 1976; Youngs, 1978). D'Arienzo et al. (1982) conducted similar research on environmental stressors. Of all the environmental stressors studied, principal leadership and support was identified as producing the most stress for teachers. More specifically, a principal that communicated ineffectively or infrequently, did not recognize or praise staff, remained distant and inaccessible and rarely listened to teacher opinions caused more stress in the teaching staff and led to higher rates of teacher burnout.

Kremer-Hayon and Kurtz (1985) examined the relationship between both individual and situational variables as a cause of not only teacher stress, but also teacher burnout. They believed that principals who promoted teacher involvement in school policy making, were responsive to their needs and wants, conducted fair and objective evaluations and communicated to staff in a timely and thorough manner aided in the reduction of environmental stressors. Brissie, Hoover-Dempsey, \& Bassler (1988) also examined the same variables and concluded that principals who permitted teachers to be part of setting 
and accomplishing goals, provided continual support for the teaching staff and increased a staff's feeling of being effective through constant communication lowered stress levels considerably. The following section focuses on principal leadership styles relationship to teacher stress levels.

\section{Principal Leadership Styles and Teacher Stress}

Perceived principal leadership behavior and its relationship to teacher stress and burnout has also been the focus of research. Hanchey and Brown (1989) examined the relationship between role strain and teachers' perceptions of principal leadership behavior. The researchers defined role strain as the complications which teachers face while accomplishing and fulfilling their duties. Findings indicated that the degree of role strain was linked to teacher stress and burnout. The most profound predictors were a principal's lack of management skills and consideration of teachers' needs and concerns.

Cook (1983) focused upon two leadership dimensions in principals: Initiating Structure and Consideration. The data indicated that principals with low-consideration leadership behavior increased teachers' stress levels in the areas of emotional exhaustion and depersonalization. Additionally, principals with high-consideration leadership behavior lowered teacher stress by increasing personal accomplishment. Johnson (1990) obtained similar results when she investigated consideration and initiating structure leadership behavior in relationship to teacher stress using four subscales: career satisfaction, perceived administrative stress, coping with job-related stress and attitudes toward students. Principals high on Consideration and Initiating Structure had teachers 
with the lowest levels of stress, and principals high on Consideration and low on Initiating Structure had lower stress levels than did their inverse.

Barnette (1990) also investigated the relationship between principal leadership behavior and teacher stress. Causes of teacher stress were defined as student behavior, employee/ administrative relations, teacher/teacher relations, parent/teacher relations, time management, intrapersonal conflicts, physical symptoms of stress, psychological/emotional symptoms of stress, and stress management techniques. The researcher's findings indicated that teachers who perceived their principal's dominant leadership style to be consideration-oriented experienced less stress than those whose dominant leadership style was initiating structure-oriented. Paré (1995), in her research into prolonged teacher stress, investigated principal leadership style adaptability. She looked at emotional exhaustion, depersonalization and personal accomplishment as factors causing teacher stress. Her findings also supported lower stress levels in teachers when the principal was "being supportive, listening to their concerns with an open mind, and demonstrating professional respect by incorporating their ideas when making decisions" (p. 127) all of which correlated to high-consideration leadership style.

Roberts (1983) investigated the relationship between principal leadership styles, teacher stress and job related outcomes - such as job performance, job satisfaction and absenteeism. Findings indicated that teachers at schools with high-consideration and highstructure principals, high-consideration and low-initiating structure principals and lowconsideration and high-structure principals experienced less occupational stress than did teachers at schools with low-consideration and low-structure principals. Blase, Dedrick 
and Strathe (1986) also examined the relationship between the factors of Consideration and Initiating Structure leadership behavior in conjunction with teacher stress, satisfaction and job performance. Their results were consistent with Robert's -- high levels of consideration and structure coincided with lower levels of perceived teacher stress. Tawari (1982) investigated principal leadership styles and teacher morale while also considering the variables of teachers' gender, training, and experience. Gender and training factors, correlated with high structure, and additionally, experience correlated with high consideration both lowered teacher stress levels and in turn raised teacher morale. Bhella (1982) investigated consideration (concern for people) and structure (concern for production) in relation to teacher morale. Data indicated that highconsideration and high-initiating structure increased teacher morale and lowered teacher stress levels.

In summary, research on principal leadership styles and teacher stress reveals that leadership behavior styles are a prominent predictor of either high or low levels of teacher stress. Studies critically reviewed in this section investigated various factors which were considered causes of teacher stress and correlated them to either consideration or initiating structure leadership styles, or a combination of the two. As stated earlier the study of leadership styles did not produce a grand theory of effective leadership behavior. However, research tends to confirm that a consideration-oriented style is generally associated with lower stress levels than a structure-oriented style, thus supporting the primary hypothesis in the next chapter. Nevertheless, the leadership styles approach does provide a framework with which a principal can evaluate his or her leadership approach, 
be it task-oriented, relationship-oriented, or a combination of the two dimensions. It equips the principal with a tool that enables him or her to be constantly cognizant of leadership styles, able to adjust them to a given situation, and able to respond according to the needs of others and/or the organization. 


\section{CHAPTER II}

\section{METHODOLOGY}

\section{Study Design}

The study design was a cross-sectional, correlation design. It was based upon research methodologies most commonly used when examining principal leadership styles and school-site conditions relationship to teacher stress levels. Similar methodologies have been successfully used in several studies including D'Arienzo, Moracco \& Krajewski (1982), Johnson (1990), Paré (1995), and Roberts (1983). Data was gathered using the Leader Behavior Description Questionnaire (LBDQ), the Teacher Stress Inventory (TSI), and a demographic information sheet (Appendices A, B, \& C). Additional information was obtained from the San Diego Unified School District's publication, School Accountability Report Cards (1998), and from the principals at each site.

The LBDQ was developed by the Ohio State University and measured two dimensions of leadership: consideration and initiating structure. Additionally, these two dimensions were identified and investigated in combination during this study: HighConsideration, High-Initiating Structure (HC-HIS); High-Consideration, Low-Initiating Structure (HC-LIS); Low-Consideration, High-Initiating Structure (LC-HIS); and LowConsideration, Low-Initiating Structure (LC-LIS). The TSI was developed by Dr. 
Michael J. Fimian and measured teacher stress levels. The level of teacher stress was determined by scores on the TSI in terms of sources of stress (time management, work related stressors, professional distress, student discipline \& motivation, and professional investment) and manifestations of occupational stress (emotional, fatigue, cardiovascular, gastronomic, and behavioral manifestations). The TSI rendered ten subscale scores (as listed above in parentheses) and one Total Stress Score for each participant.

Furthermore, school-site conditions were defined in terms of organizational factors that were common to all schools participating in the study and that could possibly have a relationship with teacher stress levels. These data were provided by SDUSD's School Accountability Report Cards, by the teacher demographic section of the survey, and by the principal at each site. School-site conditions included: school year calendar, staff size, dollars spent per pupil, unexcused student absences, student suspensions, instructional minutes per year, student ethnicity, Stanford Achievement Test (SAT-9) scores, Coordinated Compliance Review requirements (a form of program quality review required by the State of California), number of vice principals on-site, and demographic information about the principal and teachers.

The data obtained for this study were analyzed using descriptive statistical procedures (i.e., central tendency measures), Pearson's Product-Moment Correlation Coefficients to indicate the degree of relationship between all the variables, and also subjected to a stepwise multiple regression in order to predict the level of teacher stress as a function of principal leadership styles and also as a function of school-site conditions. Teacher stress was examined in two ways. First, the researcher investigated principal 
leadership styles relationship with teacher stress levels. Second, the researcher examined school-site conditions' relationship with teacher stress levels using the previously mentioned statistical procedures.

\section{$\underline{\text { Research Questions }}$}

Research Question \#1: Will there be a significant relationship between teachers' stress levels at schools with principals who are perceived as exercising High-Consideration (relationship-oriented) leadership behavior and teachers' stress levels at schools with principals who are perceived as exercising Low-Consideration (relationship-oriented) leadership behavior?

Research Question \#2: Will there be a significant relationship between teachers’ stress levels at schools with principals who are perceived as exercising High-Initiating Structure (task-oriented) leadership behavior and teachers' stress levels at schools with principals who are perceived as exercising Low-Initiating Structure (task-oriented) leadership behavior?

Research Question \#3: Will there be a significant relationship between teachers' stress levels at schools with principals who are perceived as exercising High-Consideration (relationship-oriented)/Low-Initiating Structure (task-oriented) leadership behavior and teachers' stress levels at schools with principals who are perceived as exercising LowConsideration (relationship-oriented)/High-Initiating Structure (task-oriented) leadership behavior? 
Research Question \#4: Will there be a significant relationship between teachers’ stress levels, on the one hand, and principals' leadership styles, and school-site conditions, on the other?

\section{Null Hypotheses to be Tested}

$\mathbf{H}_{1}$ : There will be no significant relationship between teachers' stress levels at schools with principals who are perceived as exercising High-Consideration (relationship-oriented) leadership behavior and teachers' stress levels at schools with principals who are perceived as exercising Low-Consideration (relationship-oriented) leadership behavior.

$\mathbf{H}_{2}$ : There will be no significant relationship between teachers' stress levels at schools with principals who are perceived as exercising High-Initiating Structure (task-oriented) leadership behavior and teachers' stress levels at schools with principals who are perceived as exercising Low-Initiating Structure (task-oriented) leadership behavior.

$\mathbf{H}_{3}$ : There will be no significant relationship between teachers' stress levels at schools with principals who are perceived as exercising High-Consideration (relationshiporiented)/Low-Initiating Structure (task-oriented) leadership behavior and teachers' stress levels at schools with principals who are perceived as exercising Low-Consideration (relationship-oriented)/High-Initiating Structure (task-oriented) leadership behavior.

$\mathbf{H}_{4}$ : There will be no significant relationship between teachers' stress levels, on the one hand, and principals' leadership styles and school-site conditions, on the other. 
Variables Evaluated in Study

Dependent Variables (as measured by TSI)

Sources of Stress

1. Time Management

2. Work-Related Stressors

3. Professional Distress

4. Student Discipline \& Motivation

5. Professional Investment
Manifestations of Occupational Stress

1. Emotional Manifestations

2. Fatigue Manifestations

3. Cardiovascular Manifestations

4. Gastronomic Manifestations

5. Behavioral Manifestations

Independent Variables

Leadership Variables (as measured by LBDQ)

1. Consideration: relationship-oriented leadership behavior

2. Initiating Structure: task-oriented leadership behavior

School-Site Conditions Variables (as obtained from School Accountability Report Cards, from the demographic information sheet, and from principals at each school-site).

1. Stanford Achievement Test, Ninth Edition (SAT-9)

2. Student Behavior/Discipline (measured by student suspensions)

3. Percentage of Unexcused Student Absences

4. Class Size

5. School Staff Size

6. Type of Class Taught (GATE, Bilingual, Sheltered, SED, Spec. Ed, etc.) 
$\underline{\text { School-Site Conditions Variables (cont.) }}$

7. Grade Level Taught

8. Type of Teaching Credential Held

9. Teachers' Years of Experience (at currrent site and in district)

10. Gender (teachers' and principals')

11. Student Ethnicities (as a percentage of the school's student population)

12. Age of Teachers

13. Instructional Minutes per Year by Elementary School and Grades

14. Highest Degree Earned (Teachers' Education Level)

15. Dollars Spent per Student by School-site

16. Principals' Demographics (years of experience, ethnicity and gender)

17. School Year Calendar (traditional or year-round)

18. Participation in Coordinated Compliance Review process (CCR)

\section{Population Description and Sampling Procedure}

San Diego Unified School District (SDUSD) is the eighth largest school district in the United States, serving almost 140,000 students and employing over 7,500 teachers. Elementary schools from SDUSD comprised the sample population used in this investigation. Those schools were selected only after approval had been received from SDUSD's Department of Research and Reporting Unit, and the University of San Diego's Committee on the Protection of Human Subjects. Their approval allowed the researcher to approach any elementary school in SDUSD for participation. However, the principals 
of each elementary school could still decline participation in the proposed research project. Permission was obtained through an E-mail sent by Dr. Mariam True, (my SDUSD Research Sponsor) to each principal of a selected school. In addition, the researcher followed-up with phone calls to each principal. The researcher explained the study and answered any questions. Once the principal agreed to allow his/her teachers to participate in the study, a day and time (during a regularly scheduled staff meeting) were agreed upon when the researcher would come to the school and explain the study to the staff. This time was also used to ask for their permission to participate in the study. The principals' permission only gave the researcher the ability to approach the teaching staff and ask their permission to participate. The responsibility for acquiring permission from a teaching staff was upon the researcher and not the principal. All schools willing to participate were administered the survey at the earliest available staff meeting.

From a pool of 115 elementary schools within SDUSD, twenty-eight sites were selected via a stratified random sampling procedure. The schools' teaching staff sizes varied from fourteen teachers to sixty-one teachers. The school sites' teacher populations are not homogeneous (i. e. staff size, academic programs offered, student populations, etc.). When this occurs "a population may instead be heterogeneous and consist of several subpopulations, which are called strata. . . we would use stratified random sampling; we would first define the strata and then take random samples of members of each stratum" (Hinkle et al., p. 183). Stratified random samples reduce the likelihood that a sample is under-representative of the studied population as a whole (Huck \& Cormier, 1996; Patten, 1997). 
The strata were determined by school teaching staff size. Specific strata were defined and arranged by the following ranges of school staff sizes:

1. 1 to 24 teachers

2. 25 to 37 teachers

3. 38 and more teachers

School staff size was obtained from SDUSD's Department of Communications and Community Relations Divisions via their School Accountability Report Cards. In conclusion, stratified random sampling by school teaching staff size ensured a more wellbalanced and representative sample of SDUSD as a whole. Additionally, it helped mask the identity of participating schools. Data were analyzed by the three strata and as an overall sample consisting of all twenty-eight schools.

Teachers at the school sites selected through stratified random sampling, and also willing to participate, were administered the LBDQ, TSI, and a demographic information sheet. Teachers had to meet the following inclusion criteria in order to participate in this study. The inclusion criteria for teachers were for those who:

1) were regular teaching-staff members of the school with a full time or part time contract with San Diego Unified School District during the 1998-1999 school year;

2) held a preliminary multiple subject teaching credential, clear professional teaching credential, an emergency teaching credential, or any other California Commission on Teacher Credentialing (CTC) recognized credential;

3) had been at the school site since August 26, 1998, the first day of the 19981999 school year. 


\section{Survey Administration Procedure}

All teachers who participated were administered the LBDQ, TSI, and demographic information sheet at the site and during a staff meeting. Most teachers completed all three instruments within twenty-five minutes and gave them directly to the researcher. All information provided by the teachers was recorded on scantron sheets. Prior to completing the three instruments, the researcher explained the study and the informed consent form, gave directions on how to complete the survey (Appendix $\mathrm{J}$, answered any questions, and had all participants sign an informed-consent form (Appendix E).

\section{Data Collection and Instrumentation}

Data for the study on principal leadership styles and school-site conditions relationship to teacher stress levels were gathered through self-report questionnaires: LBDQ, TSI, and an additional demographic information page. The LBDQ and TSI instruments were developed and tested to facilitate the collection of standardized data about perceived leadership behavior and teacher stress levels, and both have been assessed repeatedly for reliability and validity. The personal demographic information sheet was provided as part of the TSI with the understanding that additional items may be added.

The LBDQ was developed in 1957 by Ralph M. Stogdill, Alvin E. Coons and John K. Hemphill at Ohio State's Leadership Studies Program. It consisted of forty items to describe a leader's behavior style. "The final version of the LBDQ was constructed by selecting 15 items loading on the Initiating Structure factor and 15 items loading on the Consideration factor. Ten additional items were used as buffer items" (Buros, 1978, p. 
1746). Items regarding Initiating Structure measured a leader's task-oriented leadership behavior such as subordinate role responsibilities, established patterns of organization, and methods to accomplish tasks. Items regarding Consideration measured a leader's relationship-oriented behavior such as "friendship, mutual trust, respect, and warmth in relationship between the leader and members of the group" (p. 1746). Teachers responded to the questions by using an A to $\mathrm{E}$ rating scale: A-Always, B-Often, C-Occasionally, D-Seldom and E-Never. Scores were obtained for each of the two leadership dimensions. The score for Consideration and Initiating Structure leadership behavior styles were obtained by adding the scores for each of the fifteen items in each leadership dimension. The range for each one was from zero to sixty, with sixty being on the high end of either Consideration or Initiating Structure leadership styles.

The LBDQ is considered one of the most reliable and valid measurement instruments in the area of leadership behavior styles. It was originally tested and standardized on hundreds of B-29/B-50 aircraft commanders and educational administrators. The Spearman-Brown formula determined that the split half method had coefficients of .92 and .93 for consideration, and .83 and .86 for structure (Kunz \& Hoy, 1976). Fleishman (1956) and Halpin (1958) both examined the LBDQ's validity and determined that the agreement among respondents, in describing their leaders, was checked by a between versus within group analysis of variance, and $\mathrm{F}$ ratios were all found significant at a .01 level. The initiating structure and consideration factors have high coefficients of internal consistency, and interrater agreement is high enough to justify procedures outlined in the administrator's manual. Furthermore, the LBDQ has good face 
validity; items are easily understood, and they coincide with common leadership behavior typically found in various work settings. Since the development of the LBDQ in the 1940s, the instrument was refined in the 1950s and has been used now for over forty years. It is still considered one of the best measurement instruments in the field of situational leadership studies. In relation to teacher stress levels, the TSI is also considered a useful tool.

The TSI was first developed in the early 1980s and refined throughout the decade by Michael J. Fimian. It consists of 49 self-report items designed to measure the occupational stress experienced or exhibited by public school teachers (Kramer \& Conoley, 1992). Teachers respond to the questions by using the following $A$ to $E$ rating scale indicative of stress in relation to stressful events: A none, B mild, C medium, D great and $\mathrm{E}$ major. Scores are obtained for each of the ten subscales and a Total Stress Score is obtained by averaging scores for all subscales. The items are grouped by sources of stress and manifestations of occupational stress, and into ten subscales: Time Management, Work-Related Stressors, Professional Distress, Student Discipline \& Motivation, Professional Investment, Emotional Manifestations, Fatigue Manifestations, Cardiovascular Manifestations, Gastronomic Manifestations, and Behavioral Manifestations. The ten subscales were defined in the operational definition's section of chapter 1, pages 10-11.

The TSI possesses good reliability and high validity. It was assessed using expert opinion ( $n=226$ ) over five years, and the alpha coefficient was above .80 for all ten factors and above .90 for the entire scale. Internal consistency reliability, as examined by 
Cronbach's alpha, was .93, and subscale reliability varied from .75 (Professional Investment) to .88 (Gastronomic Manifestations). Test-retest reliability was conducted twice ( $n=60)$ with time spans between administration ranging from two hours to two weeks. "Test-retest reliabilities ranged from .67 (1-week interval) to .99 (2-week interval) for the whole scale" (Kramer \& Conoley, 1992, p. 919). Additionally, Fimian (1986) states that alpha estimates were $.77-.90$ for the subscales, $.91-.94$ for the whole scale, and $.83-.88$ for the short forms. Lastly, the scores can be compared to established norms determined by previous administrations of the test with a regular education sample $(n=962)$ and special education sample $(n=2,352)$.

\section{Data Analysis}

Data obtained by this study examined leadership behavior styles (two factors: consideration and initiating structure), school-site conditions, and teacher stress levels (eleven factors: time management, work-related stressors, professional distress, student discipline and motivation, professional investment, emotional manifestations, fatigue manifestations, cardiovascular manifestations, gastronomic manifestations, behavioral manifestations, and a Total Stress Score). The study design was a cross-sectional, correlation design. Pearson's Product-Moment Correlation Coefficients were calculated to indicate the degree of relationship between the variables of principal leadership styles, school-site conditions, and teacher stress levels. The data obtained for this study were also analyzed using stepwise multiple regression in order to predict the level of teacher stress as a function of principal leadership styles, and also as a function of school-site conditions. 


\section{Preliminary Analysis}

Demographic factors and school-site conditions such as sample population size (number of schools and teachers), school year calendar, and teachers' gender, ethnicity, age, education, type of class taught, and experience were described using descriptive statistical procedures.

\section{$\underline{\text { Primary Analysis }}$}

Pearson's Product-Moment Correlation Coefficients were calculated to indicate the degree of relationship between the variables of principal leadership styles, school-site conditions, and teacher stress levels. More specifically, correlations were calculated between the two independent variables of Initiating Structure and Consideration from the LBDQ and the dependent variables of teacher stress levels from the ten subscales and Total Stress Score derived from the TSI. Additionally, correlations were calculated between the independent variables of school-site conditions, and the dependent variables of teacher stress from the TSI.

The data obtained for this study were also analyzed using stepwise multiple regression. The independent variables were principal leadership styles and school-site conditions and the dependent variables were teacher stress levels. The alpha level was set at .05 . Stepwise multiple regression was conducted in order to predict the value of the dependent variables of Teacher Stress (as measured by the TSI's eleven scales) from the values of one or more independent variables comprising Principal Leadership Styles (as measured by the LBDQ) and School-Site Conditions. The computer program SPSS 
analyzed all variables in this study by using forward inclusion and backwards elimination to determine which independent variable or combination of independent variables would predict the greatest amount of variance in the dependent variables.

\section{Protection of Human Subjects}

\section{Potential Risks}

The nature of the study suggested minimal risk to participants beyond the demands on their time. The surveys focused on leadership, stress, and demographic information; they did not involve inquiry into personal beliefs or controversial issues. However, if any teacher had suffered from psychological effects, during or after participation in the study, s/he could have contacted the Employee Assistance Services for Education (EASE) at 619-277-0063 and received six free office visits per calendar year with a counselor or psychologist. Teachers received information on how to contact EASE prior to participating in the study. Furthermore, school-site administrators and school nurses could also have provided teachers with information on how to contact EASE. Additionally, the participant could also have contacted the primary investigator and/or Dr. Ronn Johnson, dissertation director.

\section{Risk Management Procedures}

Informants' rights, interests, and sensitivities were safeguarded through the use of protocols established by the San Diego Unified School District's Research and Reporting 
Unit, and the University of San Diego's Committee on the Protection of Human Subjects. No client identifiers were requested on any of the surveys. Confidentiality and anonymity were maintained. All surveys were secured away from the school district. Additionally, the researcher explained how to participate in the study, how data would be analyzed, how to obtain results, and also answered any and all questions. Furthermore, all teachers signed an informed-consent form prior to participating in the study. No teacher was forced to participate. Teachers could have declined to participate at any time during the survey without any undue or unfavorable consequences. If a teacher did refuse to participate, his/her position at the district was in no way affected (i.e. potential promotions or dismissals).

\section{Summary}

This study proposed the use of a cross-sectional, correlation design to analyze the relationship between principals leadership styles, school-site conditions, and teachers' stress levels. Additionally, the relationship between school-site conditions and teacher stress levels was examined. Such analysis was undertaken most appropriately with quantitative research methods. In this case, correlation and multiple regression analyses were used in addition to descriptive statistics. A stratified random sample of twenty-eight elementary schools in SDUSD participated in the study. All teachers who participated at the twenty-eight sites completed the Leader Behavior Description Questionnaire (LBDQ), the Teacher Stress Inventory (TSI), and a demographic information sheet. Further data were gathered from SDUSD via School Accountability Report Cards (1998). 


\section{CHAPTER IV}

\section{RESULTS}

\section{Introduction}

The primary purpose of this study was to determine if principal leadership styles and school-site conditions were associated with the stress levels of elementary teachers in the San Diego Unified School District. Leadership styles were measured by using the Leader Behavior Description Questionnaire published by the Ohio State University and defined in terms of consideration and initiating structure. These two dimensions of leadership were identified and investigated in combination during this study: HighConsideration, High-Initiating Structure (HC-HIS); High-Consideration, Low-Initiating Structure (HC-LIS); Low-Consideration, High-Initiating Structure (LC-HIS); and LowConsideration, Low-Initiating Structure (LC-LIS).

School-site conditions were defined in terms of organizational factors common to all schools participating in the study and that could possibly have a relationship with teacher stress levels. These data were provided by the San Diego Unified School District's School Accoumtability Report Cards, by the teacher demographic section of the survey, and by the principal at each site. School-site conditions included: school year calendar, staff size, dollars spent per pupil, unexcused student absences, student 
suspensions, instructional minutes per year, student ethnicities, Stanford Achievement Test (SAT-9) scores, Coordinated Compliance Review requirements (a form of program quality review required by the State of California), number of vice principals on-site, and demographic information about the principal and teachers.

Teacher Stress was measured by the Teacher Stress Inventory published by Dr. Michael J. Fimian. The level of teacher stress was determined by scores on the TSI in terms of sources of stress (time management, work-related stressors, professional distress, student discipline and motivation, and professional investment) and manifestations of occupational stress (emotional, fatigue, cardiovascular, gastronomic, and behavioral manifestations). The TSI rendered ten subscale scores (as listed above in parentheses) and one Total Stress Score for each participant.

Statistical computations used to analyze the data were performed using Statistical Package for the Social Sciences computer software (SPSS). The analyses of these data will be discussed and presented in tabular and graphical representations.

\section{$\underline{\text { Participants }}$}

Five hundred and eighty-five teachers from twenty-eight elementary schools (K-6) in the San Diego Unified School District participated in the study. Those five hundred and eighty-five teachers, who chose to participate comprised $72 \%$ of the total teacher population at the 28 school-sites in this study. The twenty-eight sites were selected via a stratified random sampling procedure. The schools' teaching staff sizes varied from fourteen teachers to sixty-one teachers. The frequencies and percentages of 
additional teacher demographic information are presented in Table 7, by the overall sample, and stratum I (1-24 staff members), stratum II (25-37 staff members), and stratum WI (38-61 staff members).

Table 7

Teacher Demographic Information

\begin{tabular}{|c|c|c|}
\hline Variable & $\mathrm{N}$ & Percent $\%$ \\
\hline \multicolumn{3}{|c|}{ Number of Teachers } \\
\hline Overall Sample & 585 & $100 \%$ \\
\hline Stratum I & 156 & $26.7 \%$ \\
\hline Stratum II & 212 & $36.2 \%$ \\
\hline Stratum III & 217 & $37.1 \%$ \\
\hline \multicolumn{3}{|l|}{ Number of Schools } \\
\hline Overall Sample & 28 & $100 \%$ \\
\hline Stratum I & 12 & $42.9 \%$ \\
\hline Stratum II & 09 & $32.1 \%$ \\
\hline Stratum III & 07 & $25.0 \%$ \\
\hline \multicolumn{3}{|l|}{ Female Teachers } \\
\hline Overall Sample & 515 & $88 \%$ \\
\hline Stratum I & 129 & $22.1 \%$ \\
\hline Stratum II & 189 & $32.3 \%$ \\
\hline Stratum III & 197 & $33.6 \%$ \\
\hline \multicolumn{3}{|l|}{ Male Teachers } \\
\hline Overall Sample & 70 & $12 \%$ \\
\hline Stratum I & 27 & $04.6 \%$ \\
\hline Stratum II & 23 & $04.0 \%$ \\
\hline Stratum III & 20 & $03.4 \%$ \\
\hline \multicolumn{3}{|c|}{$\begin{array}{l}\text { Teachers Years at Current School Site } \\
\text { Overall Sample }\end{array}$} \\
\hline $0-5$ years & 345 & $59 \%$ \\
\hline $6-10$ years & 103 & $17.6 \%$ \\
\hline $11-20$ years & 106 & $18.1 \%$ \\
\hline $21-29$ years & 20 & $3.4 \%$ \\
\hline 30 or more & 11 & $01.9 \%$ \\
\hline
\end{tabular}


Table 7 (cont.)

Teacher Demographic Information

\begin{tabular}{lll}
\hline Variable & N & Percent \% \\
\hline
\end{tabular}

Teachers Years at Current School Site (cont.)

Stratum I

$\begin{array}{lll}0-5 \text { years } & 91 & 58.3 \% \\ 6-10 \text { years } & 26 & 16.7 \% \\ 11-20 \text { years } & 30 & 19.2 \% \\ 21-29 \text { years } & 05 & 03.3 \% \\ 30 \text { or more } & 04 & 02.6 \%\end{array}$

Stratum II

$0-5$ years 123

$58.0 \%$

6-10 years 37

$17.5 \%$

11-20 years 42

$19.8 \%$

21-29 years 06

$02.8 \%$

30 or more

04

$01.9 \%$

Stratum III

$0-5$ years 13

6-10 years 40

$60.4 \%$

11-20 years 34

$18.4 \%$

21-29 years

09

$15.7 \%$

30 or more

03

$04.1 \%$

$01.4 \%$

Teachers' Total Years Teaching

Overall Sample

$0-5$ years

6-10 years

155

95

11-20 years

172

21-29 years

113

30 or more

50

$26.5 \%$

$16.2 \%$

$29.4 \%$

$19.3 \%$

$08.5 \%$

Stratum I

$0-5$ years 41

$26.3 \%$

6-10 years

26

$16.7 \%$

11-20 years

46

$29.5 \%$

21-29 years

29

$18.6 \%$

30 or more

14

$09.0 \%$ 
Table 7 (cont.)

Teacher Demographic Information

Variable
Teachers' Total Years Teaching (cont.)
Stratum

Stratum II

$0-5$ years
$6-10$ years
$11-20$ years
$21-29$ years
30 or more

Stratum III

$$
\begin{aligned}
& 0-5 \text { years } \\
& 6-10 \text { years } \\
& 11-20 \text { years } \\
& 21-29 \text { years } \\
& 30 \text { or more }
\end{aligned}
$$

\section{Degrees Held by Teachers}

Overall Sample

B.S. or B.A.

Masters

Ph. D. or Ed. D.

\section{Stratum I}

B.S. or B.A.

Masters

Ph. D. or Ed. D.

Stratum II

B.S. or B.A.

Masters

Ph. D. or Ed. D.

Stratum III

B.S. or B.A.

Masters

Ph. D. or Ed. D.
$20.8 \%$

$13.7 \%$

$33.0 \%$

$21.7 \%$

$10.8 \%$
63

82

70

40

56

38

13

213

357

15

68

83

05

$43.6 \%$

$53.2 \%$

$03.2 \%$

144

05

$29.7 \%$

$67.9 \%$

$02.4 \%$

130

05
$37.8 \%$

$59.9 \%$

$02.3 \%$ 
Table 7 (cont.)

Teacher Demographic Information

Variable

Overall Sample

Multiple Subject CLAD

$55.7 \%$

Multiple Subject BCLAD

$9.2 \%$

Emergency Credential

$4.3 \%$

Single Subject

Other Teaching Credential

152

$4.8 \%$

$26 \%$

Stratum I

Multiple Subject CLAD

93

$59.6 \%$

Multiple Subject BCLAD

03

$01.9 \%$

Emergency Credential

13

$08.3 \%$

Single Subject

$03.2 \%$

Other CTC Credential

05

$26.9 \%$

Stratum III

Multiple Subject CLAD

135

$63.7 \%$

Multiple Subject BCLAD

10

$04.7 \%$

Emergency Credential

03

$01.4 \%$

Single Subject

12

$05.7 \%$

Other CTC Credential

52

$24.5 \%$

Stratum III

Multiple Subject CLAD

$45.2 \%$

Multiple Subject BCLAD

41

$18.9 \%$

Emergency Credential

09

$04.1 \%$

Single Subject

11

$05.1 \%$

Other CTC Credential

58

$26.7 \%$

\section{Type of Class Taught}

Overall Sample

Regular English

296

$50.6 \%$

Bilingual, Sheltered, or Transition

139

$23.8 \%$

G.A.T.E. and Seminar

69

$11.8 \%$

Resource Specialist or Special Ed.

32

Prep Teachers (P.E., Library, etc.)

37

$5.5 \%$

Other

12

$6.3 \%$

$2.0 \%$ 
Table 7 (cont.)

Teacher Demographic Information

\begin{tabular}{lll}
\hline Variable & N & Percent \\
\hline $\begin{array}{l}\text { Type of Class Taught (cont.) } \\
\text { Stratum I }\end{array}$ & \\
Regular English & & \\
Bilingual, Sheltered, or Transition & 97 & $62.3 \%$ \\
G.A.T.E. and Seminar & 27 & $17.3 \%$ \\
Resource Specialist or Special Ed. & 18 & $11.5 \%$ \\
Prep Teacher (P.E., Library, etc.) & 07 & $04.5 \%$ \\
Other & 07 & $04.5 \%$ \\
& 00 & $00.0 \%$
\end{tabular}

Stratum II

Regular English $\quad 120$

$56.6 \%$

Bilingual, Sheltered, or Transition

$10.8 \%$

G.A.T.E. and Seminar

36

$17.0 \%$

Resource Specialist or Special Ed.

11

$05.2 \%$

Prep Teacher (P.E., Library, etc.)

18

$08.5 \%$

Other

04

$01.9 \%$

Stratum III

Regular English

$36.4 \%$

Bilingual, Sheltered, or Transition

$41.0 \%$

G.A.T.E. and Seminar

15

$06.9 \%$

Resource Specialist or Special Ed.

14

$06.5 \%$

Prep Teacher (P.E., Library, etc.)

12

$05.5 \%$

Other

08

$03.7 \%$

\section{Class Size}

Overall Sample

1-10 students

24

$4.1 \%$

11-20 students

378

$64.6 \%$

21-30 students

85

$14.5 \%$

31 or more students

98

$16.8 \%$

Stratum I

1-10 students

06

$03.8 \%$

11-20 students

110

$70.5 \%$

21-30 students

19

$12.2 \%$

31 or more students

21

$13.5 \%$ 
Table 7 (cont.)

Teacher Demographic Information

\begin{tabular}{lll}
\hline Variable & N & Percent \% \\
\hline
\end{tabular}

Class Size (cont.)

Stratum II

1-10 students

11-20 students

21-30 students

31 or more students
07

138

28

39
$03.3 \%$

$65.1 \%$

$13.2 \%$

$18.4 \%$

\section{Stratum III}

1-10 students

11-20 students

11

130

21-30 students

31 or more students

38

38

$05.1 \%$

$59.9 \%$

$17.5 \%$

$17.5 \%$

Teacher Age

Overall Sample

$20-29$

$30-39$

$40-49$

$50-59$

60 or older

Stratum I

$20-29$

$30-39$

$40-49$

$50-59$

60 or older

Stratum II
$20-29$
$30-39$
$40-49$
$50-59$
60 or older

90

132

168

167

28

25

32

37

53

09
$15.4 \%$

$22.6 \%$

$28.7 \%$

$28.5 \%$

$4.8 \%$

$16.0 \%$

$20.5 \%$

$23.7 \%$

$34.0 \%$

$05.8 \%$ 
Table 7 (cont.)

Teacher Demographic Information

\begin{tabular}{lll}
\hline Variable & N & Percen \\
\hline Teacher Age (cont.) & & \\
Stratum III & & \\
$20-29$ & 40 & $18.4 \%$ \\
$30-39$ & 53 & $24.4 \%$ \\
$40-49$ & 60 & $27.6 \%$ \\
$50-59$ & 51 & $23.5 \%$ \\
60 or older & 13 & $06.0 \%$
\end{tabular}

Teachers' Ethnicity

Overall Sample

$\begin{array}{lll}\text { African-American } & 24 & 4.1 \% \\ \text { Asian } & 35 & 6.0 \% \\ \text { Caucasian } & 425 & 72.6 \% \\ \text { Latino/a } & 64 & 10.9 \% \\ \text { Other } & 37 & 6.3 \%\end{array}$

Stratum I

$\begin{array}{lll}\text { African-American } & 09 & 05.8 \%\end{array}$

Asian 11

$07.1 \%$

Caucasian 117

$75.0 \%$

Latino/a

$07.1 \%$

Other

11

$05.1 \%$

Stratum II

African-American

09

$04.2 \%$

Asian

09

Caucasian

166

$04.2 \%$

Latino/a

15

$78.3 \%$

Other

13

$07.1 \%$

$06.1 \%$

Stratum III

African-American 06

$02.8 \%$

Asian

15

Caucasian

142

Latino/a

38

Other

16

$06.9 \%$

$65.4 \%$

$17.5 \%$

$07.4 \%$ 
Table 7 (cont.)

Teacher Demographic Information

\begin{tabular}{|c|c|c|}
\hline Variable & $\mathbf{N}$ & Percent $\%$ \\
\hline \multicolumn{3}{|l|}{$\begin{array}{l}\text { Grade Level Taught } \\
\text { Overall Sample }\end{array}$} \\
\hline Kindergarten & 114 & $19.5 \%$ \\
\hline $1 \mathrm{st}$ & 100 & $17.1 \%$ \\
\hline 1st-2nd combination & 46 & $7.9 \%$ \\
\hline 2nd & 66 & $11.3 \%$ \\
\hline 2nd-3rd combination & 26 & $4.4 \%$ \\
\hline $3 r d$ & 77 & $13.2 \%$ \\
\hline 4 th & 35 & $6.0 \%$ \\
\hline 4th-5th combination & 38 & $6.5 \%$ \\
\hline 5 th & 31 & $5.3 \%$ \\
\hline 5th-6th combination & 10 & $1.7 \%$ \\
\hline 6 th & 5 & $0.9 \%$ \\
\hline All Grades (Prep Teachers) & 37 & $6.3 \%$ \\
\hline \multicolumn{3}{|l|}{ Stratum I } \\
\hline Kindergarten & 30 & $19.2 \%$ \\
\hline 1st & 26 & $16.7 \%$ \\
\hline 1st-2nd combination & 11 & $07.1 \%$ \\
\hline 2nd & 20 & $12.8 \%$ \\
\hline 2nd-3rd combination & 13 & $08.3 \%$ \\
\hline $3 r d$ & 17 & $10.9 \%$ \\
\hline 4th & 08 & $05.1 \%$ \\
\hline 4th-5th combination & 13 & $08.3 \%$ \\
\hline 5 th & 09 & $05.8 \%$ \\
\hline 5th-6th combination & 01 & $00.6 \%$ \\
\hline 6 th & 01 & $00.6 \%$ \\
\hline All Grades (Prep Teachers) & 07 & $04.5 \%$ \\
\hline \multicolumn{3}{|l|}{ Stratum II } \\
\hline Kindergarten & 41 & $19.3 \%$ \\
\hline lst & 34 & $16.0 \%$ \\
\hline 1st-2nd combination & 19 & $09.0 \%$ \\
\hline 2nd & 22 & $10.4 \%$ \\
\hline 2nd-3rd combination & 04 & $01.9 \%$ \\
\hline 3 rd & 31 & $14.6 \%$ \\
\hline 4th & 16 & $07.5 \%$ \\
\hline 4th-5th combination & 10 & $04.7 \%$ \\
\hline 5 th & 14 & $06.6 \%$ \\
\hline
\end{tabular}


Table 7 (cont.)

Teacher Demographic Information

\begin{tabular}{lll}
\hline Variable & N & Percent \% \\
\hline Grade Level Taught (cont.) & & \\
Stratum II & & \\
5th-6th combination & 02 & $00.9 \%$ \\
6th & 01 & $00.5 \%$ \\
All Grades (Prep Teachers) & 18 & $08.5 \%$ \\
& & \\
Stratum III & & \\
Kindergarten & 43 & $19.8 \%$ \\
1st & 40 & $18.4 \%$ \\
1st-2nd combination & 16 & $07.4 \%$ \\
2nd & 24 & $11.1 \%$ \\
2nd-3rd combination & 09 & $04.1 \%$ \\
3rd & 29 & $13.4 \%$ \\
4th & 11 & $05.1 \%$ \\
4th-5th combination & 15 & $06.9 \%$ \\
5th & 08 & $03.7 \%$ \\
5th-6th combination & 07 & $03.2 \%$ \\
6th & 03 & $01.4 \%$ \\
All Grades (Prep Teachers) & 12 & $05.5 \%$ \\
& &
\end{tabular}

\section{Principals' Demographic Information}

Five hundred and eighty-five teachers from twenty-eight elementary schools $(\mathrm{K}-6)$ in the San Diego Unified School District described the leadership styles of their principals $(n=28)$. The frequencies and percentages of the principals' demographic information are presented in Table 8 , by the overall sample and strata $I, \Pi$ and $I I I$. 
Table 8

Principal Demographic Information: Overall Sample and Strata I, II, and III

\begin{tabular}{|c|c|c|}
\hline Variable & $\mathrm{N}$ & Percent $\%$ \\
\hline \multicolumn{3}{|l|}{ Number of Principals } \\
\hline Overall Sample & 28 & $100 \%$ \\
\hline Stratum I & 12 & $42.9 \%$ \\
\hline Stratum II & 09 & $32.1 \%$ \\
\hline Stratum III & 07 & $25.0 \%$ \\
\hline \multicolumn{3}{|l|}{$\begin{array}{l}\text { Principals' Gender } \\
\text { Overall Sample }\end{array}$} \\
\hline Female & 19 & $67.9 \%$ \\
\hline Male & 09 & $32.1 \%$ \\
\hline \multicolumn{3}{|l|}{ Stratum I } \\
\hline Female & 07 & $25.0 \%$ \\
\hline Male & 05 & $17.9 \%$ \\
\hline \multicolumn{3}{|l|}{ Stratum II } \\
\hline Female & 07 & $25.0 \%$ \\
\hline Male & 02 & $07.1 \%$ \\
\hline \multicolumn{3}{|l|}{ Stratum III } \\
\hline Female & 05 & $17.9 \%$ \\
\hline Male & 02 & $07.1 \%$ \\
\hline \multicolumn{3}{|l|}{ Principals' Ethnicity } \\
\hline \multicolumn{3}{|l|}{ Overall Sample } \\
\hline African-American & 04 & $14.3 \%$ \\
\hline Caucasian & 22 & $78.6 \%$ \\
\hline Latino/a & 02 & $07.1 \%$ \\
\hline \multicolumn{3}{|l|}{ Stratum I } \\
\hline African-American & 03 & $10.7 \%$ \\
\hline Caucasian & 07 & $25 \%$ \\
\hline Latino/a & 02 & $07.1 \%$ \\
\hline \multicolumn{3}{|l|}{ Stratum II . } \\
\hline African-American & 01 & $03.6 \%$ \\
\hline Caucasian & 08 & $28.6 \%$ \\
\hline Latino/a & 00 & $00.0 \%$ \\
\hline
\end{tabular}


Table 8 (cont.)

Principal Demographic Information: Overall Sample and Strata I, II, and III

\begin{tabular}{lll}
\hline Variable & $\mathrm{N}$ & Percent \\
\hline Principals' Ethnicity (cont.) & & \\
Stratum III & & \\
$\quad$ African-American & 00 & $00.0 \%$ \\
$\quad$ Caucasian & 07 & $25.0 \%$ \\
$\quad$ Latino/a & 00 & $00.0 \%$
\end{tabular}

Principals' Mean Years at Current Site

Overall Sample

Stratum I

Stratum II

3.25 years

$100 \%$

3.76 years

$42.9 \%$

Stratum III

3.13 years

$32.1 \%$

2.88 years

$25.0 \%$

Principals' Mean Years as a Principal in SDUSD

Overall Sample

Stratum I

5.94 years

$100 \%$

Stratum II

6.43 years

$42.9 \%$

Stratum III

5.02 years

$32.1 \%$

$25.0 \%$

Principals' Mean Years as an employee in SDUSD

Overall Sample

Stratum I

Stratum II

Stratum III
24.74 years

24.59 years

23.79 years

25.80 years
$100 \%$

$42.9 \%$

$32.1 \%$

$25.0 \%$

School-Site Demographic Information

Twenty-eight elementary schools (K-6) in the San Diego Unified School District participated in the study. The frequencies and percentages of the school-site demographic information are presented in Table 9 by the overall sample and strata I, II, and III. 
Table 9

School-Site Demographic Information: Overall Sample and Strata I, II, and III

\begin{tabular}{|c|c|c|}
\hline Variable & $\mathrm{N}$ & Percent \% \\
\hline \multicolumn{3}{|c|}{$\begin{array}{l}\text { School Year Calendar } \\
\text { Overall Sample }\end{array}$} \\
\hline Traditional & 23 & $82.1 \%$ \\
\hline Year Round & 05 & $17.9 \%$ \\
\hline \multicolumn{3}{|l|}{ Stratum I } \\
\hline Traditional & 12 & $42.8 \%$ \\
\hline Year Round & 00 & $00.0 \%$ \\
\hline \multicolumn{3}{|l|}{ Stratum II } \\
\hline Traditional & 08 & $28.6 \%$ \\
\hline Year Round & 01 & $03.6 \%$ \\
\hline \multicolumn{3}{|l|}{ Stratum III } \\
\hline Traditional & 03 & $10.7 \%$ \\
\hline Year Round & 04 & $14.3 \%$ \\
\hline \multicolumn{3}{|c|}{$\begin{array}{l}\text { Number of VPs at Site } \\
\text { Overall Sample }\end{array}$} \\
\hline $0 \mathrm{VPs}$ & 20 & $71.4 \%$ \\
\hline $1 \mathrm{VPs}$ & 06 & $21.4 \%$ \\
\hline $2 \mathrm{VPs}$ & 02 & $07.2 \%$ \\
\hline \multicolumn{3}{|l|}{ Stratum I } \\
\hline $0 \mathrm{VPs}$ & 12 & $42.9 \%$ \\
\hline 1 VPs & 00 & $00.0 \%$ \\
\hline 2 VPs & 00 & $00.0 \%$ \\
\hline \multicolumn{3}{|l|}{ Stratum II } \\
\hline 0 VPs & 08 & $28.6 \%$ \\
\hline 1 VPs & 01 & $03.6 \%$ \\
\hline 2 VPs & 00 & $00.0 \%$ \\
\hline \multicolumn{3}{|l|}{ Stratum III } \\
\hline 0 VPs & 00 & $00.0 \%$ \\
\hline 1 VPs & 05 & $17.8 \%$ \\
\hline 2 VPs & 02 & $07.1 \%$ \\
\hline
\end{tabular}


Table 9 (cont.)

School-Site Demographic Information: Overall Sample and Strata I, II, and III

\begin{tabular}{lll}
\hline Variable & N & Percen \\
\hline $\begin{array}{l}\text { Required to Complete } \\
\text { Coordinated Compliance Review (CCR) }\end{array}$ & & \\
Overall Sample & 11 & $39.3 \%$ \\
Stratum I & 04 & $14.3 \%$ \\
Stratum II & 03 & $10.7 \%$ \\
Stratum III & 04 & $14.3 \%$
\end{tabular}

School Staff Size

Overall Sample

Stratum I (1-24 Teachers)

156

$26.7 \%$

Stratum II (25-37 Teachers)

212

$36.2 \%$

Stratum III (38-61Teachers)

217

$37.1 \%$

Schools' Student Ethnicity (means of percentages of school-site student populations [unweighted]) Overall Sample

African-American

$19.79 \%$

Asian

$\begin{array}{ll}-- & 19.79 \% \\ -- & 02.81 \% \\ -- & 36.03 \% \\ -- & 05.04 \% \\ -- & 05.84 \% \\ -- & 28.41 \% \\ -- & 02.08 \%\end{array}$

Stratum I

$\begin{array}{lll}\text { African-American } & -- & 19.96 \% \\ \text { Asian } & -- & 02.82 \% \\ \text { Caucasian } & -- & 46.76 \% \\ \text { Filipino } & -- & 01.30 \% \\ \text { Indochinese } & -- & 02.96 \% \\ \text { Latino/a } & --- & 26.90 \% \\ \text { Other } & --- & 01.69 \%\end{array}$


Table 9 (cont.)

School-site Demographic Information: Overall Sample and Strata I, II, and III

\begin{tabular}{lll}
\hline Variable & $\mathrm{N}$ & Percent $\%$ \\
\hline Schools' Student Ethnicity (means of school-site averages) (cont.) & \\
Stratum II & & \\
$\quad$ African-American & -- & $17.70 \%$ \\
Asian & -- & $03.36 \%$ \\
Caucasian & - & $43.76 \%$ \\
Filipino & -- & $08.09 \%$ \\
Indochinese & -- & $04.17 \%$ \\
Latino/a & - & $20.47 \%$ \\
Other & -- & $02.95 \%$
\end{tabular}

Stratum III

$\begin{array}{lll}\text { African-American } & -- & 21.72 \% \\ \text { Asian } & -- & 02.28 \% \\ \text { Caucasian } & --- & 20.78 \% \\ \text { Filipino } & --- & 04.76 \% \\ \text { Indochinese } & -- & 09.56 \% \\ \text { Latino/a } & -- & 37.25 \% \\ \text { Other } & -- & 02.92 \%\end{array}$

Principal Leadership Styles as Measured by the LBDQ for the Overall Sample

Leadership styles of the principals were determined by analyses of the LBDQ scales identifying the two leadership variables of Initiating Structure and Consideration. Items regarding Initiating Structure measured a leader's task-oriented leadership behavior such as subordinate role responsibilities, established patterns of organization, and methods of accomplishing tasks. Items regarding Consideration measured a leader's relationshiporiented behavior such as "friendship, mutual trust, respect, and warmth in relationship between the leader and members of the group" (Buros, 1978, p. 1746). The means of the two scales, as described by teachers, are shown in Table 10. Additionally, these means 
were compared to the means set out in the LBDQ's administration manual developed by the Ohio State University. The means of the two variables in the administration manual were 37.90 (Initiating Structure) and 44.70 (Consideration).

Principals who were above the mean in both Initiating Structure and Consideration were identified as possessing High-Initiating Structure and High-Consideration leadership styles (HIS, HC). Principals who were above the mean in Initiating Structure and below the mean in Consideration were identified as possessing High-Initiating Structure and Low-Consideration leadership styles (HIS, LC). Principals who were below the mean in Initiating Structure and above the mean in Consideration were identified as possessing Low-Initiating Structure and High-Consideration leadership styles (LIS, HC). Principals who were below the mean in both Initiating Structure and Consideration were identified as possessing Low-Initiating Structure and Low-Consideration leadership styles (LIS, LC).

The largest group of teachers $(n=252)$ at ten schools described their principals as having High-Initiating Structure and Low-Consideration leadership styles. The next two largest groups fell in the High-Initiating Structure and High-Consideration styles $(n=159)$ at seven schools and the Low-Initiating Structure and Low-Consideration leadership styles $(n=134)$ at eight schools. The smallest group of teachers $(n=40)$ at three schools described their principals as having Low-Initiating Structure and High-Consideration leadership styles. Descriptions of principals' 'éadership styles for the overall sample and strata I, II, and III are shown in Tables 10-17 and graphically represented in Figures 1-4. 
Table 10

Leader Behavior Description Questionnaire: Means and Standard Deviations From LBDQ

Manual, Overall Sample, Strata I, II, and III

\begin{tabular}{|c|c|c|c|c|}
\hline Variable & Mean & Std Dev & Minimum & $\operatorname{Max}$ \\
\hline \multicolumn{5}{|l|}{ LBDQ Manual } \\
\hline Initiating Structure & 37.90 & 4.40 & $\cdots$ & -.-- \\
\hline Consideration & 44.70 & 6.00 & ---- & --- \\
\hline \multicolumn{5}{|c|}{ Overall Sample $(n=585)$} \\
\hline Initiating Structure & 39.22 & 7.56 & 10.00 & 60.00 \\
\hline Consideration & 42.01 & 8.81 & 14.00 & 58.00 \\
\hline \multicolumn{5}{|l|}{ Stratum I $(n=156)$} \\
\hline Initiating Structure & 37.85 & 8.95 & 10.00 & 60.00 \\
\hline Consideration & 40.12 & 9.84 & 14.00 & 57.00 \\
\hline \multicolumn{5}{|l|}{ Stratum II $(n=212)$} \\
\hline Initiating Structure & 39.83 & 6.71 & 22.00 & 56.00 \\
\hline Consideration & 43.33 & 8.64 & 20.00 & 58.00 \\
\hline \multicolumn{5}{|c|}{ Stratum III $(n=217)$} \\
\hline Initiating Structure & 39.60 & 7.16 & 15.00 & 57.00 \\
\hline Consideration & 42.07 & 7.94 & 21.00 & 58.00 \\
\hline
\end{tabular}

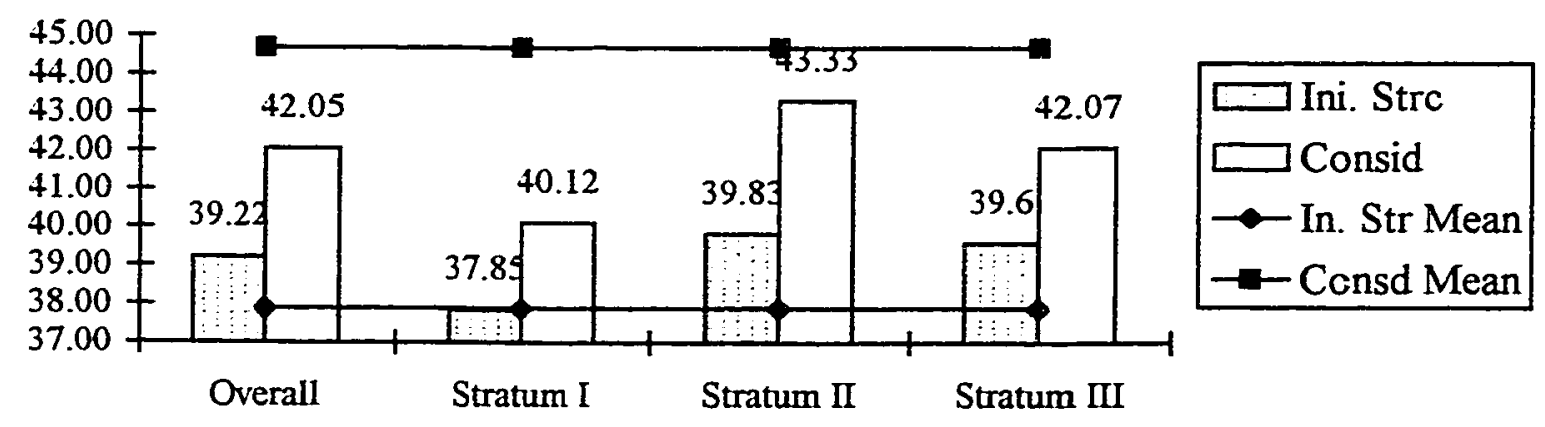

Figure 1.

Graphic Representation of Initiating Structure and Consideration Mean Scores as Measured by the LBDQ for the Overall Sample and Strata I, II, and III with the Means from the LBDQ Manual for Comparison Depicted by the Diamond and Square Lines. 
Table 11

Four Different Principal Leadership Styles for Overall Sample $(n=585)$

\begin{tabular}{llll}
\hline Leadership Style & Frequency (teachers) & Frequency (schools) & Percentage (teachers) \\
\hline
\end{tabular}

$\begin{array}{llll}\text { HIS-HC } & 159 & 07 & 27.2 \% \\ \text { HIS-LC } & 252 & 10 & 43.1 \% \\ \text { LIS-HC } & 40 & 03 & 06.8 \% \\ \text { LIS-LC } & 134 & 08 & 22.9 \%\end{array}$

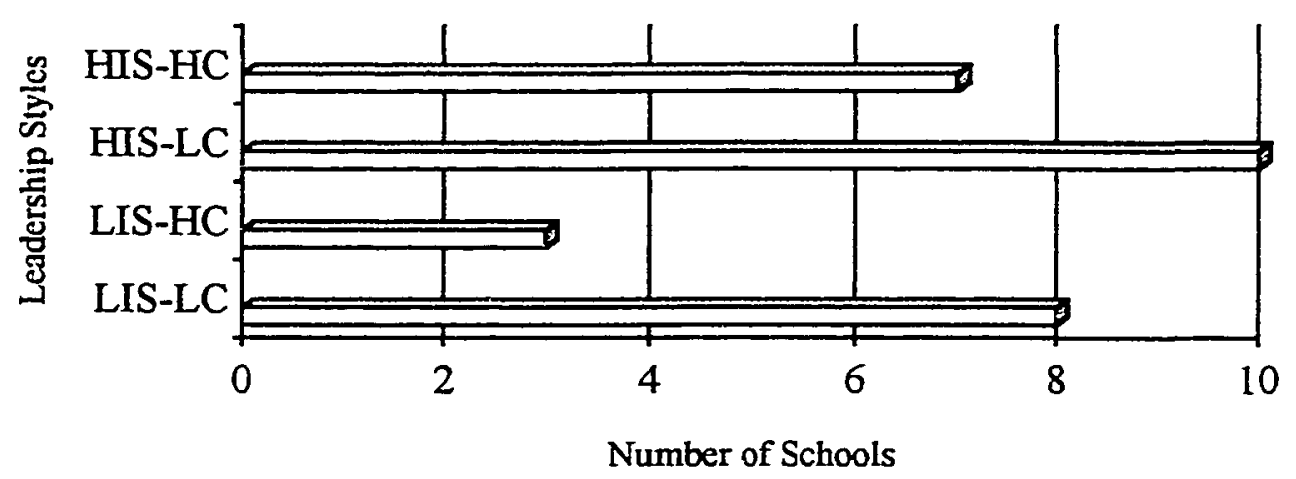

\section{Principal Leadership Styles as Measured by the LBDQ for Stratum I}

Stratum I was comprised of twelve schools with teaching staffs of 1 to 24 teachers and a sample size of 156 teachers. This stratum described the leadership styles of twelve principals. The largest group of teachers $(n=72)$ at six schools described their principals as having Low-Initiating Structure and Low-Consideration leadership styles. The next largest group $(n=51)$ at three schools described their principals as having High-Initiating Structure and Low-Consideration leadership styles. The last two groups of teachers described their principals as having Low-Initiating Structure and High-Consideration leadership styles $(n=19)$ at two schools and High-Initiating Structure and HighConsideration leadership styles $(n=14)$ at one school. Descriptions of principals' 
leadership styles for each school in stratum I are shown in Tables $12 \& 13$ and graphically represented in Figure 2.

Table 12

Leader Behavior Description Questionnaire: Means for Stratum I - 12 Schools $(n=156)$

All Schools Listed Individually by Randomly Assigned Identification Numbers

\begin{tabular}{lllll}
\hline Variable & Mean & Std Dev & Minimum & Maximum \\
\hline School 1: $(\boldsymbol{n}=\mathbf{1 6})$ & & & & \\
Initiating Structure & 44.25 & 5.79 & 31.00 & 53.00 \\
Consideration & 43.25 & 6.13 & 34.00 & 56.00 \\
& & & & \\
School 4: $(\boldsymbol{n}=\mathbf{1 2})$ & & & & \\
Initiating Structure & 28.58 & 9.89 & 15.00 & 45.00 \\
Consideration & 37.58 & 10.08 & 26.00 & 57.00 \\
& & & & \\
School 12: $(\boldsymbol{n}=16)$ & & & & \\
Initiating Structure & 40.81 & 5.97 & 27.00 & 52.00 \\
Consideration & 43.69 & 10.28 & 18.00 & 55.00 \\
& & & & \\
School 13: $(\boldsymbol{n}=\mathbf{8})$ & & & & \\
Initiating Structure & 26.75 & 9.07 & 10.00 & 38.00 \\
Consideration & 29.13 & 8.66 & 20.00 & 48.00 \\
& & & & \\
School 15: $(\boldsymbol{n}=\mathbf{7})$ & & & & \\
Initiating Structure & 37.57 & 5.44 & 29.00 & 44.00 \\
Consideration & 45.29 & 4.23 & 39.00 & 51.00 \\
& & & & \\
School 16: $(\boldsymbol{n}=\mathbf{1 9})$ & & & 34.00 & 60.00 \\
Initiating Structure & 47.58 & 6.27 & 26.00 & 53.00 \\
Consideration & 41.21 & 8.77 & & \\
& & & & \\
School 20: $(\boldsymbol{n}=\mathbf{1 4})$ & & & & \\
Initiating Structure & 34.29 & 4.83 & 26.00 & 42.00 \\
Consideration & 33.79 & 9.54 & 15.00 & 50.00 \\
School 21: $(\boldsymbol{n}=\mathbf{1 3})$ & & & & \\
Initiating Structure & 31.08 & 6.59 & 22.00 & 44.00 \\
Consideration & 35.00 & 10.29 & 14.00 & 49.00
\end{tabular}


Table 12 (cont.)

Leader Behavior Description Questionnaire: Means for Stratum I - 12 Schools ( $n=156)$

All Schools Listed Individually by Randomly Assigned Identification Numbers

Variable
School 22: $(n=12)$
Initiating Structure

Consideration

Mean

Std Dev

Minimum

Maximum

School 24: $(n=14)$

Initiating Structure

Consideration

35.75

8.08

6.93

18.00

47.00

33.00

54.00

School 26: $(n=12)$

Initiating Structure

Consideration

42.43

5.03

31.00

53.00

7.92

31.00

55.00

School 27: $(n=13)$

Initiating Structure

Consideration

35.83

37.75

9.19

12.77

20.00

15.00

49.00

52.00
4.58

8.43

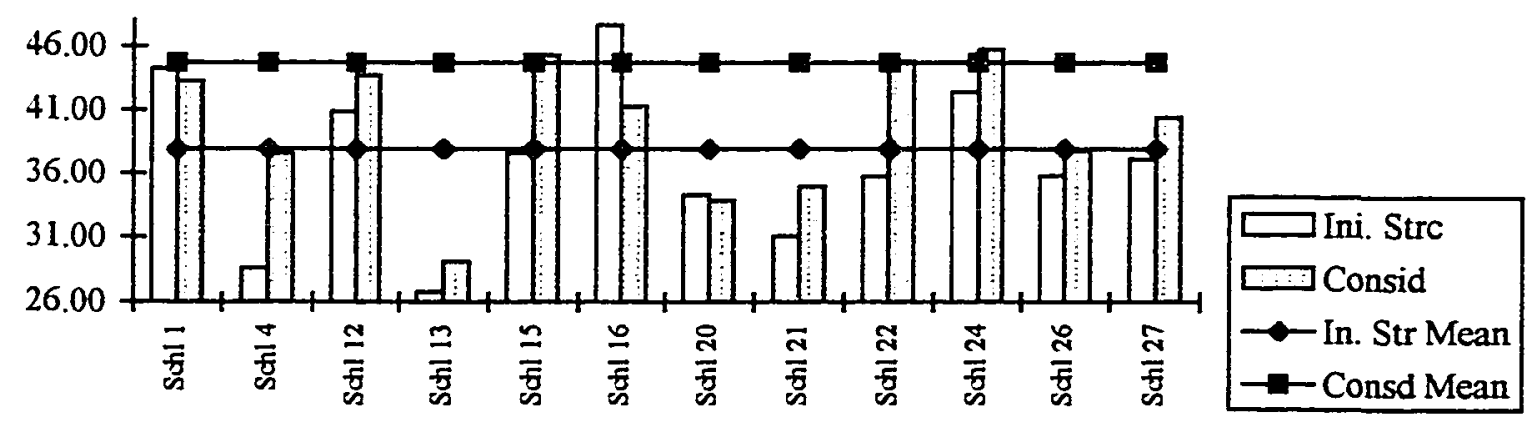

Figure 2.

Graphic Representation of Initiating Structure and Consideration Mean Scores as Measured by the LBDQ for All 12 Schools in Stratum I with the Means from the LBDQ Manual for Comparison Depicted by the Diamond and Square Lines. 
Table 13

Four Different Principal Leadership Styles for Stratum I ( $n=156)$

\begin{tabular}{lccc}
\hline Leadership Style & Frequency (teachers) & Frequency (schools) & Percentage (teachers) \\
\hline HIS-HC & 14 & 01 & $08.9 \%$ \\
HIS-LC & 51 & 03 & $32.7 \%$ \\
LIS-HC & 19 & 02 & $12.2 \%$ \\
LIS-LC & 72 & 06 & $46.2 \%$
\end{tabular}

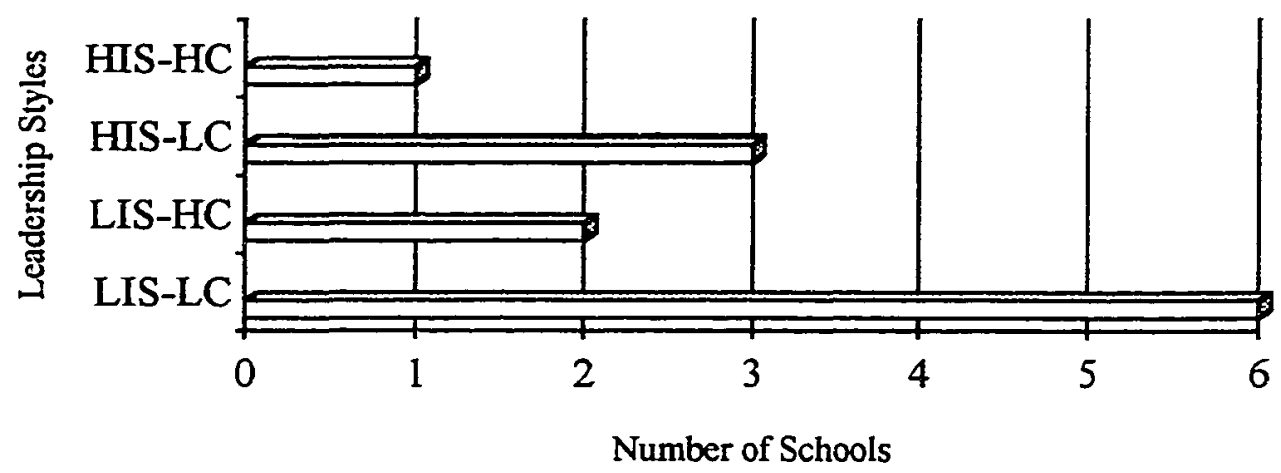

Principal Leadership Styles as Measured by the LBDQ for Stratum II

Stratum II was comprised of nine schools with teaching staffs of 25 to 37 teachers and a sample size of 212 teachers. This stratum described the leadership styles of nine principals. The largest group of teachers $(n=91)$ at four schools described their principals as having High-Initiating Structure and High-Consideration. The next largest group $(n=74)$ at three schools described their principals as having High-Initiating Structure and Low-Consideration leadership styles. The last two groups of teachers described their principals as having Low-Initiating Structure and Low-Consideration leadership styles $(n=26)$ at one school and Low-Initiating Structure and High-Consideration leadership styles $(n=21)$ at one school. Descriptions of principals' leadership styles for each school in stratum II are shown in Tables $14 \& 15$ and graphically represented in Figure 3. 
Table 14

Leader Behavior Description Questionnaire: Means for Stratum II - 9 Schools ( $n=212)$ All Schools Listed Individually by Randomly Assigned Identification Numbers

\begin{tabular}{lllll}
\hline Variable & Mean & Std Dev & Minimum & Maxim \\
\hline School 3: $(\boldsymbol{n}=\mathbf{1 8})$ & & & & \\
Initiating Structure & 38.50 & 5.85 & 29.00 & 52.00 \\
Consideration & 45.67 & 7.10 & 31.00 & 58.00
\end{tabular}

School 8: $(n=27)$

Initiating Structure

44.04

5.55

34.00

54.00

Consideration

45.11

8.23

26.00

58.00

School 10: $(n=24)$

Initiating Structure

37.88

8.45

24.00

51.00

Consideration

36.92

9.29

21.00

53.00

School 11: $(\boldsymbol{n}=\mathbf{2 5})$

Initiating Structure

44.24

6.48

29.00

55.00

Consideration

42.32

8.01

25.00

58.00

School 14: $(n=25)$

Initiating Structure

39.80

5.94

31.00

54.00

Consideration

45.92

5.90

32.00

55.00

School 18: $(n=26)$

Initiating Structure

35.42

5.71

29.00

49.00

Consideration

41.65

9.70

24.00

56.00

School 23: $(n=21)$

Initiating Structure

38.76

3.60

33.00

48.00

Consideration

47.14

6.16

33.00

57.00

School 25: $(n=21)$

Initiating Structure

Consideration

36.24

6.59

22.00

48.00

48.29

6.17

34.00

58.00

School 28: $(n=25)$

Initiating Structure

Consideration

42.28

5.14

30.00

56.00

38.64

9.30

20.00

58.00 


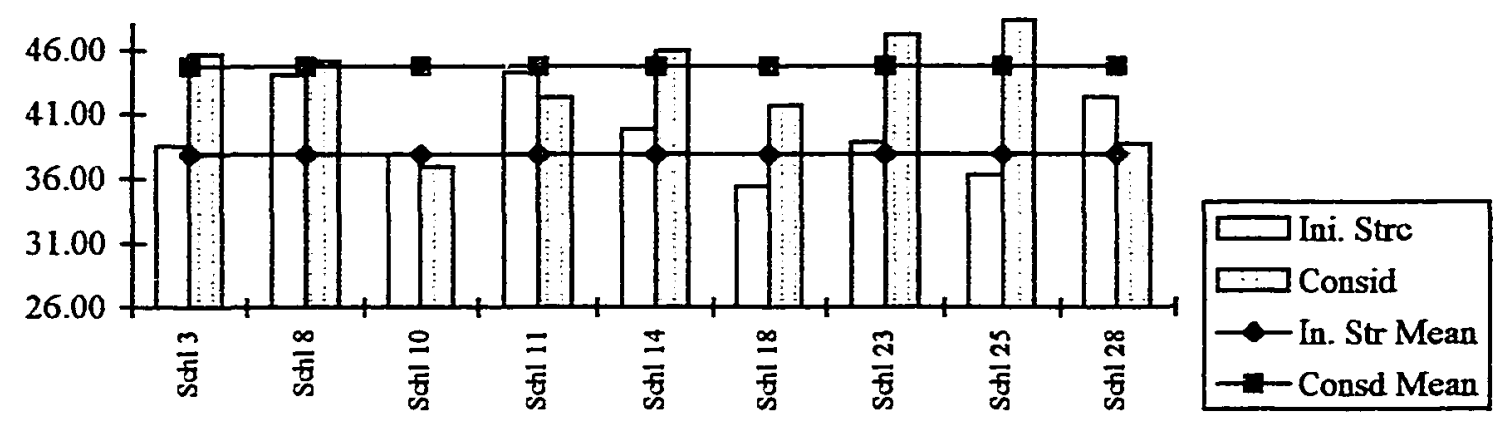

Figure 3.

Graphic Representation of Initiating Structure and Consideration Mean Scores as Measured by the LBDQ for All 9 Schools in Stratum II with the Means from the LBDQ Manual for Comparison Depicted by the Diamond and Square Lines.

Table 15

Four Different Principal Leadership Styles for Stratum II ( $n=212)$

\begin{tabular}{lccc}
\hline Leadership Style & Frequency (teachers) & Frequency (schools) & Percentage (teachers) \\
\hline HIS-HC & 91 & 04 & $42.9 \%$ \\
HIS-LC & 74 & 03 & $34.9 \%$ \\
LIS-HC & 21 & 01 & $09.9 \%$ \\
LIS-LC & 26 & 01 & $12.3 \%$
\end{tabular}

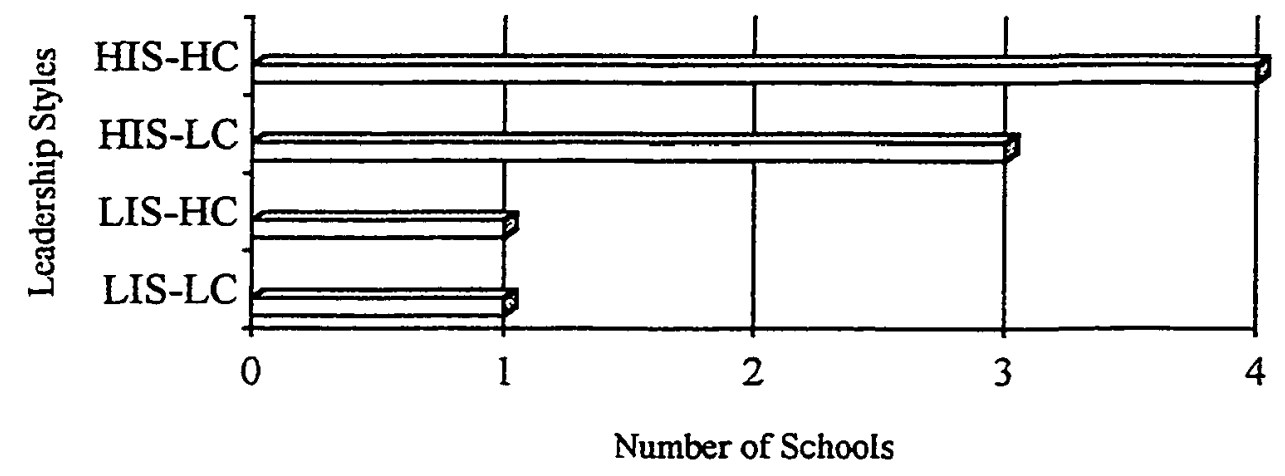




\section{Principal Leadership Styles as Measured by the LBDQ for Stratum III}

Stratum III was comprised of seven schools with teaching staffs of 38 to 61 teachers and a sample size of 217 teachers. This stratum described the leadership styles of seven principals. The largest group of teachers $(n=127)$ at four schools described their principals as having High-Initiating Structure and Low-Consideration leadership styles. The next two largest groups described their principals as having High-Initiating Structure and High-Consideration leadership styles $(n=54)$ at two schools and Low-Initiating Structure and Low-Consideration leadership styles $(n=36)$ at one school. The last leadership style of Low-Initiating Structure and High-Consideration leadership styles was not evident with any of the principals described in stratum III. Descriptions of principals' leadership styles for each school in stratum $\mathrm{II}$ are shown in Tables $16 \& 17$ and graphically represented in Figure 4.

\section{Table 16}

Leader Behavior Description Questionnaire: Means for Stratum III - 7 Schools ( $n=217)$

All Schools Listed Individually by Randomly Assigned Identification Numbers

Variable

Initiating Structure

Mean

Std Dev

Minimum

Maximum

Consideration

37.72

8.35

15.00

47.00

7.87

21.00

53.00

School 5: $(n=32)$

Initiating Structure

6.85

24.00

56.00

Consideration

45.00

7.91

21.00

58.00

School 6: $(n=22)$

Initiating Structure

Consideration

41.00

5.49

30.00

52.00

46.45

6.16

33.00

56.00 
Table 16 (cont.)

Leader Behavior Description Questionnaire: Means for Stratum III - 7 Schools $(n=217)$

All Schools Listed Individually by Randomly Assigned Identification Numbers

Variable
School 7: $(n=48)$
Initiating Structur

Consideration

41.15

5.32

29.00

52.00

42.71

7.30

22.00

58.00

School 9: $(\boldsymbol{n}=20)$

Initiating Structure

39.75

5.37

29.00

50.00

Consideration

37.40

7.11

28.00

53.00

School 17: $(n=30)$

Initiating Structure

Consideration

43.10

6.26

29.00

57.00

41.67

8.15

25.00

54.00

School 19: $(n=29)$

Initiating Structure

Consideration

40.14

7.11

24.00

57.00

43.52

7.11

25.00

56.00

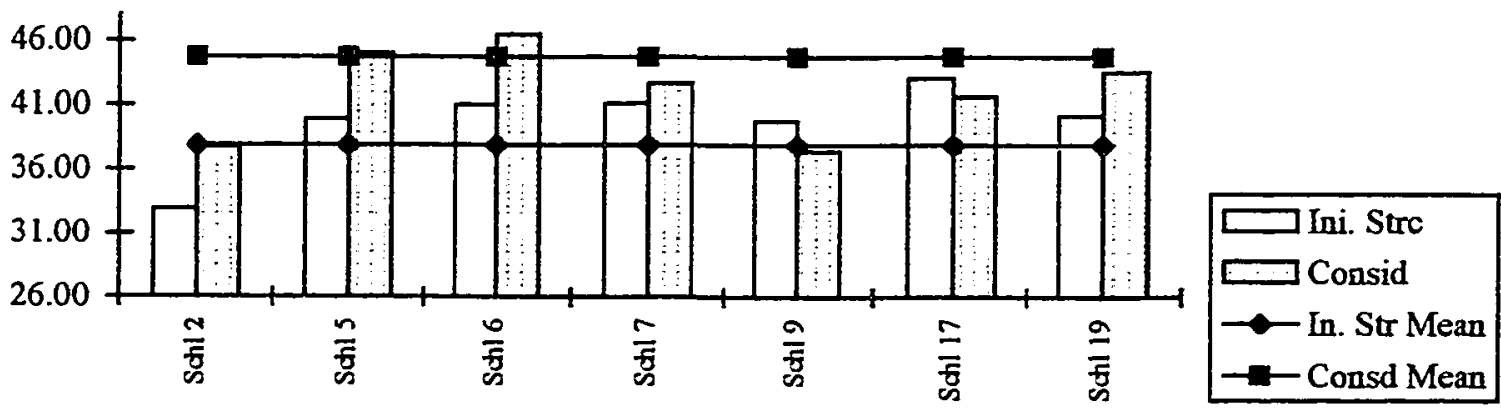

Figure 4.

Graphic Representation of Initiating Structure and Consideration Mean Scores as Measured by the LBDQ for All 7 Schools in Stratum III with the Means from the LBDQ Manual for Comparison Depicted by the Diamond and Square Lines. 
Table 17

Four Different Principal Leadership Styles for Stratum III $(n=217)$

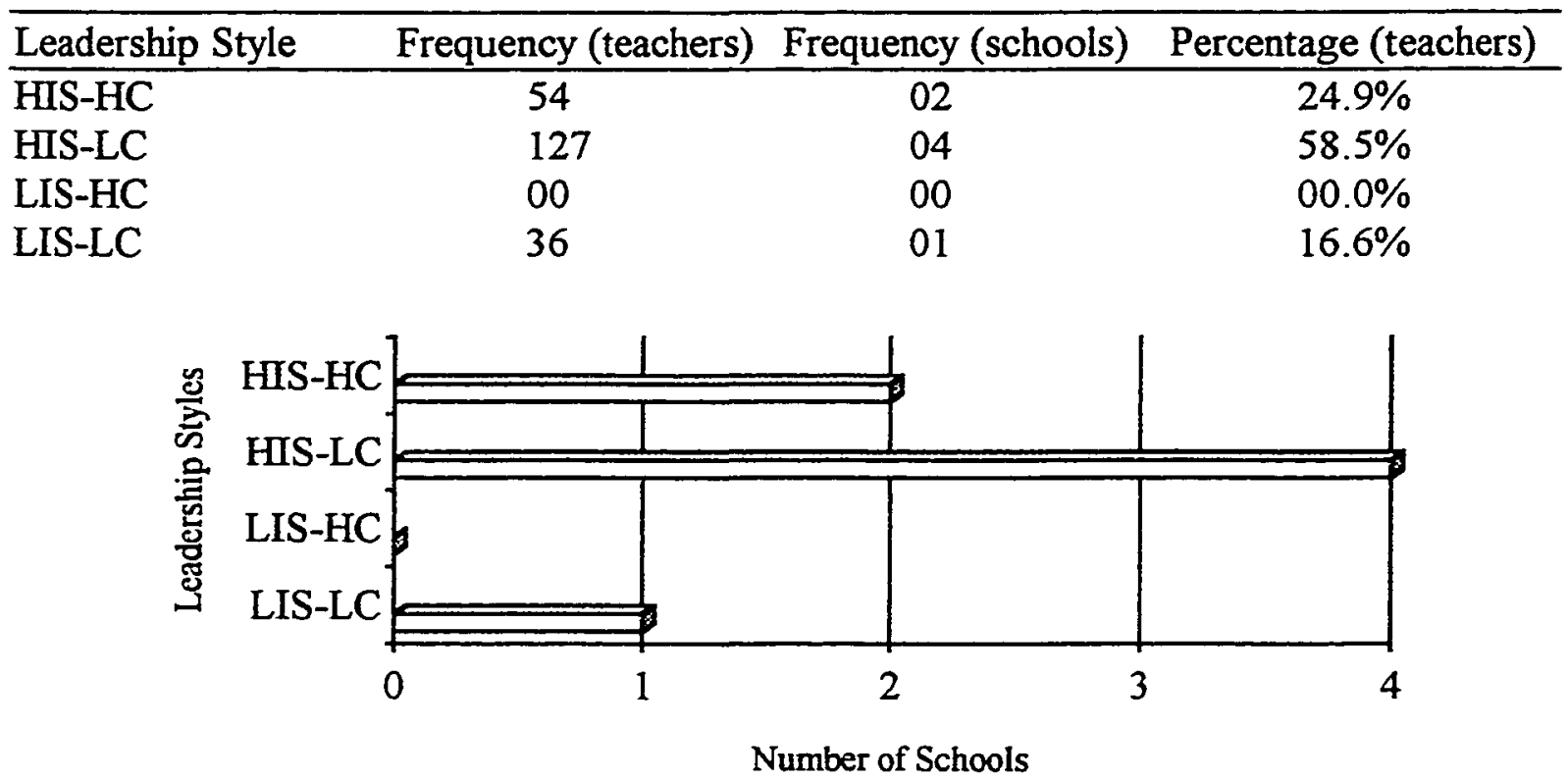

Teacher Stress Levels as Measured by the Teacher Stress Inventory

Teacher Stress was measured by the Teacher Stress Inventory. The level of teacher stress was determined by scores on the TSI in terms of sontres of stress (time management, work-related stressors, professional distress, student discipline \& motivation, and professional investment) and manifestations of occupational stress (emotional, fatigue, cardiovascular, gastronomic, and behavioral manifestations). The TSI rendered ten subscale scores (as listed above in parentheses) and one Total Stress Score computed by averaging all ten subscales. The ten subscales were defined in the operational definition's section of chapter 1, pages 10-11.

The ten subscale scores and the Total Stress Score for the overall sample and strata I, II, and III were directly compared to the aggregated norm group of 3,401 
teachers in order to determine whether the respondents were experiencing significantly stronger, moderate, or weaker stress levels. The TSI scores were compared to the normed groups' scores from the TSI Manual and graphically represented in Figure 5. An average subscale score for a teacher would fall directly on the normed group mean and represent a teacher experiencing moderate levels of stress. A subscale score falling on or below a significant low subscale norm score would represent a teacher experiencing weak levels of stress and a subscale norm score falling on or above a significantly high subscale score would represent a teacher experiencing strong levels of stress.

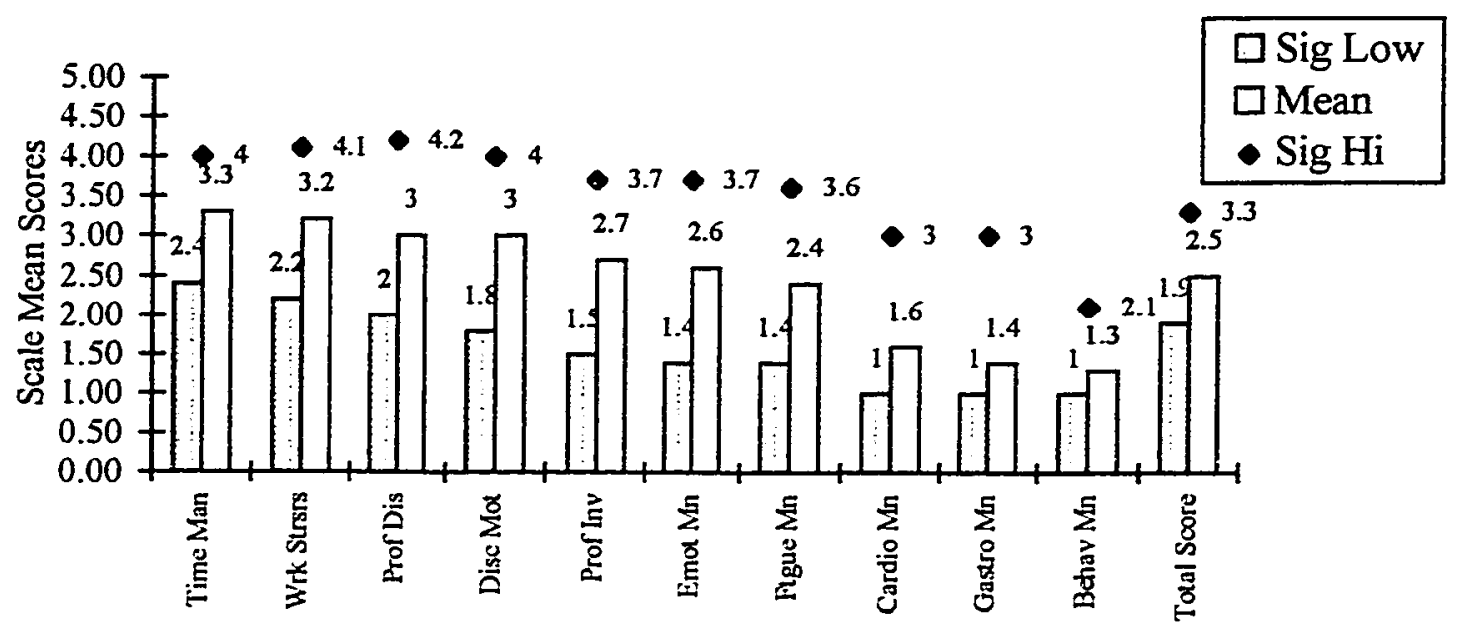

TSI Subscales \& Total Stress Score

Figure 5.

Graphic Representation of High-Low Cut-Off Points for the TSI Subscale and Subscale Mean Scores

\section{Teacher Stress Levels: Overall Sample}

The overall sample's Total Stress Score mean was 2.41 , nearly equal to the aggregated norm group's mean of 2.50. The Total Stress Score of 2.41 fell in the 
moderate stress level range and described slightly lower-than-average stress levels. The two subscales which measured the greatest sources of stress were Work-Related Stressors and Time Management. The TSI aggregated norm mean score for Work-Related Stressors was 3.20, while the overall sample's mean score for Work-Related Stressors was 3.44 for this investigation. The TSI aggregated norm mean score for Time Management was 3.30, while the overall sample's mean score for Time Management was 3.35. These two subscale mean scores fell in the moderate stress level range and described slightly higherthan-average stress levels. The remaining subscale means for Professional Distress, Student Discipline \& Motivation, and Professional Investment in the overall sample fell below the aggregated norm mean scores and described teachers as having below-average stress levels from those sources of stress.

The subscales which measured manifestations of stress were Emotional, Fatigue, Cardiovascular, Gastronomical, and Behavioral Manifestations. The overall sample's mean subscale scores were all above the TSI's aggregated norm mean scores with the exception of Emotional Manifestations which fell directly on the aggregated norm mean score of 2.60. The overall sample's subscale mean scores for manifestations of stress fell in the moderate stress level range and described slightly higher-than-average stress levels for manifestations of stress. 
Table 18

Teacher Stress Inventory: Overall Subscale Means from Least Stress Producing Subscale

to Greatest Stress Producing Subscale for the Overall Sample of 28 Schools $(n=585)$

\begin{tabular}{lllll}
\hline Variable & Mean & Std Dev & Minimum & Maximum \\
\hline Behavioral Manifestations & 1.47 & .62 & 1.00 & 4.75 \\
Gastronomical Manifestations & 1.62 & .94 & 1.00 & 5.00 \\
Cardiovascular Manifestations & 1.88 & .96 & 1.00 & 5.00 \\
Professional Investment & 2.14 & .85 & 1.00 & 5.00 \\
TSI Total Stress Score & $\mathbf{2 . 4 1}$ & .56 & 1.27 & 4.46 \\
Fatigue Manifestations & 2.45 & .97 & 1.00 & 5.00 \\
Professional Distress & 2.52 & 1.01 & 1.00 & 5.00 \\
Emotional Manifestations & 2.60 & 1.01 & 1.00 & 5.00 \\
Discipline \& Motivation & 2.64 & 1.03 & 1.00 & 5.00 \\
Time Management & 3.35 & .70 & 1.25 & 5.00 \\
Work-Related Stressors & 3.44 & .87 & 1.00 & 5.00
\end{tabular}

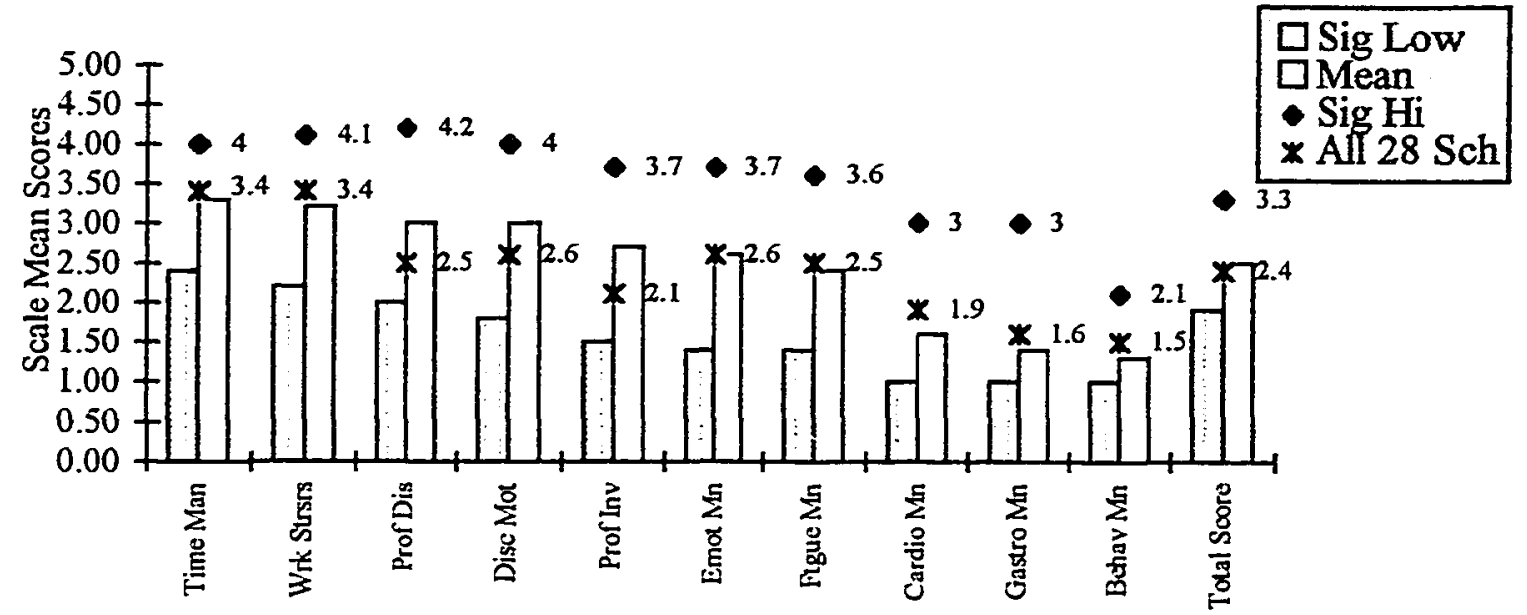

TSI Subscales \& Total Stress Score

Figure 6.

Graphic Representation of High-Low Cut-Off Points for the TSI Subscale and Subscale Mean Scores Compared to the Subscale Mean Scores of all 28 participating Elementary Schools in the San Diego Unified School District. 


\section{Teacher Stress Levels: Stratum I}

Stratum I was comprised of twelve schools with teaching staffs of 1 to 24 teachers and a sample size of 156 teachers. The Total Stress Score mean was 2.47 , nearly equal to the aggregated norm group's mean of 2.50. The Total Stress Score of 2.47 fell in the moderate stress level range and described slightly lower-than-average stress levels for teachers in stratum I. The two subscales which measured the greatest sources of stress were Work-Related Stressors and Time Management. The TSI aggregated norm mean score for Work-Related Stressors was 3.20, while stratum I's mean score for WorkRelated Stressors was 3.46. The TSI aggregated norm mean score for Time Management was 3.30, while stratum I's mean score for Time Management was 3.36. These two subscale mean scores fell in the moderate stress level range and described slightly higherthan-average stress levels. The remaining subscale means for Professional Distress, Student Discipline \& Motivation, and Professional Investment in stratum I fell below the aggregated norm mean scores and described teachers as having below-average stress levels from those sources of stress.

The subscales which measured manifestations of stress were Emotional, Fatigue, Cardiovascular, Gastronomical, and Behavioral Manifestations. Stratum I's mean subscale scores were all above the TSI's aggregated norm mean scores. Stratum I's subscale mean scores for manifestations of stress fell in the moderate stress level range and described slightly higher than average stress levels for manifestations of stress. 
Table 19

Teacher Stress Inventory: Overall Subscale Means from Least Stress Producing Subscale

to Greatest Stress Producing Subscale for the 12 Schools in Stratum I ( $n=156)$

\begin{tabular}{lllll}
\hline Variable & Mean & Std Dev & Minimum & Maximum \\
\hline Behavioral Manifestations & 1.52 & .69 & 1.00 & 4.00 \\
Gastronomical Manifestations & 1.63 & .98 & 1.00 & 5.00 \\
Cardiovascular Manifestations & 1.95 & .98 & 1.00 & 5.00 \\
Professional Investment & 2.26 & .94 & 1.00 & 5.00 \\
TSI Total Stress Score & $\mathbf{2 . 4 7}$ & $\mathbf{. 5 8}$ & $\mathbf{1 . 2 9}$ & $\mathbf{4 . 4 5}$ \\
Fatigue Manifestations & 2.50 & 1.02 & 1.00 & 5.00 \\
Emotional Manifestations & 2.64 & .97 & 1.00 & 5.00 \\
Professional Distress & 2.65 & 1.08 & 1.00 & 5.00 \\
Discipline \& Motivation & 2.69 & 1.02 & 1.00 & 5.00 \\
Time Management & 3.36 & .73 & 1.25 & 5.00 \\
Work-Related Stressors & 3.46 & .88 & 1.00 & 5.00
\end{tabular}

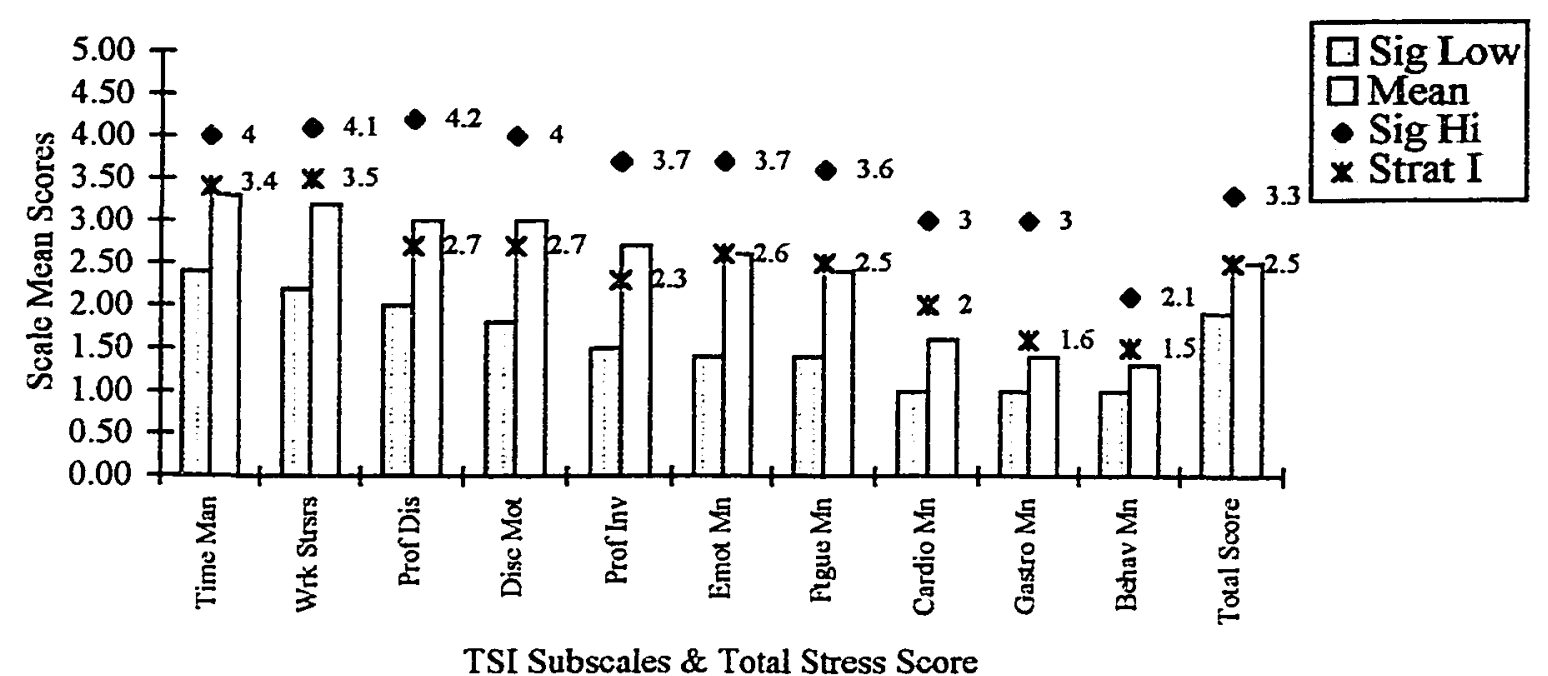

Figure 7.

Graphic Representation of High-Low Cut-Off Points for the TSI Subscale and Subscale Mean Scores Compared to the Subscale Mean Scores of Stratum I 


\section{Teacher Stress Levels: Stratum II}

Stratum II was comprised of nine schools with teaching staffs of 25 to 37 teachers and a sample size of 212 teachers. Stratum II's Total Stress Score mean was 2. 35 and fell slightly below the aggregated norm group's mean of 2.50 . The Total Stress Score of 2.35 fell in the moderate stress level range and described slightly lower-than-average stress levels. The two subscales which measured the greatest sources of stress were WorkRelated Stressors and Time Management. The TSI aggregated norm mean score for Work-Related Stressors was 3.20, while stratum II's mean score for Work-Related Stressors was 3.42. The TSI aggregated norm mean score for Time Management was 3.30, while stratum II's mean score for Time Management was 3.33. These two subscale mean scores fell in the moderate stress level range and described slightly higher-thanaverage stress levels. The remaining subscale means for Professional Distress, Student Discipline \& Motivation, and Professional Investment in stratum II fell below the aggregated norm mean scores and described teachers as having below-average stress levels from those sources of stress.

The subscales which measured manifestations of stress were Emotional, Fatigue, Cardiovascular, Gastronomical, and Behavioral Manifestations. Stratum II's mean subscale scores for Cardiovascular, Gastronomical, and Behavioral Manifestations were all above the TSI's aggregated norm mean scores. These three subscale mean scores fell in the moderate stress level range and described slightly higher-than-average stress levels. Stratum II's subscale mean scores for Emotional and Fatigue Manifestations fell in the 
moderate stress level range and described slightly lower-than-average stress levels for manifestations of stress.

Table 20

Teacher Stress Inventory: Overall Subscale Means from Least Stress Producing Subscale to Greatest Stress Producing Subscale for the 9 Schools in Stratum $\Pi(n=212)$

\begin{tabular}{lllll}
\hline Variable & Mean & Std Dev & Minimum & Maximum \\
\hline & & & & \\
Behavioral Manifestations & 1.42 & .55 & 1.00 & 4.75 \\
Gastronomical Manifestations & 1.57 & .84 & 1.00 & 5.00 \\
Cardiovascular Manifestations & 1.80 & .91 & 1.00 & 5.00 \\
Professional Investment & 2.01 & .77 & 1.00 & 4.50 \\
TSI Total Stress Score & $\mathbf{2 . 3 5}$ & $\mathbf{. 5 2}$ & $\mathbf{1 . 2 8}$ & $\mathbf{3 . 7 2}$ \\
Fatigue Manifestations & 2.38 & .89 & 1.00 & 5.00 \\
Professional Distress & 2.47 & .96 & 1.00 & 5.00 \\
Emotional Manifestations & 2.51 & 1.00 & 1.00 & 5.00 \\
Discipline \& Motivation & 2.58 & 1.04 & 1.00 & 5.00 \\
Time Management & 3.33 & .69 & 1.25 & 5.00 \\
Work-Related Stressors & 3.42 & .88 & 1.17 & 5.00
\end{tabular}

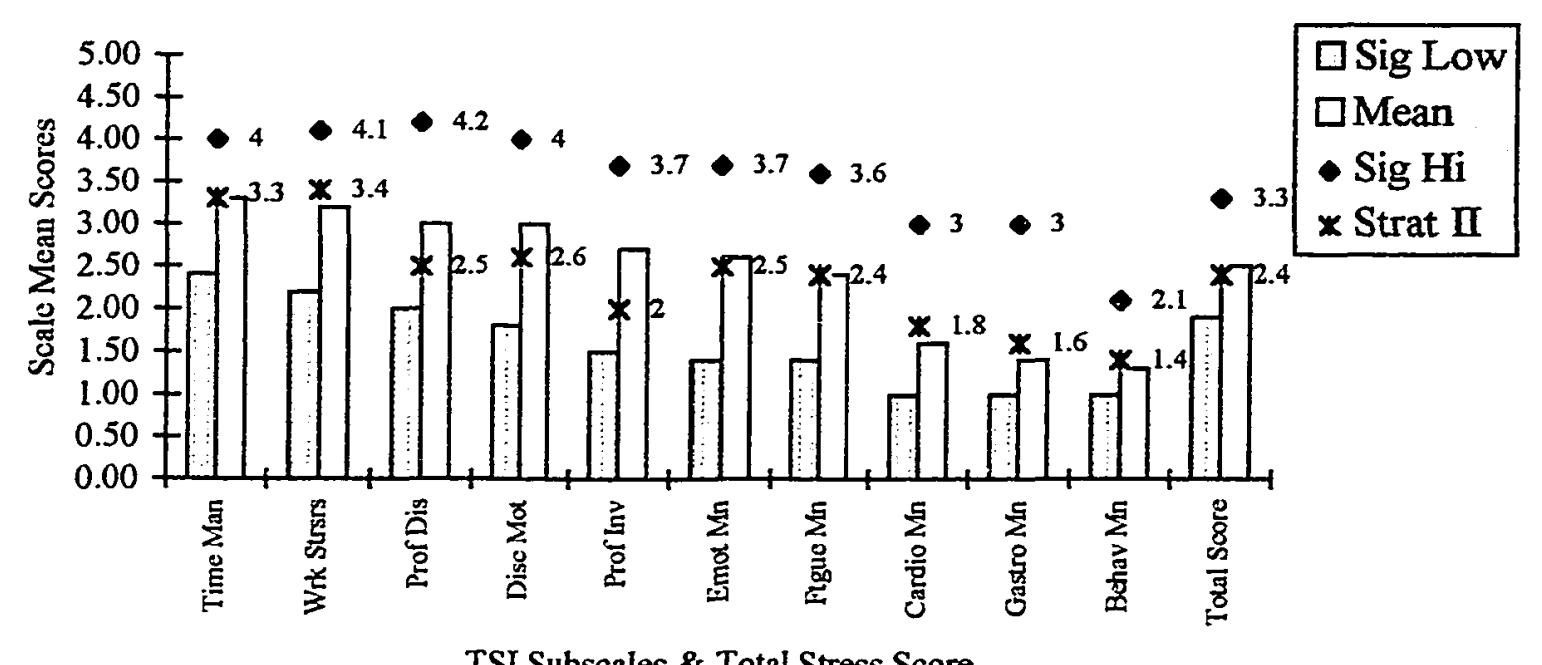

TSI Subscales \& Total Stress Score

Figure 8.

Graphic Representation of High-Low Cut-Off Points for the TSI Subscale and Subscale Mean Scores Compared to the Subscale Mean Scores of Stratum II. 


\section{Teacher Stress Levels: Stratum III}

Stratum III was comprised of seven schools with teaching staffs of 38 to 61 teachers and a sample size of 217 teachers. Stratum III's Total Stress Score mean was 2.43 , nearly equal to the aggregated norm group's mean of 2.50. The Total Stress Score of 2.43 fell in the moderate stress level range and described slightly lower-than-average stress levels. The two subscales which measured the greatest sources of stress were Work-Related Stressors and Time Management. The TSI aggregated norm mean score for Work-Related Stressors was 3.20, while stratum III's mean score for Work-Related Stressors was 3.45. The TSI aggregated norm mean score for Time Management was 3.30, while stratum II's mean score for Time Management was 3.35. These two subscale mean scores fell in the moderate stress level range and described slightly higher-thanaverage stress levels. The remaining subscale means for Professional Distress, Student Discipline \& Motivation, and Professional Investment in stratum III fell below the aggregated norm mean scores and described teachers as having below-average stress levels from those sources of stress.

The subscales which measured manifestations of stress were Emotional, Fatigue, Cardiovascular, Gastronomical, and Behavioral Manifestations. Stratum III's mean subscale scores were all above the TSI's aggregated norm mean scores with the exception of Emotional Manifestations which fell directly on the aggregated norm mean score of 2.60. Stratum III's subscale mean scores for manifestations of stress fell in the moderate stress level range and described slightly higher-than-average stress levels from manifestations of stress. 
Table 21

Teacher Stress Inventory: Overall Subscale Means from Least Stress Producing Subscale to Greatest Stress Producing Subscale for the 7 Schools in Stratum III ( $n=217)$

\begin{tabular}{lllll}
\hline Variable & Mean & Std Dev & Minimum & Maximum \\
\hline & & & & \\
Behavioral Manifestations & 1.47 & .63 & 1.00 & 4.50 \\
Gastronomical Manifestations & 1.66 & 1.00 & 1.00 & 5.00 \\
Cardiovascular Manifestations & 1.90 & .99 & 1.00 & 5.00 \\
Professional Investment & 2.18 & .85 & 1.00 & 4.50 \\
TSI Total Stress Score & $\mathbf{2 . 4 3}$ & .59 & 1.27 & 4.46 \\
Professional Distress & 2.47 & .99 & 1.00 & 5.00 \\
Fatigue Manifestations & 2.48 & 1.00 & 1.00 & 5.00 \\
Emotional Manifestations & 2.64 & 1.06 & 1.00 & 5.00 \\
Discipline \& Motivation & 2.66 & 1.03 & 1.00 & 5.00 \\
Time Management & 3.35 & .69 & 1.63 & 4.88 \\
Work-Related Stressors & 3.45 & .85 & 1.17 & 5.00
\end{tabular}

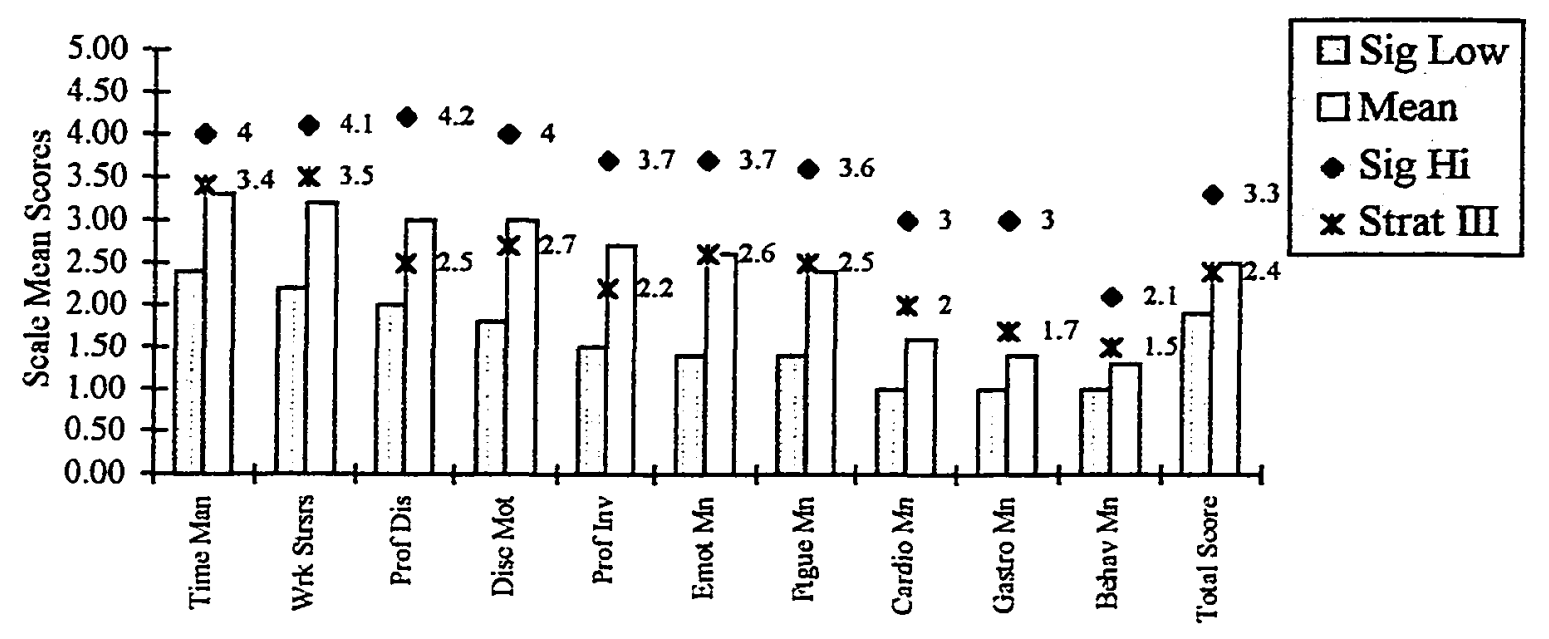

TSI Subscales \& Total Stress Score

Figure 9.

Graphic Representation of High-Low Cut-Off Points for the TSI Subscale and Subscale Mean Scores Compared to the Subscale Mean Scores of Stratum III. 
Reliability Coefficients: Alpha, Guttman Split-half, and Spearman-Brown

Reliability coefficients were calculated for the LBDQ and the TSI. The TSI had higher reliability coefficients than did the LBDQ. This may be explained, in part, by the fact that principals' leadership styles varied greatly from site-to-site as opposed to the sources and manifestations of teacher stress levels which possessed more commonality district-wide. The LBDQ's reliability coefficients were within an acceptable range, indicating that the reliability was good. The TSI's reliability coefficients were high, indicating that it had very good to excellent reliability. Reliability coefficients are shown in Table 22.

Table 22

Reliability Coefficients: Alpha, Guttman Split-half, and Spearman-Brown ( $n=585)$.

\begin{tabular}{lll}
\hline Reliability Coefficient & LBDQ & TSI \\
\hline Cronbach's Alpha & & \\
Guttman Split-half & .5579 & .8570 \\
Spearman-Brown & .5579 & .7143 \\
& .5626 & .7185
\end{tabular}

\section{Pearson's Product-Moment Correlation Coefficients}

Pearson's Correlation Coefficients were calculated to indicate the degree of relationship between the variables of principal leadership styles, school-site conditions, and teacher stress levels. More specifically, correlations were calculated between the two independent variables of Initiating Structure and Consideration from the LBDQ and the dependent variaúles of teacher stress levels from the ten subscales and Total Stress Score derived from the TSI. Additionally, correlations were calculated between the independent 
variables of school-site conditions, and the dependent variables of teacher stress from the TSI. Correlations were calculated for an overall sample and also for strata I, I, and III.

Correlation Coefficients were discussed in terms of strength. They ranged from negligible to moderate strength, and had direct and inverse relationships. This study used the following taxonomy for discussing the relationship of a correlation coefficient (Best \& Kahn, 1986, p.240):

$\begin{array}{ll}\text { Coefficient } & \text { Relationship } \\ .00 \text { to } .19 & \text { Negligible } \\ .20 \text { to } .39 & \text { Low } \\ .40 \text { to } .59 & \text { Moderate } \\ .60 \text { to } .79 & \text { Substantial } \\ .80 \text { to } 1.00 & \text { High to Very High }\end{array}$

The variables from the LBDQ and TSI had the strongest relationships, with correlation coefficients ranging from -.0044 to -.4811 (negligible to moderate relationships). The variables from school-site conditions and the TSI had relatively weak relationships with correlation coefficients ranging from .1000 to -.2381 (negligible to low relationships). Due to the hundreds of correlation coefficients calculated between schoolsite conditions and the TSI, only those coefficients, reaching a minimum value of at least .1000 or -.1000 with $\mathrm{P}$ Values of .05 or less, were reported in the Results Chapter.

\section{Correlations Between the LBDQ and the TSI}

The strongest relationships between principal leadership styles and teacher stress levels involved the same combination of variables for the overall sample, and strata $I, I$, and $\amalg$. The variable of Consideration from the LBDQ had negative relationships, ranging 
from negligible to moderate strength, with the variables of Professional Distress, Professional Investment, and the Total Stress Score from the TSI (see Table 23). In the overall sample and strata I, II, and III, Consideration and Professional Investment had the strongest correlation coefficients. The inverse relationship between these two variables indicated that a negative association, ranging from low to moderate strength, existed between Consideration (relationship-oriented leadership) and stress from the source of Professional Investment. Furthermore, in the overall sample, stratum I, and stratum III, Initiating Structure (task-oriented leadership) and Professional Investment had a low strength, inverse relationship indicating that, to a lesser degree, Initiating Structure and stress from the source of Professional Investment were negatively associated.

In the overall sample and strata I, II, and III, Consideration and Professional Distress had negligible to moderate strength relationships. The inverse relationship between these two variables indicated that a negative association, ranging from negligible to moderate strength, existed between Consideration (relationship-oriented leadership) and stress from the source of Professional Distress. Additionally, in stratum I Initiating Structure and Professional Distress had a low strength, inverse relationship indicating that in smaller schools, Initiating Structure and stress from the source of Professional Distress were negatively associated.

Consideration and the Total Stress Score from the TSI had low strength, inverse relationships indicating that Consideration and teacher stress from overall sources and manifestations were negatively associated. In stratum III, Consideration and the two TSI variables of Work-Related Stressors and Behavioral Manifestations had low strength, 
inverse relationships indicating that negative associations existed. The only direct relationship with negligible strength existed between Initiating Structure (task-oriented leadership) and stress from Work-Related Stressors in stratum II. The direct relationship between these two variables indicated that task-oriented leadership, in medium sized schools, and Work-Related Stressors were associated, but negligibly. The correlation coefficients between the LBDQ and TSI are represented below in Table 23 .

\section{Table 23}

Pearson Correlation Coefficients Between LBDQ and TSI Variables

\begin{tabular}{|c|c|c|c|c|}
\hline Variables & Overall & Stratum I & Stratum II & Stratum III \\
\hline $\begin{array}{l}\text { Ini. Struct. } \\
\& \text { Time Mang }\end{array}$ & $-.0360(p=.385)$ & $-.0959(p=.233)$ & $.0782(\mathrm{p}=.257)$ & $-.0818(\mathrm{p}=.230)$ \\
\hline $\begin{array}{l}\text { Consideration } \\
\& \text { Time Mang }\end{array}$ & $-.0901(\mathrm{p}=.029)$ & $-.1423(p=.076)$ & $.0287(p=678)$ & $-.1656(p=.015)$ \\
\hline $\begin{array}{l}\text { Ini. Struct. } \\
\& \text { Work Stres }\end{array}$ & $\begin{array}{l}.0203(\mathrm{p}=.623) \\
\text { sors }\end{array}$ & $-.0715(\mathrm{p}=.375)$ & $.1457(p=.034)$ & $-.0077(\mathrm{p}=.911)$ \\
\hline $\begin{array}{l}\text { Consideration } \\
\& \text { Work Stres: }\end{array}$ & $\begin{array}{l}-.1122(\mathrm{p}=.007) \\
\text { sors }\end{array}$ & $-.1736(p=.030)$ & $.0288(\mathrm{p}=.676)$ & $-.2067(\mathrm{p}=.002)$ \\
\hline $\begin{array}{l}\text { Ini. Struct. } \\
\text { \& Prof. Distre }\end{array}$ & $\begin{array}{l}-.1358(p=.001) \\
\text { ss }\end{array}$ & $-.2974(\mathrm{p}=.000)$ & $.0800(p=.246)$ & $-.1479(\mathrm{p}=.029)$ \\
\hline $\begin{array}{l}\text { Consideration } \\
\& \text { Prof. Distre }\end{array}$ & $\begin{array}{l}-.2984(p=.000) \\
\text { ss }\end{array}$ & $-.4706(\mathrm{p}=.000)$ & $-.1885(p=.006)$ & $-.2262(p=.001)$ \\
\hline $\begin{array}{l}\text { Ini. Struct. } \\
\text { \& Student Dis } \\
\text { Motivation }\end{array}$ & $\begin{array}{l}-.0728(p=.079) \\
\text { cipline }\end{array}$ & $-.0702(\mathrm{p}=.384)$ & $-.0106(p=.879)$ & $-.1254(p=.065)$ \\
\hline $\begin{array}{l}\text { Consideration } \\
\text { \& Student Dis } \\
\text { Motivation }\end{array}$ & $\begin{array}{l}-.1196(p=.004) \\
\text { cipline }\end{array}$ & $-.1184(p=.141)$ & $-.0930(p=.177)$ & $-.1370(p=.044)$ \\
\hline
\end{tabular}


Table 23 (cont.)

Pearson Correlation Coefficients Between LBDQ and TSI Variables

\begin{tabular}{|c|c|c|c|}
\hline Variables & Stratum I & Stratum II & Stratum III \\
\hline $\begin{array}{l}\text { Ini. Struct. } \quad-.1990(p=.000) \\
\text { \& Prof. Investment }\end{array}$ & $-.2380(p=.003)$ & $-.0131(\mathrm{p}=.850)$ & $-.2925(\mathrm{p}=.000)$ \\
\hline $\begin{array}{l}\text { Consideration }-.4073(p=.000) \\
\& \text { Prof. Investment }\end{array}$ & $-.4811(\mathrm{p}=.000)$ & $-.3231(\mathrm{p}=.000)$ & $-.3921(\mathrm{p}=.000)$ \\
\hline $\begin{array}{l}\text { Ini. Struct. }-.0918(p=.026) \\
\text { \& Emotional } \\
\text { Manifestations }\end{array}$ & $-.1406(p=.080)$ & $-.0044(p=.949)$ & $-.1209(\mathrm{p}=.075)$ \\
\hline $\begin{array}{l}\text { Consideration }-.1291(\mathrm{p}=.002) \\
\text { \& Emotional } \\
\text { Manifestations }\end{array}$ & $-.1232(\mathrm{p}=.125)$ & $-.0750(p=.277)$ & $-.1748(\mathrm{p}=.010)$ \\
\hline $\begin{array}{l}\text { Ini. Struct. } \quad-.0484(p=.242) \\
\& \text { Fatigue } \\
\text { Manifestations }\end{array}$ & $-.0427(p=.597)$ & $-.0207(\mathrm{p}=.764)$ & $-.0666(p=.329)$ \\
\hline $\begin{array}{l}\text { Consideration }-.1155(\mathrm{p}=.005) \\
\& \text { Fatigue } \\
\text { Manifestations }\end{array}$ & $-.0991(\mathrm{p}=.218)$ & $-.0707(p=.305)$ & $-.1582(p=.020)$ \\
\hline $\begin{array}{l}\text { Ini. Struct. } .0159(p=.701) \\
\& \text { Cardiovascular } \\
\text { Manifestations }\end{array}$ & $.0716(p=.374)$ & $.0678(p=.326)$ & $-.0608(p=.373)$ \\
\hline $\begin{array}{l}\text { Consideration }-.0994(\mathrm{p}=.016) \\
\text { \& Cardiovascular } \\
\text { Manifestations }\end{array}$ & $-.0104(p=.898)$ & $-.0743(p=.281)$ & $-.1810(p=.008)$ \\
\hline $\begin{array}{l}\text { Ini. Struct. } \quad-.0516(p=.213) \\
\& \text { Gastronomical } \\
\text { Manifestations }\end{array}$ & $-.0300(p=.710)$ & $.0920(p=.182)$ & $-.1786(p=.008)$ \\
\hline $\begin{array}{l}\text { Consideration }-.0911(\mathrm{p}=.028) \\
\text { \& Gastronomical } \\
\text { Manifestations }\end{array}$ & $-.1308(p=.104)$ & $-.0249(\mathrm{p}=.719)$ & $-.1097(p=.107)$ \\
\hline
\end{tabular}


Table 23 (cont.)

\section{Pearson Correlation Coefficients Between LBDQ and TSI Variables}

\begin{tabular}{|c|c|c|c|c|}
\hline Variables & Overall & Stratum I & Stratum II & Stratum III \\
\hline $\begin{array}{l}\text { Ini. Struct. } \\
\text { \& Behavioral } \\
\text { Manifestations }\end{array}$ & $-.0547(p=.187)$ & $-.0468(\mathrm{p}=.562)$ & $.0886(\mathrm{p}=.199)$ & $-.1625(\mathrm{p}=.017)$ \\
\hline $\begin{array}{l}\text { Consideration } \\
\text { \& Behavioral } \\
\text { Manifestations }\end{array}$ & $-.1323(p=.001)$ & $-.0818(\mathrm{p}=.310)$ & $-.0018(\mathrm{p}=.979)$ & $-.2846(\mathrm{p}=.000)$ \\
\hline $\begin{array}{l}\text { Ini. Struct. } \\
\text { \& Total Stress } \\
\text { Score }\end{array}$ & $-.1056(p=.011)$ & $-.1583(\mathrm{p}=.048)$ & $.0781(p=.257)$ & $-.1894(p=.005)$ \\
\hline $\begin{array}{l}\text { Consideration } \\
\text { \& Total Stress } \\
\text { Score }\end{array}$ & $-.2546(p=.000)$ & $-.3014(\mathrm{p}=.000)$ & $-.1373(\mathrm{p}=.046)$ & $-.3037(\mathrm{p}=.000)$ \\
\hline
\end{tabular}

\section{Correlations Between School-Site Conditions and the TSI}

The correlations between school-site conditions and teacher stress levels had direct and inverse relationships ranging from negligible to low strength. Additionally, those few correlation coefficients that had low strength were not as consistent between the overall sample, and strata I, II, and II, as was the case between the LBDQ and TSI variables discussed in the previous section. In this section, those correlations were not discussed individually due to the negligible or low strength relationships which existed between them. However, correlation coefficients were calculated in order to be predictors -- no matter how weak -- of relationships between school-site conditions and teacher stress levels. Discussion regarding those correlation coefficients in tandem with stepwise multiple regression analyses will be presented in chapter 5. 
Table 24

$\underline{\text { Pearson Correlation Coefficients Between School-Site Conditions and TSI Variables }}$

for the Overall Sample $(n=585)$

Variables

Work-Related Stressors

\& Class Size

Discipline \& Motivation

$\&$ Class Size

Discipline \& Motivation

\& Grade Level

Behavior Manifestations

\& Number New Teachers

Behavior Manifestations

\& Percentage New Teachers

Work-Related Stressors

\& Teacher Degree

Professional Investment

\& Teacher Degree

Work-Related Stressors

\& Years Teaching

Professional Investment

\& Years Teaching
Correlation Coefficient

.1376

.1443

.1342

.001

$-.1025$

.013

$-.1154$

.005

.1000

.016

.1166

.005

.1409

.001

.1018

.014 
Table 25

Pearson Correlation Coefficients Between School-Site Conditions and TSI Variables

for Stratum I $(n=156)$

Variables

Discipline \& Motivation

\& Class Taught

Total Stress Score

\& Class Taught

Behavior Manifestations

\& Number New Teachers

Time Management

\& Principals Years

at Current Site

Time Management

\& SAT9 Scores 3rd

Grade Reading

Time Management

\& Teacher Gender

Emotional Manifestations

\& Teacher Gender

Fatigue Manifestations

$\&$ Teacher Gender

Behavior Manifestations

\& Student Suspensions
Correlation Coefficient

$-.2074$

$-.1912$

$-.2178$

.006

.1564

.051

.2133

.007

$-.2267$

.004

$-.2381$

.003

$-.2114$

.008

$-.1893$

.018 
Table 26

Pearson Correlation Coefficients Between School-Site Conditions and TSI Variables

for Stratum II (n=212)

Variables

Discipline \& Motivation

$\&$ Class Size

Discipline \& Motivation

\& African-American Students

Discipline \& Motivation

\& Asian Students

Discipline \& Motivation

\& Number of Instructional Minutes

for Grades 1-3

Discipline \& Motivation

\& Grade Level

Gastronomical Manifestations

\& Grade Level

Discipline \& Motivation

\& Number of Instructional Minutes

for Grades 4-6

Gastronomical Manifestations

\& Latino/a Students

Work-Related Stressors

\& SAT9 Scores 3rd

Grade Math

Work-Related Stressors

\& SAT9 Scores 3rd

Grade Reading

Professional Distress

\& Teacher Race
.2020

.1571

$-.2086$

.002

.2199

.2025

.003

.1903

.005

.1732

.012

$P$ value

.000

.022

.003

.001

.002

.004

$-.1823$

.008 
Table 27

Pearson Correlation Coefficients Between School-Site Conditions and TSI Variables

for Stratum III ( $n=217)$

Variables

Work-Related Stressors

\& Coordinate Compliance

Review

Discipline \& Motivation

\& African-American Students

Discipline \& Motivation

\& Asian Students

Discipline \& Motivation

\& Caucasian Students

Work-Related Stressors

\& Dollars Spent Per Pupil

Fatigue Manifestations

\& Number of VPs at

the School-Site

Behavior Manifestations

$\&$ Number New Teachers

Work-Related Stressors

\& Principal Gender

Fatigue Manifestations

\& Principals Years at

Current Site

Work-Related Stressors

\& Teacher Race

Professional Distress

\& Teacher Age
.1967

.1772

.009

$-.1414$

.037

$-.1352$

.047

$-.2111$

.002

.1681

.013

$-.1859$

.006

$-.1921$

.005

.1603

.018

.1682

.013

$-.1985$

.003 
Stepwise Multiple Regression Analyses

The data obtained for this study were also analyzed using stepwise multiple regression. The independent variables were principal leadership styles and school-site conditions and the dependent variables were teacher stress levels. The alpha level was set at .05. Stepwise multiple regression was conducted in order to predict the value of the dependent variables of Teacher Stress (as measured by the TSI's eleven scales) from the values of one or more independent variables comprising Principal Leadership Styles (as measured by the LBDQ) and School-Site Conditions. The computer program SPSS analyzed all variables in this study by using forward inclusion and backwards elimination to determine which independent variable or combination of independent variables would predict the greatest amount of variance (Adjusted $R^{2}$ ) in the dependent variables. These analyses were conducted for the overall sample, strata I, $I$, and III and reported in tabular form for all those variables which predicted at least $10 \%$ of the variance in the Teacher Stress variables. These analyses were used to either accept or reject the null hypotheses.

Stepwise Multiple Regression: Overall Sample ( $n=585)$

Equation one, a one-step regression analysis, using the independent variable of Consideration, explained $16 \%$ of the variance in the dependent variable of Professional Investment (Table 28). Equation two, a three-step regression analysis which added the two variables of Number of Instructional Minutes for Grades 4-6 for Entire School Year and Teacher Gender to equation one, explained an additional $2 \%$ of the variance in the dependent variable of Professional Investment for a total of $18 \%$ (Table 29). Equation 
three, a three-step regression analysis using the independent variables of Consideration, Suspensions of Students, and Teacher Gender explained $10 \%$ of the variance in the dependent variable of Professional Distress (Table 30). In the overall sample, the independent variable of Consideration was the best predictor of teacher stress in the dependent variable of Professional Investment.

Table 28

Stepwise Multiple Regressions Depicted by Step(s) for the Overall Sample $(n=585)$

Equation Number 1: Dependent Variable - Professional Investment

Variable(s) Entered on Step Number

1. CONSID LBDQ: Consideration - Relationship-Oriented Leadership

Multiple R $\quad .40725$

R Square $\quad .16586$

Adjusted R Square .16443

Standard Error $\quad .77984$

Analysis of Variance

$\begin{array}{lrrc} & \text { DF } & \text { Sum of Squares } & \text { Mean Square } \\ \text { Regression } & 1 & 70.49679 & 70.49679 \\ \text { Residual } & 583 & 354.55086 & .60815\end{array}$

$F=115.92026 \quad$ Signif $F=.0000$ 
Table 29

Stepwise Multiple Regressions Depicted by Step(s) for the Overall Sample ( $n=585)$

Equation Number 2: Dependent Variable - Professional Investment

Variable(s) Entered on Step Number

1. CONSID LBDQ: Consideration - Relationship-Oriented Leadership

Multiple R $\quad .40725$

R Square $\quad .16586$

Adjusted R Square .16443

Standard Error $\quad .77984$

Analysis of Variance

$\begin{array}{lrrr} & \text { DF } & \text { Sum of Squares } & \text { Mean Square } \\ \text { Regression } & 1 & 70.49679 & 70.49679 \\ \text { Residual } & 583 & 354.55086 & .60815\end{array}$

$F=115.92026 \quad$ Signif $F=.0000$

Variable(s) Entered on Step Number

2. INSTMN46: Number of Instructional Mimutes for Grades 4-6 for Entire School Year

Multiple R $\quad .41984$

R Square $\quad .17627$

Adjusted R Square $\quad .17344$

Standard Error $\quad .77562$

Analysis of Variance

$\begin{array}{lrrr} & \text { DF } & \text { Sum of Squares } & \text { Mean Square } \\ \text { Regression } & 2 & 74.92260 & 37.46130 \\ \text { Residual } & 582 & 350.12505 & .60159\end{array}$

$F=62.27054 \quad$ Signif $F=.0000$ 
Table 29 (cont.)

Stepwise Multiple Regressions Depicted by Step(s) for the Overall Sample ( $n=585)$

Equation Number 2: Dependent Variable - Professional Investment

Variable(s) Entered on Step Number

3. TCHGENDR: Teacher Gender

Multiple R $\quad .42761$

R Square $\quad .18285$

Adjusted R Square $\quad .17863$

Standard Error $\quad .77318$

Analysis of Variance

$\begin{array}{lrrr} & \text { DF } & \text { Sum of Squares } & \text { Mean Square } \\ \text { Regression } & 3 & 77.71984 & 25.90661 \\ \text { Residual } & 581 & 347.32781 & .59781\end{array}$

$F=43.33584 \quad$ Signif $F=.0000$

Table 30

$\underline{\text { Stepwise Multiple Regressions Depicted by Step(s) for the Overall Sample ( } n=585)}$

Equation Number 3: Dependent Variable - Professional Distress

Variable(s) Entered on Step Number

1. CONSID LBDQ: Consideration - Relationship-Oriented Leadership

Multiple R $\quad .29839$

R Square $\quad .08904$

Adjusted R Square $\quad .08748$

Standard Error $\quad .96131$

Analysis of Variance

$\begin{array}{lrrc} & \text { DF } & \text { Sum of Squares } & \text { Mean Square } \\ \text { Regression } & 1 & 52.65818 & 52.65818 \\ \text { Residual } & 583 & 538.75611 & .92411\end{array}$

$\mathrm{F}=56.98259 \quad$ Signif $\mathrm{F}=.0000$ 
Table 30 (cont.)

Stepwise Multiple Regressions Depicted by Step(s) for the Overall Sample ( $n=585)$

Equation Number 3: Dependent Variable - Professional Distress

Variable(s) Entered on Step Number

2. SUSPNSN: Suspensions of Students

Multiple R $\quad .31007$

R Square $\quad .09614$

Adjusted R Square $\quad .09304$

Standard Error $\quad .95837$

Analysis of Variance

$\begin{array}{lrrc} & \text { DF } & \text { Sum of Squares } & \text { Mean Square } \\ \text { Regression } & 2 & 56.85953 & 28.42976 \\ \text { Residual } & 582 & 534.55476 & .91848\end{array}$

$F=30.95309 \quad$ Signif $F=.0000$

Variable(s) Entered on Step Number

3. TCHGENDR: Teacher Gender

Multiple R $\quad .32091$

R Square $\quad .10298$

Adjusted R Square $\quad .09835$

Standard Error $\quad .95556$

Analysis of Variance

\begin{tabular}{lrcr} 
& DF & \multicolumn{1}{c}{ Sum of Squares } & Mean Square \\
Regression & 3 & 60.90468 & 20.30156 \\
Residual & 581 & 530.50961 & .91310
\end{tabular}

$F=22.23373 \quad$ Signif $F=.0000$ 
Results by Null Hypotheses for the Overall Sample ( $n=585)$

Hypothesis 1 stated that there would be no significant relationship between teachers' stress levels at schools with principals who were perceived as exercising high-consideration (relationship-oriented) leadership behavior and teachers' stress levels at schools with principais who were perceived as exercising low-consideration (relationship-oriented) leadership behavior.

In equation 1 , Table 28 , the stepwise multiple regression analysis entered the independent variable of Consideration from the LBDQ and the dependent variables of Teacher Stress from the TSI. Hypothesis 1 was rejected because the independent variable of Consideration explained $16 \%$ of the variance in the dependent variable of stress from the source of Professional Investment with the F Value significant beyond the alpha $=.000$.

Hypothesis 2 stated that there would be no significant relationship between teachers' stress levels at schools with principals who were perceived as exercising high-initiating structure (task-oriented) leadership behavior and teachers'stress levels at schools with principals who were perceived as exercising low-initiating structure (task-oriented) leadership behavior.

After testing the null hypothesis for a significant relationship between the independent variable of Initiating Structure and the dependent variable of Teacher Stress, no predictor variables were either entered into or removed from the regression equation. Therefore, the null hypothesis was failed to reject.

Hypothesis 3 stated that there would be no significant relationship between teachers' stress levels at schools with principals who were perceived as exercising high-consideration 
(relationship-oriented)/low-initiating structure (task-oriented) leadership behavior and teachers' stress levels at schools with principals who were perceived as exercising lowconsideration (relationship-oriented)/high-initiating structure (task-oriented) leadership behavior.

After testing the null hypothesis for a significant relationship between the independent variables of Consideration and Initiating Structure and the dependent variable of Teacher Stress, no predictor variables were either entered into or removed from the regression equation. Therefore, the null hypothesis was failed to reject.

Hypothesis 4 stated that there would be no significant relationship between teachers' stress levels, on the one hand, and principals' leadership styles and school site conditions, on the other. In equation 2 , Table 29 , the stepwise multiple regression analysis entered the independent variables of Consideration, Initiating Structure and school-site conditions, and the dependent variables of Teacher Stress from the TSI. Hypothesis 4 was rejected because the independent variables of Consideration, Number of Instructional Minutes for Grades 4-6 for Entire School Year, and Teacher Gender explained 18\% of the variance in the dependent variable of stress from the source of Professional Investment with the F Value significant beyond the alpha $=.000$. Additionally, in equation 3 , Table 30 , the independent variables of Consideration, Suspensions of Students, and Teacher Gender explained $10 \%$ of the variance in the dependent variable of stress from the source of Professional Distress with the $F$ Value significant beyond the alpha $=.000$ 
Stepwise Multiple Regression: Stratum I ( $n=156)$

Equation one, a one-step regression analysis, using the independent variable of Consideration, explained $22 \%$ of the variance in the dependent variable of Professional Distress. (Table 31). Equation two, a three-step regression analysis which added the two variables of Percentage of Asian Students and Percentage of Filipino Students to equation one, explained an additional $4 \%$ of the variance in the dependent variable of Professional Distress for a total of $26 \%$ (Table 32). Equation three, a one-step regression analysis, using the independent variable of Consideration, explained $23 \%$ of the variance in the dependent variable of Professional Investment (Table 33). Equation four, a two-step regression analysis which added the variable of African-American Students to equation three, explained an additional $2 \%$ of the variance in the independent variable of Professional Investment for a total of $25 \%$ (Table 34). Equation five, a four-step regression analysis, using the independent variables of Teacher Gender, SAT9 3rd Grade Total Reading Scores of Students at or above the 50th Percentile, Coordinated Compliance Review and Initiating Structure explained 15\% of the variance in the dependent variable of Time Management (Table 35). In stratum I, the independent variable of Consideration was the best predictor of teacher stress in the dependent variable of Professional Distress. 
Table 31

Stepwise Multiple Regressions Depicted by Step(s) for Stratum I ( $n=156)$

Equation Number 1: Dependent Variable - Professional Distress

Variable(s) Entered on Step Number

1. CONSID LBDQ-Consideration: Relationship-Oriented Leadership

Multiple R $\quad .47060$

R Square $\quad .22146$

Adjusted R Square .21641

Standard Error $\quad .95485$

Analysis of Variance

$\begin{array}{lrrc} & \text { DF } & \text { Sum of Squares } & \text { Mean Square } \\ \text { Regression } & 1 & 39.94010 & 39.94010 \\ \text { Residual } & 154 & 140.40760 & .91174\end{array}$

$F=43.80657 \quad$ Signif $F=.0000$

Table 32

Stepwise Multiple Regressions Depicted by Step(s) for Stratum I ( $n=156)$

Equation Number 2: Dependent Variable - Professional Distress

Variable(s) Entered on Step Number

1. CONSID LBDQ: Consideration Relationship-Oriented Leadership

Multiple R $\quad .47060$

R Square $\quad .22146$

Adjusted R Square .21641

Standard Error $\quad .95485$

Analysis of Variance

$\begin{array}{lrrc} & \text { DF } & \text { Sum of Squares } & \text { Mean Square } \\ \text { Regression } & 1 & 39.94010 & 39.94010 \\ \text { Residual } & 154 & 140.40760 & .91174\end{array}$

$F=43.80657 \quad$ Signif $F=.0000$ 
Table 32 (cont.)

Stepwise Multiple Regressions Depicted by Step(s) for Stratum I ( $n=156)$

Equation Number 2: Dependent Variable - Professional Distress

Variable(s) Entered on Step Number

2. ASIAN: Perceniage of Asian Students

Multiple R $\quad .49413$

R Square $\quad .24416$

Adjusted R Square $\quad .23428$

Standard Error $\quad .94390$

Analysis of Variance

$\begin{array}{lrrc} & \text { DF } & \text { Sum of Squares } & \text { Mean Square } \\ \text { Regression } & 2 & 44.03399 & 22.01699 \\ \text { Residual } & 153 & 136.31370 & .89094\end{array}$

$F=24.71212 \quad$ Signif $F=.0000$

Variable(s) Entered on Step Number

3. FILIPINO Percentage of Filipino Students

Multiple R $\quad .51989$

R Square $\quad .27028$

Adjusted R Square .25588

Standard Error $\quad .93049$

Analysis of Variance

$\begin{array}{lrrc} & \text { DF } & \text { Sum of Squares } & \text { Mean Square } \\ \text { Regression } & 3 & 48.74495 & 16.24832 \\ \text { Residual } & 152 & 131.60274 & .86581\end{array}$

$F=\quad 18.76666 \quad$ Signif $F=.0000$ 
Table 33

Stepwise Multiple Regressions Depicted by Step(s) for Stratum I ( $n=156)$

Equation Number 3: Dependent Variable - Professional Investment

Variable(s) Entered on Step Number

1. CONSID LBDQ: Consideration - Relationship-Oriented Leadership

Multiple R $\quad .48111$

R Square $\quad .23147$

Adjusted R Square .22648

Standard Error $\quad .82570$

Analysis of Variance

$\begin{array}{lrrc} & \text { DF } & \text { Sum of Squares } & \text { Mean Square } \\ \text { Regression } & 1 & 31.62321 & 31.62321 \\ \text { Residual } & 154 & 104.99538 & .68179\end{array}$

$F=\quad 46.38276 \quad$ Signif $F=.0000$

Table 34

Stepwise Multiple Regressions Depicted by Step(s) for Stratum I ( $n=156)$

Equation Number 4: Dependent Variable - Professional Investment

Variable(s) Entered on Step Number

1. CONSID LBDQ: Consideration Relationship-Oriented Leadership

Multiple R .48111

R Square $\quad .23147$

Adjusted R Square $\quad .22648$

Standard Error $\quad .82570$

Analysis of Variance

$\begin{array}{lrrc} & \text { DF } & \text { Sum of Squares } & \text { Mean Square } \\ \text { Regression } & 1 & 31.62321 & 31.62321 \\ \text { Residual } & 154 & 104.99538 & .68179\end{array}$

$F=46.38276 \quad$ Signif $F=.0000$ 
Table 34 (cont.)

Stepwise Multiple Regressions Depicted by Step(s) for Stratum I ( $n=156)$

Equation Number 4: Dependent Variable - Professional Investment

Variable(s) Entered on Step Number

2. AFR_AM: Percentage of African-American Students

Multiple R $\quad .50700$

R Square $\quad .25705$

Adjusted R Square $\quad .24734$

Standard Error $\quad .81449$

Analysis of Variance

$\begin{array}{lrrr} & \text { DF } & \text { Sum of Squares } & \text { Mean Square } \\ \text { Regression } & 2 & 35.11812 & 17.55906 \\ \text { Residual } & 153 & 101.50047 & .66340\end{array}$

$F=26.46821 \quad$ Signif $F=.0000$

Table 35

Stepwise Multiple Regressions Depicted by Step(s) for Stratum I ( $n=156)$

Equation Number 5: Dependent Variable - Time Management

Variable(s) Entered on Step Number

I. TCHGENDR: Teacher Gender

Multiple R $\quad .22669$

R Square $\quad .05139$

Adjusted R Square .04523

Standard Error $\quad .71616$

Analysis of Variance

$\begin{array}{lrrc} & \text { DF } & \text { Sum of Squares } & \text { Mean Square } \\ \text { Regression } & 1 & 4.27877 & 4.27877 \\ \text { Residual } & 154 & 78.98525 & .51289\end{array}$

$F=\quad 8.34246 \quad$ Signif $F=.0044$ 
Table 35 (cont.)

Stepwise Multiple Regressions Depicted by Step(s) for Stratum I ( $n=156)$

Equation Number 5: Dependent Variable - Time Management

Variable(s) Entered on Step Number

2. SAT9_3R: SAT9 3rd Grade Total Reading Scores of Students at or above the 50th Percentile

Multiple R $\quad .31357$

R Square $\quad .09833$

Adjusted R Square $\quad .08654$

Standard Error $\quad .70050$

Analysis of Variance

$\begin{array}{lrrc} & \text { DF } & \text { Sum of Squares } & \text { Mean Square } \\ \text { Regression } & 2 & 8.18714 & 4.09357 \\ \text { Residual } & 153 & 75.07689 & .49070\end{array}$

$F=8.34233 \quad$ Signif $F=.0004$

Variable(s) Entered on Step Number

3. CCR: Coordinated Compliance Review

Multiple R $\quad .37181$

R Square $\quad .13824$

Adjusted R Square $\quad .12123$

Standard Error $\quad .68707$

Analysis of Variance

$\begin{array}{lrrc} & \text { DF } & \text { Sum of Squares } & \text { Mean Square } \\ \text { Regression } & 3 & 11.51048 & 3.83683 \\ \text { Residual } & 152 & 71.75354 & .47206\end{array}$

$F=8.12779 \quad$ Signif $F=.0000$ 
Table 35 (cont.)

Stepwise Multiple Regressions Depicted by Step(s) for Stratum I ( $n=156)$

Equation Number 5: Dependent Variable - Time Management

Variable(s) Entered on Step Number

4. INI_STRC LBDQ: Initiating Structure - Task-Oriented Leadership

Multiple R $\quad .41195$

R Square $\quad .16970$

Adjusted R Square .14771

Standard Error $\quad .67664$

Analysis of Variance

$\begin{array}{lrrr} & \text { DF } & \text { Sum of Squares } & \text { Mean Square } \\ \text { Regression } & 4 & 14.13027 & 3.53257 \\ \text { Residual } & 151 & 69.13375 & .45784\end{array}$

$\mathrm{F}=\quad 7.71573 \quad$ Signif $\mathrm{F}=.0000$

Results by Null Hypotheses for Stratum I $(n=156)$

Hypothesis 1 stated that there would be no significant relationship between teachers' stress levels at schools with principals who were perceived as exercising high-consideration (relationship-oriented) leadership behavior and teachers' stress levels at schools with principals who were perceived as exercising low-consideration (relationship-oriented) leadership behavior.

In equation 1, Table 31, the stepwise multiple regression analysis entered the independent variable of Consideration from the LBDQ and the dependent variables of Teacher Stress from the TSI. Hypothesis 1 was rejected because the independent variable of Consideration explained $22 \%$ of the variance in the dependent variable of stress from the source of Professional Distress with the F Value significant beyond the alpha $=.000$. 
Additionally, in equation 3, Table 32, the independent variable of Consideration explained $23 \%$ of the variance in the dependent variable of stress from the source of Professional Investment with the $\mathrm{F}$ Value significant beyond the alpha $=.000$

Hypothesis 2 stated that there would be no significant relationship between teachers' stress levels at schools with principals who were perceived as exercising high-initiating structure (task-oriented) leadership behavior and teachers' stress levels at schools with principals who were perceived as exercising low-initiating structure (task-oriented) leadership behavior.

After testing the null hypothesis for a significant relationship between the independent variable of Initiating Structure and the dependent variable of Teacher Stress, no predictor variables were either entered into or removed from the regression equation. Therefore, the null hypothesis was failed to reject.

Hypothesis 3 stated that there would be no significant relationship between teachers' stress levels at schools with principals who were perceived as exercising high-consideration (relationship-oriented)/low-initiating structure (task-oriented) leadership behavior and teachers' stress levels at schools with principals who were perceived as exercising lowconsideration (relationship-oriented)/high-initiating structure (task-oriented) leadership behavior.

After testing the null hypothesis for a significant relationship between the independent variables of Consideration and Initiating Structure and the dependent variable of Teacher Stress, no predictor variables were either entered into or removed from the regression equation. Therefore, the null hypothesis was failed to reject. 
Hypothesis 4 stated that there would be no significant relationship between teachers' stress levels, on the one hand, and principals' leadership styles and school-site conditions, on the other. In equation 2 , Table 32 , the stepwise multiple regression analysis entered the independent variables of Consideration, Initiating Structure, and school-site conditions, and the dependent variables of Teacher Stress from the TSI. Hypothesis 4 was rejected because the independent variables of Consideration, Percentage of Asian Students, and Percentage of Filipino Students explained $26 \%$ of the variance in the dependent variable of stress from the source of Professional Distress with the F Value significant beyond the alpha $=$ .000 . In equation 4, Table 34, the independent variables of Consideration and Percentage of African-American Students explained $25 \%$ of the variance in the dependent variable of stress from the source of Professional Investment with the $\mathrm{F}$ Value significant beyond the alpha $=$ .000 . Additionally, in equation 5, Table 35, the independent variables of Teacher Gender, SAT9 3rd Grade Total Reading Scores of Students at or above the 50th Percentile, CCR, and Initiating Structure, explained $15 \%$ of the variance in the dependent variable of stress from the source of Time Management with the $\mathrm{F}$ Value significant beyond the alpha $=.000$.

\section{Stepwise Multiple Regression: Stratum II (n=212)}

Equation one, a one-step regression analysis, using the independent variable of Consideration, explained $10 \%$ of the variance in the dependent variable of Professional Investment (Table 36). Equation two, a three-step regression analysis which added the two variables of Dollars Spent per Pupil by the School and Principals' Years at Site to equation one, explained an additional $5 \%$ of the variance in the dependent variable of 
Professional Investment for a total of $15 \%$ (Table 37). Equation three, a five-step regression analysis, using the independent variables of SAT9 3rd Grade Total Math Scores of Students at or above the 50th Percentile, SAT9 5th Grade Total Math Scores of Students at or above the 50th Percentile, Class Size, Number of Instructional Minutes for Kindergarten for Entire School Year, and Staff Size, explained $9 \%$ of the variance in the dependent variable of Work-Related Stressors (Table 38). Equation four, a three-step regression analysis, using the independent variables of Class Size, Number of Instructional Minutes for Kindergarten for Entire School Year, and Unexcused Student Absences, explained $11 \%$ of the variance in the dependent variable of Discipline \& Motivation of Students (Table 39). In Stratum II, the independent variable of Consideration was the best predictor of teacher stress in the dependent variable of Professional Investment.

Table 36

Stepwise Multiple Regressions Depicted by Step(s) for Stratum II ( $n=212)$

Equation Number 1: Dependent Variable - Professional Investment

Variable(s) Entered on Step Number

1. CONSID LBDQ-Consideration: Relationship-Oriented Leadership

Multiple R $\quad .32313$

R Square $\quad .10441$

Adjusted R Square $\quad .10015$

Standard Error $\quad .72864$

Analysis of Variance

$\begin{array}{lrrc} & \text { DF } & \text { Sum of Squares } & \text { Mean Square } \\ \text { Regression } & 1 & 12.99812 & 12.99812 \\ \text { Residual } & 210 & 111.49127 & .53091\end{array}$

$F=24.48267 \quad$ Signif $F=.0000$ 
Table 37

Stepwise Multiple Regressions Depicted by Step(s) for Stratum II ( $n=212)$

Equation Number 2: Dependent Variable - Professional Investment

Variable(s) Entered on Step Number

1. CONSID LBDQ: Consideration Relationship-Oriented Leadership

Multiple R $\quad .32313$

R Square $\quad .10441$

Adjusted R Square .10015

Standard Error $\quad .72864$

Analysis of Variance

$\begin{array}{lrcc}\text { Regression } & 1 & 12.99812 & 12.99812 \\ \text { Residual } & 210 & 111.49127 & .53091\end{array}$

$F=24.48267 \quad$ Signif $F=.0000$

Variable(s) Entered on Step Number

2. MONPUPIL: Dollars Spent per Pupil by School Site

Multiple R $\quad .37119$

R Square $\quad .13778$

Adjusted R Square .12953

Standard Error $\quad .71664$

Analysis of Variance

$\begin{array}{lrrc} & \text { DF } & \text { Sum of Squares } & \text { Mean Square } \\ \text { Regression } & 2 & 17.15200 & 8.57600 \\ \text { Residual } & 209 & 107.33739 & .51358\end{array}$

$F=16.69860 \quad$ Signif $F=.0000$ 
Table 37 (cont.)

Stepwise Multiple Regressions Depicted by Step(s) for Stratum II ( $n=212)$

Equation Number 2: Dependent Variable - Professional Investment

Variable(s) Entered on Step Number

3. PRYRSITE: Principal Years at Current Site

Multiple R $\quad .39643$

R Square $\quad .15716$

Adjusted R Square .14500

Standard Error $\quad .71024$

Analysis of Variance

$\begin{array}{lrrr} & \text { DF } & \text { Sum of Squares } & \text { Mean Square } \\ \text { Regression } & 3 & 19.56463 & 6.52154 \\ \text { Residual } & 208 & 104.92476 & .50445\end{array}$

$F=12.92813 \quad$ Signif $F=.0000$

Table 38

Stepwise Multiple Regressions Depicted by Step(s) for Stratum II ( $n=212)$

Equation Number 3: Dependent Variable - Work-Related Stressors

Variable(s) Entered on Step Number

1. SAT9_3M: SAT9 3rd Grade Total Math Scores of Students at or above the 50th

Percentile

Multiple R $\quad .19031$

R Square $\quad .03622$

Adjusted R Square .03163

Standard Error $\quad .86410$

Analysis of Variance

$\begin{array}{lrrcc} & \text { DF } & \text { Sum of Squares } & \text { Mean Square } \\ \text { Regression } & 1 & 5.89223 & 5.89223 \\ \text { Residual } & 210 & 156.80209 & .74668\end{array}$

$F=\quad 7.89127 \quad$ Signif $F=.0054$ 
Table 38 (cont.)

Stepwise Multiple Regressions Depicted by Step(s) for Stratum II (n=212)

Equation Number 3: Dependent Variable - Work-Related Stressors

Variable(s) Entered on Step Number

2. SAT9_5M: SAT9 5th Grade Total Math Scores of Students at or above the 50th Percentile

Multiple R $\quad .24218$

R Square $\quad .05865$

Adjusted R Square .04964

Standard Error $\quad .85603$

Analysis of Variance

$\begin{array}{lrrc} & \text { DF } & \text { Sum of Squares } & \text { Mean Square } \\ \text { Regression } & 2 & 9.54206 & 4.77103 \\ \text { Residual } & 209 & 153.15225 & .73279\end{array}$

$F=6.51081 \quad$ Signif $F=.0018$

Variable(s) Entered on Step Number

3. CLASSIZE: Class Size

Multiple R $\quad .27908$

R Square $\quad .07788$

Adjusted R Square $\quad .06458$

Standard Error $\quad .84927$

Analysis of Variance

$\begin{array}{lrrc} & \text { DF } & \text { Sum of Squares } & \text { Mean Square } \\ \text { Regression } & 3 & 12.67122 & 4.22374 \\ \text { Residual } & 208 & 150.02309 & .72126\end{array}$

$F=\quad 5.85602 \quad$ Signif $F=.0007$

Variable(s) Entered on Step Number

4. INSTMNK: Number of Instructional Mimites for Kindergarten for Entire School Year

Multiple R $\quad .30924$

R Square $\quad .09563$

Adjusted R Square $\quad .07815$

Standard Error $\quad .84309$ 
Table 38 (cont.)

Stepwise Multiple Regressions Depicted by Step(s) for Stratum II ( $n=212)$

Equation Number 3: Dependent Variable - Work-Related Stressors

Analysis of Variance

$\begin{array}{lrrr}\text { Regression } & 4 & 15.55850 & 3.88962 \\ \text { Residual } & 207 & 147.13582 & .71080\end{array}$

$F=\quad 5.47217 \quad$ Signif $F=.0003$

Variable(s) Entered on Step Number

5. STAFSIZE: School Staff Size

Multiple R $\quad .33923$

R Square $\quad .11508$

Adjusted R Square $\quad .09360$

Standard Error $\quad .83600$

Analysis of Variance

$\begin{array}{llll}\text { Regression } & 5 & 18.72251 & 3.74450\end{array}$

$\begin{array}{llll}\text { Residual } & 206 & 143.97181 & .69889\end{array}$

$F=\quad 5.35777 \quad$ Signif $F=.0001$

Table 39

Stepwise Multiple Regressions Depicted by Step(s) for Stratum II ( $n=212)$

Equation Number 4: Dependent Variable - Discipline and Motivation of Students

Variable(s) Entered on Step Number

1. CLASSIZE: Class Size

Multiple R $\quad .25548$

R Square $\quad .06527$

Adjusted R Square .06082

Standard Error $\quad 1.00696$ 
Table 39 (cont.)

Stepwise Multiple Regressions Depicted by Step(s) for Stratum II ( $n=212)$

Equation Number 4: Dependent Variable - Discipline and Motivation of Students

Analysis of Variance

$\begin{array}{llll}\text { Regression } & 1 & 14.86828 & 14.86828\end{array}$

$\begin{array}{llll}\text { Residual } & 210 & 212.93518 & 1.01398\end{array}$

$F=14.66333 \quad$ Signif $F=.0002$

Variable(s) Entered on Step Number

2. INSTMNI 3: Number of Instructional Mimutes for Grades 1 -3 for Entire School Year

Multiple R $\quad .31593$

R Square $\quad .09981$

Adjusted R Square .09120

Standard Error $\quad .99054$

Analysis of Variance

$\begin{array}{lrcc} & \text { DF } & \text { Sum of Squares } & \text { Mean Square } \\ \text { Regression } & 2 & 22.73733 & 11.36866 \\ \text { Residual } & 209 & 205.06613 & .98118\end{array}$

$\mathrm{F}=11.58675 \quad$ Signif $\mathrm{F}=.0000$

Variable(s) Entered on Step Number

3. ABSUNEXC: Percentage of Unexcused Student Absences

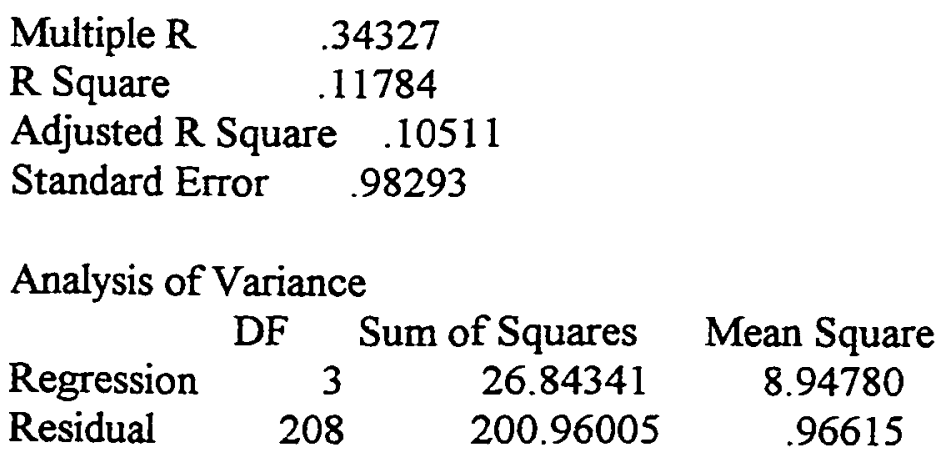

$F=\quad 9.26126 \quad$ Signif $F=.0000$ 
Results by Null Hypotheses for Stratum II $(n=212)$

Hypothesis 1 stated that there would be no significant relationship between teachers' stress levels at schools with principals who were perceived as exercising high-consideration (relationship-oriented) leadership behavior and teachers' stress levels at schools with principals who were perceived as exercising low-consideration (relationship-oriented) leadership behavior.

In equation 1, Table 36, the stepwise multiple regression analysis entered the independent variable of Consideration from the LBDQ and the dependent variables of Teacher Stress from the TSI. Hypothesis 1 was rejected because the independent variable of Consideration explained $10 \%$ of the variance in the dependent variable of stress from the source of Professional Investment with the F Vahe significant beyond the alpha $=.000$.

Hypothesis 2 stated that there would be no significant relationship between teachers' stress levels at schools with principals who were perceived as exercising high-initiating structure (task-oriented) leadership behavior and teachers' stress levels at schools with principals who were perceived as exercising low-initiating structure (task-oriented) leadership behavior.

After testing the null hypothesis for a significant relationship between the independent variable of Initiating Structure and the dependent variable of Teacher Stress, no predictor variables were either entered into or removed from the regression equation. Therefore, the null hypothesis was failed to reject.

Hypothesis 3 stated that there would be no significant relationship between teachers' stress levels at schools with principals who were perceived as exercising high-consideration 
(relationship-oriented)/low-initiating structure (task-oriented) leadership behavior and teachers' stress levels at schools with principals who were perceived as exercising lowconsideration (relationship-oriented)/high-initiating structure (task-oriented) leadership behavior.

After testing the null hypothesis for a significant relationship between the independent variables of Consideration and Initiating Structure and the dependent variable of Teacher Stress, no predictor variables were either entered into or removed from the regression equation. Therefore, the null hypothesis was failed to reject.

Hypothesis 4 stated that there would be no significant relationship between teachers' stress levels, on the one hand, and principals' leadership styles, and school-site conditions on the other. In equation 2 , Table 32 , the stepwise multiple regression analysis entered the independent variables of Consideration, Initiating Structure, and school-site conditions, and the dependent variables of Teacher Stress from the TSI. Hypothesis 4 was rejected because the independent variables of Consideration, Dollars Spent per Pupil by the School Site, and Principal Years at Current Site, explained $15 \%$ of the variance in the dependent variable of stress from the source of Professional Investment with the F Value significant beyond the alpha $=.000$.

In equation 3, Table 38, the independent variables of SAT9 3rd Grade Total Math Scores of Students at or above the 50th Percentile, SAT9 5th Grade Total Math Scores of Students at or above the 50th Percentile, Class Size, Number of Instructional Minutes for Kindergarten for Entire School Year and Staff Size, explained almost 10\% of the variance in the dependent variable of stress from the source of Worked-Related Stressors with the F Value 
significant beyond the alpha $=.000$. Additionally, in equation 4 , Table 39, the independent variables of Class Size, Number of Instructional Minutes for Grades 1-3 for Entire School Year, and Unexcused Student Absences, explained 11\% of the variance in the dependent variable of stress from the source of Student Discipline \& Motivation with the F Value significant beyond the alpha $=.000$.

\section{Stepwise Multiple Regression: Stratum III ( $n=217)$}

Equation one, a two-step regression analysis, using the independent variables of Consideration and Initiating Structure, explained $16 \%$ of the variance in the dependent variable of Professional Investment (Table 40). Equation two, a three-step regression analysis which added the variable of Unexcused Student Absences to equation one explained an additional 3\% of the variance in the dependent variable of Professional Investment for a total of $19 \%$ (Table 41 ). Equation three, a two-step regression analysis, using the independent variables of Consideration and Unexcused Student Absences, explained $10 \%$ of the variance in the dependent variable of Total Stress Score (Table 42). Equation four, a three-step regression analysis, using the independent variables of Other Student Ethnicities, Consideration, and Class Size explained $12 \%$ of the variance in the dependent variable of Work-Related Stressors (Table 43). In Stratum III, the independent variable of Consideration was the best predictor of teacher stress in the dependent variable of Professional Investment. 
Table 40

Stepwise Multiple Regressions Depicted by Step(s) for Stratum III ( $n=217)$

Equation Number 1: Dependent Variable - Professional Investment

Variable(s) Entered on Step Number

I. CONSID LBDQ: Consideration - Relationship-Oriented Leadership

Multiple R $\quad .39214$

R Square $\quad .15377$

Adjusted R Square .14984

Standard Error $\quad .78795$

Analysis of Variance

$\begin{array}{lrrrc} & \text { DF } & \text { Sum of Squares } & \text { Mean Square } \\ \text { Regression } & 1 & 24.25615 & 24.25615 \\ \text { Residual } & 215 & 133.48464 & .62086\end{array}$

$F=39.06870 \quad$ Signif $F=.0000$

Variable(s) Entered on Step Number

2. INI_STRC LBDQ - Initiating Structure: Task-Oriented Leadership

Multiple R $\quad .41436$

R Square $\quad .17169$

Adjusted R Square .16395

Standard Error $\quad .78138$

Analysis of Variance

$\begin{array}{lrrcc} & \text { DF } & \text { Sum of Squares } & \text { Mean Square } \\ \text { Regression } & 2 & 27.08296 & 13.54148 \\ \text { Residual } & 214 & 130.65782 & .61055\end{array}$

$\mathrm{F}=22.17913 \quad$ Signif $\mathrm{F}=.0000$ 
Table 41

Stepwise Multiple Regressions Depicted by Step(s) for Stratum III ( $n=217)$

Equation Number 2: Dependent Variable - Professional Investment

Variable(s) Entered on Step Number

1. CONSID LBDQ: Consideration - Relationship-Oriented Leadership

Multiple R $\quad .39214$

R Square $\quad .15377$

Adjusted R Square $\quad .14984$

Standard Error $\quad .78795$

Analysis of Variance

$\begin{array}{lrrc} & \text { DF } & \text { Sum of Squares } & \text { Mean Square } \\ \text { Regression } & 1 & 24.25615 & 24.25615 \\ \text { Residual } & 215 & 133.48464 & .62086\end{array}$

$F=39.06870 \quad$ Signif $F=.0000$

Variable(s) Entered on Step Number

2. ABSUNEXC: Percentage of Unexcused Student Absences

Multiple R $\quad .42706$

R Square $\quad .18238$

Adjusted R Square . .17474

Standard Error $\quad .77632$

Analysis of Variance

$\begin{array}{lrrc} & \text { DF } & \text { Sum of Squares } & \text { Mean Square } \\ \text { Regression } & 2 & 28.76921 & 14.38461 \\ \text { Residual } & 214 & 128.97157 & .60267\end{array}$

$F=23.86809 \quad$ Signif $F=.0000$ 
Table 41 (cont.)

Stepwise Multiple Regressions Depicted by Step(s) for Stratum III ( $n=217)$

Equation Number 2: Dependent Variable - Professional Investment

Variable(s) Entered on Step Number

3. INI_STRC LBDQ: Initiating Structure - Task-Oriented Leadership

Multiple R $\quad .44830$

R Square $\quad 20097$

Adjusted R Square .18972

Standard Error $\quad .76924$

Analysis of Variance

$\begin{array}{lrrc} & \text { DF } & \text { Sum of Squares } & \text { Mean Square } \\ \text { Regression } & 3 & 31.70169 & 10.56723 \\ \text { Residual } & 213 & 126.03909 & .59173\end{array}$

$F=17.85811 \quad$ Signif $F=.0000$

Table 42

Stepwise Multiple Regressions Depicted by Step(s) for Stratum III ( $n=217$ )

Equation Number 3: Dependent Variable - Total Stress Score

Variable(s) Entered on Step Number

I. CONSID LBDQ: Consideration - Relationship-Oriented Leadership

Multiple R $\quad .30370$

R Square $\quad .09223$

Adjusted R Square .08801

Standard Error $\quad .56656$

Analysis of Variance

$\begin{array}{lrrc} & \text { DF } & \text { Sum of Squares } & \text { Mean Square } \\ \text { Regression } & 1 & 7.01209 & 7.01209 \\ \text { Residual } & 215 & 69.01230 & .32099\end{array}$

$F=21.84537 \quad$ Signif $F=.0000$ 
Table 42 (cont.)

Stepwise Multiple Regressions Depicted by Step(s) for Stratum III ( $n=217$ )

Equation Number 3: Dependent Variable - Total Stress Score

Variable(s) Entered on Step Number

2. ABSUNEXC: Percentage of Unexcused Student Absences

Multiple R $\quad .33656$

R Square $\quad .11327$

Adjusted R Square $\quad .10498$

Standard Error $\quad .56126$

Analysis of Variance

$\begin{array}{lrrc} & \text { DF } & \text { Süm of Squares } & \text { Mean Square } \\ \text { Regression } & 2 & 8.61128 & 4.30564 \\ \text { Residual } & 214 & 67.41310 & .31501\end{array}$

$F=13.66808 \quad$ Signif $F=.0000$

Table 43

Stepwise Multiple Regressions Depicted by Step(s) for Stratum III ( $n=217)$

Equation Number 4: Dependent Variable - Work-Related Stressors

Variable(s) Entered on Step Number

1. OTHER: Percentage of Other Student Ethnicities (i.e. Native American, Pacific Islander, and other student ethnicities categorized as "Other Ethnicities" by The San Diego Unified School District)

Multiple R $\quad .21460$

R Square $\quad .04605$

Adjusted R Square $\quad .04162$

Standard Error $\quad .83529$

Analysis of Variance

$\begin{array}{lrrc} & \text { DF } & \text { Sum of Squares } & \text { Mean Square } \\ \text { Regression } & 1 & 7.24196 & 7.24196 \\ \text { Residual } & 215 & 150.00689 & .69771\end{array}$

$F=10.37966 \quad$ Signif $F=.0015$ 
Table 43 (cont.)

Stepwise Multiple Regressions Depicted by Step(s) for Stratum III ( $n=217)$

Equation Number 4: Dependent Variable - Work-Related Stressors

Variable(s) Entered on Step Number

2. CONSID LBDQ: Consideration - Relationship-Oriented Leadership

Multiple R $\quad .33159$

R Square $\quad .10995$

Adjusted R Square $\quad .10164$

Standard Error $\quad .80871$

Analysis of Variance

$\begin{array}{lrrr} & \text { DF } & \text { Sum of Squares } & \text { Mean Square } \\ \text { Regression } & 2 & 17.29020 & 8.64510 \\ \text { Residual } & 214 & 139.95865 & .65401\end{array}$

$F=\quad 13.21856 \quad$ Signif $F=.0000$

Variable(s) Entered on Step Number

3. CLASSIZE: Class Size

Multiple R $\quad .35977$

R Square $\quad .12944$

Adjusted R Square .11718

Standard Error $\quad .80169$

Analysis of Variance

$\begin{array}{lrrr} & \text { DF } & \text { Sum of Squares } & \text { Mean Square } \\ \text { Regression } & 3 & 20.35384 & 6.78461 \\ \text { Residual } & 213 & 136.89500 & .64270\end{array}$

$F=10.55643 \quad$ Signif $F=.0000$

Results by Null Hypotheses for Stratum III ( $n=217$ )

Hypothesis 1 stated that there would be no significant relationship between teachers' stress levels at schools with principals who were perceived as exercising high-consideration (relationship-oriented) leadership behavior and teachers' stress levels at schools with principals 
who were perceived as exercising low-consideration (relationship-oriented) leadership behavior.

In equation 1, Table 40, the stepwise multiple regression analysis entered the independent variable of Consideration from the LBDQ and the dependent variables of Teacher Stress from the TSI. Hypothesis 1 was rejected because the independent variable of Consideration explained $15 \%$ of the variance in the dependent variable of stress from the source of Professional Investment with the F Value significant beyond the alpha $=.000$.

Hypothesis 2 stated that there would be no significant relationship between teachers' stress levels at schools with principals who were perceived as exercising high-initiating structure (task-oriented) leadership behavior and teachers' stress levels at schools with principals who were perceived as exercising low-initiating structure (task-oriented) leadership behavior.

After testing the null hypothesis for a significant relationship between the independent variable of Initiating Structure and the dependent variable of Teacher Stress, no predictor variables were either entered into or removed from the regression equation. Therefore, the null hypothesis was failed to reject.

Hypothesis 3 stated that there would be no significant relationship between teachers' stress levels at schools with principals who were perceived as exercising high-consideration (relationship-oriented)/low-initiating structure (task-oriented) leadership behavior and teachers' stress levels at schools with principals who were perceived as exercising lowconsideration (relationship-oriented)/high-initiating structure (task-oriented) leadership behavior. 
In equation 1, Table 40, the stepwise multiple regression analysis entered the independent variables of Consideration and Initiating Structure from the LBDQ and the dependent variables of Teacher Stress from the TSI. Hypothesis 3 was rejected because the independent variables of Consideration and Initiating Structure explained $16 \%$ of the variance in the dependent variable of stress from the source of Professional Investment with the F Value significant beyond the alpha $=.000$.

Hypothesis 4 stated that there would be no significant relationship between teachers' stress levels, on the one hand, and principals' leadership styles, and school-site conditions on the other. In equation 2 , Table 41 , the stepwise multiple regression analysis entered the independent variables of Consideration, Initiating Structure, and school-site conditions and the dependent variables of Teacher Stress from the TSI. Hypothesis 4 was rejected because the independent variables of Consideration, Unexcused Student Absences, and Initiating Structure explained $19 \%$ of the variance in the dependent variable of stress from the source of Professional Investment with the F Value significant beyond the alpha $=.000$. In equation 3, Table 42, the independent variables of Consideration and Unexcused Student Absences explained $10 \%$ of the variance in the dependent variable of the Total Stress Score with the $F$ Value significant beyond the alpha $=.000$. Additionally, in equation 4 , Table 43 , the independent variables of Percentage of Other Student Ethnicities, Consideration, and Class Size, explained $12 \%$ of the variance in the dependent variable of stress from the source of Work-related Stressors with the F Value significant beyond the alpha $=.000$. 


\section{Summary}

In summary, results of correlation and multiple regression analyses revealed:

- a statistically significant relationship between the leadership dimension of Consideration (relationship-oriented leadership) and teacher stress from the source of Professional Investment in the overall sample of twenty-eight schools, stratum I (staff sizes 1-24), stratum II (staff sizes 25-37), and stratum III (staff sizes 38-61)

- a statistically significant relationship between the leadership dimension of Consideration (relationship-oriented leadership) and teacher stress from the source of Professional Distress in stratum I (staff sizes 1-24)

- a statistically significant relationship between the leadership dimensions of Consideration (relationship-oriented leadership) and Initiating Structure (task-oriented leadership), on the one hand, and teacher stress from the source of Professional Investment in stratum III (staff sizes 38-61), on the other.

- a statistically significant relationship between the leadership dimension of Consideration (relationship-oriented leadership) and the school-site conditions of Number of Instructional Minutes for Grades 4-6 for Entire School Year and Teacher Gender), on the one hand, and teacher stress from the source of Professional Investment in the overall sample of twenty-eight schools, on the other

- a statistically significant relationship between the leadership dimension of Consideration (relationship-oriented leadership) and the school-site conditions of Suspensions of Students and Teacher Gender), on the one hand, and teacher stress from 
the source of Professional Distress in the overall sample of twenty-eight schools, on the other.

- a statistically significant relationship between the leadership dimension of Consideration (relationship-oriented leadership) and the school-site conditions of Percentage of Asian Students and Percentage of Filipino students, on the one hand, and teacher stress from the source of Professional Distress in stratum I (staff sizes 1-24), on the other.

- a statistically significant relationship between the leadership dimension of Consideration (relationship-oriented leadership) and the school-site conditions of Percentage of African-American students, on the one hand, and teacher stress from the source of Professional Investment in stratum I (staff sizes 1-24), on the other.

- a statistically significant relationship between the leadership dimension of Initiating Structure (task-oriented leadership) and the school-site conditions of Teacher Gender, SAT9 3rd Grade Total Reading Scores of Students at or above the 50th Percentile, and Coordinated Compliance Review (CCR), on the one hand, and teacher stress from the source of Time Management in stratum I (staff sizes 1-24), on the other.

- a statistically significant relationship between the leadership dimension of Consideration (relationship-oriented leadership) and the school-site conditions of Dollars Spent per Pupil by the School-Site and Principal Years at Current Site, on the one hand, and teacher stress from the source of Professional Investment in stratum II (staff sizes 2537), on the other. 
- a statistically significant relationship between the school-site conditions of SAT9 3rd Grade Total Math Scores of Students at or above the 50th Percentile, SAT9 5th Grade Total Math Scores of Students at or above the 50th Percentile, Class Size, Number of Instructional Minutes for Kindergarten for Entire School Year, and Staff Size, on the one hand, and teacher stress from the source of Work-Related Stressors in stratum II (staff sizes 25-37), on the other.

- a statistically significant relationship between the school-site conditions of Class Size, Number of Instructional Minutes for Grades 1-3 for Entire School Year, and Unexcused Student Absences, on the one hand, and teacher stress from the source of Student Discipline \& Motivation in stratum II (staff sizes 25-37), on the other.

- a statistically significant relationship between the leadership dimensions of Consideration (relationship-oriented leadership), Initiating Structure (task-oriented leadership) and the school-site condition of Unexcused Student Absences, on the one hand, and teacher stress from the source of Professional Investment in stratum III (staff sizes 38-61), on the other.

- a statistically significant relationship between the leadership dimension of Consideration (relationship-oriented leadership), and the school-site condition of Unexcused Student Absences, on the one hand, and teacher stress from the source of the TSI's Total Stress Score in stratum III (staff sizes 38-61), on the other.

- a statistically significant relationship between the leadership dimension of Consideration (relationship-oriented leadership), and the school-site conditions of Percentage of Other Student Ethnicities, and Class Size, on the one hand, and teacher 
stress from the source of Work-Related Stressors in stratum III (staff sizes 38-61), on the other.

All of the relationships are depicted in Table 44 which summarizes the number of times a hypothesis was failed to reject or rejected.

Table 44

Tabular Summary of Failed to Reject and Rejected Null Hypotheses for the Overall Sample, and Strata I, II, and III

\begin{tabular}{lllll}
\hline Hypothesis & Overall Sample & Stratum I & Stratum II & Stratum III \\
\hline & & & & \\
$\mathrm{H}_{1}$ & Rejected & Rejected & Rejected & Rejected \\
$\mathrm{H}_{2}$ & Failed to Reject & Failed to Reject & Failed to Reject & Failed to Reject \\
$\mathrm{H}_{3}$ & Failed to Reject & Failed to Reject & Failed to Reject & Rejected \\
$\mathrm{H}_{4}$ & Rejected & Rejected & Rejected & Rejected
\end{tabular}

This concludes the presentation of results. Chapter $V$ offers detailed discussion of these findings, policy and leadership implications, study limitations, and recommendations for future research. 


\section{CHAPTER V}

\section{DISCUSSION OF RESULTS}

\section{Introduction}

The purpose of this study was to determine if principal leadership styles and school-site conditions were associated with the stress levels of elementary teachers. The study focused on the relationship between the independent variables of principal leadership styles and school-site conditions and the dependent variable of teacher stress levels. A survey composed of the Leader Behavior Description Questionnaire (LBDQ), Teacher Stress Inventory (TS1), and a demographic information sheet was administered to 585 teachers from 28 elementary schools. A total of $72 \%$ of all teachers at these 28 schoolsites chose to participate: 585 teachers out of 813 . This study was conducted in the San Diego Unified School District during the 1998-1999 school year.

The LBDQ was developed by the Ohio State University and measured two variables of leadership: Consideration and Initiating Structure. Additionally, these two variables were identified and investigated in tandem: High-Consideration, High-Initiating Structure (HC-HIS); High-Consideration, Low-Initiating Structure (HC-LIS); LowConsideration, High-Initiating Structure (LC-HIS); and Low-Consideration, Low- 
Initiating Structure (LC-LIS). The TSI was developed by Dr. Michael J. Fimian and measured teacher stress levels. The level of teacher stress was determined by scores on the TSI in terms of sources of stress (time management, work-related stressors, professional distress, student discipline and motivation, and professional investment) and manifestations of occupational stress (emotional, fatigue, cardiovascular, gastronomic, and behavioral manifestations). The TSI rendered ten subscale scores (as listed above in parentheses) and one Total Stress Score for each participant.

School-site conditions were defined in terms of organizational factors common to all schools participating in the study and that could possibly have a relationship with teacher stress levels. These data were provided by the San Diego Unified School District's School Accountability Report Cards, by the teacher demographic section of the survey, and by the principal at each site. School-site conditions included: school year calendar, staff size, dollars spent per pupil, unexcused student absences, student suspensions, instructional minutes per year, student ethnicities, Stanford Achievement Test (SAT-9) scores, Coordinated Compliance Review requirements (a form of program quality review required by the State of California), number of vice principals on-site, and demographic information about the principals and teachers.

\section{The San Diego Unified School District During the 1998-1999 School Year}

The San Diego Unified School District (SDUSD) is the eighth largest school district in the United States, serving almost 140,000 students and employing over 7,500 teachers. In the fall of 1997 , after five years as superintendent, Dr. Bertha O. Pendleton 
announced her retirement which took effect in June of 1998 . This event initiated the search for a new superintendent. One of the primary qualifications sought in the new superintendent was a candidate who would be coming from a field other than education and be a non-traditional superintendent. The sentiment that it was time for a more business-minded leader reflected a nation-wide trend focused on educational reform through new leadership approaches. One of the most pronounced examples of a large urban school district searching for a superintendent from a field outside of education and embracing new leadership practices was in Seattle, Washington. John Stanford, a retired officer from the United States Marine Corps., took a tough stand on many issues and began successfully to reform the Seattle School District before his untimely death from leukemia.

With this underlying sentiment for educational reform and new leadership practices, the San Diego Unified Superintendent Search Committee decided to offer the position of Superintendent of Public Education and Secretary of the Board of Education to Alan D. Bersin. Mr. Bersin, at the time of the interviewing process, was a United States District Attorney in San Diego. His record for change and progress was exemplary, specifically in the area of illegal immigration from Mexico, and other border issues.

Since Mr. Bersin began as superintendent on July 1, 1998 there have been several changes throughout the SDUSD. Within weeks of his arrival, he made changes to the Central Office's levels of bureaucracy by discontinuing the district's use of Clusters (a form of mini-districts within SDUSD) and eliminating the positions of Assistant Superintendent -- who were the supervisors of those Clusters. As a "trouble-shooter," 
Mr. Bersin brought on board his long time colleague, Terrance L. Smith, a retired officer from the United States Marine Corps. Mr. Smith is an administrator equal in educational reform and leadership to Mr. Bersin. At the school-site level a new focus was taken on reading. Mr. Bersin made literacy the number one priority. In March of 1999, Mr. Bersin announced the elimination of many administrative and clerical positions at San Diego Unified's Central Office. These monies are now going to be applied to the implementation of Curriculum Resource Teachers, a type of School-Site Teaching Coach. These coaches will be mentors for the teachers at 115 school-sites around the district during the 19992000 school year.

The new Superintendent in San Diego Unified School District has used a new approach to leadership and begun educational reform targeted at improving student achievement. Change is never easy and much of this change has been a "shock" to the system felt by all from top administrators to teachers in the classroom and everyone in between.

This background information is included to depict the broad environment of San Diego Unified during the 1998-1999 academic school year and give the reader a deeper understanding about its effects upon all members of that district. Additionally, this macrocosm view of the district will enable the reader to better understand the relationship(s) of the results discussed in this chapter and also the policy implications. 


\section{Discussion of Results}

Results from this study investigated the principal leadership styles and school-site conditions relationship to teacher stress levels across the overall sample and strata I, II, and III. The following discussion of those results focuses on teacher stress levels as a function of principal leadership styles and the second part as a function of school-site conditions. The strongest relationships were between principal leadership styles and teacher stress levels. The relationships between school-site conditions and teacher stress levels were substantially weaker.

In the results section, stepwise multiple regression examined the independent variables of leadership styles and school-site conditions predictability of teacher stress levels in the dependent variables of the ten TSI subscales and Total Stress Score. The variance explained (Adjusted $R^{2}$ ) in the dependent variable by the combination of independent variables would seem to indicate that those independent variables had a direct and potentially causal influence on the dependent variable, teacher stress. It is always possible of course that the direction of the relationship could flow from the dependent variable (teacher stress) to the independent variables (leadership styles and school-site conditions). However, given the fact that this study utilized forty-one independent variables and conducted stepwise multiple regression analyses, which controlled for those forty-one variables, the direction of the relationship would seem to flow from the selected independent variables (leadership styles and school-site conditions) to the dependent variable (teacher stress). The reader should be cautioned that causality can never be 
determined with any finality, but stepwise multiple regression analyses strongly supports the conclusions which will be drawn below.

\section{Teacher Stress as a Function of Principal Leadership Styles}

The strongest associations between principal leadership styles and teacher stress levels were relatively consistent across the overall sample and strata I, II, and III. Looking at stress from a global perspective, Consideration and the Total Stress Score from the TSI had negligible to low strength inverse relationships. Additionally, a two-step multiple regression analysis of stratum III revealed that the independent variable of Consideration (coupled with Unexcused Student Absences) explained 9\% of the variance in the dependent variable of the Total Stress Score, thus implying that relationshiporiented leadership assisted in the reduction of teacher stress levels from overall sources and manifestations of stress. On the other hand, Initiating Structure and the Total Stress Score had negligible strength inverse relationships, thus indicating that task-oriented leadership and teacher stress levels had a negative association with no statistical significance.

More specifically, across the overall sample and strata $I, \Pi$, and $\Pi$, the leadership variable of Consideration had negligible to moderate inverse relationships with the variables of teacher stress from Professional Distress and Professional Investment. On the other hand, Initiating Structure had from negligible to low strength inverse relationships with both. Stepwise multiple regression analyses of two or three steps revealed that the independent variable of Consideration explained from $9 \%$ to $23 \%$ of the variance in the 
dependent variables of Professional Distress and Professional Investment, thus implying that relationship-oriented leadership assisted in the reduction of teacher stress levels from the sources of Professional Distress and Professional Investment. The regression analyses mentioned above are located in chapter 4 , Tables 28 through 43 . Furthermore, to better understand Professional Distress and Professional Investment, they are defined and the items from the those subscales are listed below:

\section{Professional Distress Definition and Subscale Items from TSI}

Professional Distress: job-dissatisfaction or distress from lack of promotion or advancement opportunities, status and respect on the job, and inadequate salary and recognition.

I lack promotion and/or advancement opportunities.

I am not progressing in my job as rapidly as I would like.

I need more status and respect on my job.

I receive an inadequate salary for the work I do.

I lack recognition for the extra work and/or good teaching I do.

\section{Professional Investment Definition and Subscale Items from TSI}

Professional Investment: lack of control over decisions made about the classroom and school matters, lack of opportunities to be intellectually stimulated on the job or improve professionally, and inability to express opinions openly and honestly.

My personal opinions are not sufficiently aired.

I lack control over decisions made about classroom/school matters.

I am not emotionally/intellectually stimulated on the job.

I lack opportunities for professional improvement. 
Teacher stress from the sources of Professional Investment and Professional Distress both treat the area of job dissatisfaction from the perspective of opportunities for advancement and professional improvement, job status, salary, recognition, open channels of communication within the organization (school and district), and control over classroom and school matters. The average teacher in SDUSD feels very strongly about job dissatisfaction. One of the most powerful pieces of tangible evidence supporting this statement would be the Teacher Strike of February 1996.

Most teacher strikes focus on the key issue of money. Teachers, through union negotiations, demand a higher salary scale, if the district and the union fail to come to agreement, and if the situation remains unresolved, the Teachers' Union calls a strike. SDUSD's 1996 teacher strike was not typical. Negotiations were not solely based on the salary scale. Several successfully negotiated issues, as important as if not more than salary, focused on, site-based decision making (control over classroom/school matters), respect (in part, job-status and open channels of communications), and recognition of the professionalism of certificated teaching staff. Many teachers in the district would affirm that continued efforts in this area are still needed. However, results such as the first successfully negotiated three year teachers' contract (1998-2001) between the district and teachers' union prior to the expiration of an existing contract depicts an improving situation.

In conclusion, the negligible to moderate strength inverse relationships between Consideration (relationship-oriented leadership) and the sources of teacher stress from Professional Investment and Professional Distress and stepwise multiple regression 
analyses of the same variables confirmed earlier findings about job satisfaction and principals who utilized relationship-oriented leadership (Cook, 1983; Johnson, 1990; Paré, 1995). However, this study revealed that principal leader styles explained a greater amount of the variance in the dependent variable of teacher stress than did school-site conditions' variables. Historically, teacher stress research has identified leadership styles as variables associated with teacher stress levels but, usually school-site conditions explained more of the variance in teacher stress and, thus were stronger predictors of stress (Coates \& Thoresen, 1976; Swick \& Hanley, 1985; Wisniewski \& Gargiulo, 1997).

\section{Teacher Stress as a Function of School-Site Conditions}

The strongest and most frequent associations between school-site conditions and teacher stress levels were fairly consistent for the overall sample and strata $I$, $\Pi$, and III. The three principle sources of stress displaying the strongest correlation coefficients, both direct and inverse with school-site conditions, were Student Discipline \& Motivation, Time Management, and Work-Related Stressors. In the overall sample, Work-Related Stressors and Student Discipline \& Motivation were the two primary sources of stress; in stratum I Time Management was the primary source; in stratum II Work-Related Stressors and Student Discipline \& Motivation; and in stratum III Work-Related Stressors and Student Discipline \& Motivation were once again the two primary sources.

Additionally, across the overall sampie and strata I, II, and III, stepwise multiple regression analyses, of two to five steps, revealed that the independent variable of schoolsite conditions explained from $3 \%$ to $12 \%$ of the variance in the dependent variables of 
Student Discipline \& Motivation, Time Management and Work-Related Stressors, thus implying that school-site conditions contributed to teacher stress levels from the above mentioned sources.

In the following sections the results will be discussed by the overall sample and also by strata I, II, and III. In order to convey a clearer understanding to the reader, TSI subscales of Student Discipline \& Motivation, Time Management, and Work-Related Stressors are defined and the items are listed below:

Student Discipline \& Motivation Definition and Subscale Items from TSI Student Discipline \& Motivation: frustration resulting from student discipline problems, monitoring pupil behavior, poorly motivated students, inadequate or poorly defined discipline problems or policies, and rejected authority by both students and administration.

I feel frustrated because of discipline problems in my classroom. I feel frustrated having to monitor pupil behavior.

I feel frustrated because some students would do better if they tried. I feel frustrated attempting to teach students who are poorly motivated. I feel frustrated because of inadequate/poorly defined discipline problems. I feel frustrated when my authority is rejected by pupils/administration.

\section{Time Management Definition and Subscale Items from TSI}

Time Management: job-related commitments or responsibilities which require managing or coping with limited time resources, time constraints, or insufficient time to complete a task or group of tasks.

I easily overcommit myself.

I become impatient if others do things too slowly. I have to try doing more than one thing at a time.

I have little time to relax/enjoy the time of day. 
Time Management Definition and Subscale Items from the TSI (cont.)

I think about unrelated matters during conversations.

I feel uncomfortable wasting time.

There isn't enough time to get things done.

I rush in my speech.

\section{Work-Related Stressors Definition and Subscale Items from the TSI}

Work-Related Stressors: Duties, responsibilities and tasks which compose a teachers workload and consume the hours of a workday at the school-site.

There is little time to prepare for my lessons/responsibilities.

There is too much work to do.

The pace of the schoolday is too fast.

My caseload/class is too big.

My personal priorities are being shortchanged due to time demands.

There is too much administrative paperwork in my job.

\section{Teacher Stress as a Function of School-Site Conditions: Overall Sample ( $n=585)$}

The two predominant sources of stress for the overall sample came from WorkRelated Stressors and Student Discipline \& Motivation (see Table 24, chapter 4). The school-site condition variables were negligible strength, direct relationships with the teacher stress variables, thus implying that there was an extremely weak relationship with teacher stress. However, stepwise multiple regression analysis entered the independent variables of Class Size and Percentage of Asian Students at School-Site which explained $4 \%$ of the variance in the dependent variable of Student Discipline \& Motivation. Another, stepwise multiple regression analysis entered the independent variables of Class Size and Percentage of Other Student Ethnicities at School-Site which explained 3\% of the variance in the dependent variable of Work-Related Stressors. The percentage of 
variance explained in the dependent variables of Student Discipline \& Motivation and Work-Related Stressors was minimal at best, but the school-site condition of class size appeared to increase stress. Furthermore, the issue of class size in California took on new dimensions in 1996 with the State's Class Size Reduction Initiative and it merits discussion.

In the summer of 1996, Pete Wilson, the Governor of the state of California, implemented legislation to lower class sizes. It stated that all classes -- kindergarten through third grade -- were eligible for additional funding if their size remained at 20 students or less. This legislation afforded kindergarten through third grade teachers a "luxury" that fourth through sixth grade teachers were not afforded. In a typical school, the K-3 teachers had 20 or fewer students while the 4-6 grade teachers had up to 36 students. This difference of almost $50 \%$ in student numbers has probably lowered stress from one group of teachers $(\mathrm{K}-3)$, while the other group (4-6) remains unaffected.

Teacher Stress as a Function of School-Site Conditions: Stratum I ( $n=156)$

The predominant source of stress for stratum I came from Time Management (see Table 25 , chapter 4). The school-site conditions variables ranged from negligible to low strength, direct and inverse, relationships with the teacher stress variable of Time Management. More specifically, the school-site conditions of principals' years at current site and SAT9 3rd grade reading scores had a direct relationship with stress from the source of Time Management, thus indicating that they had a positive association. Additionally, the school-site condition of teacher gender had an inverse relationship with 
stress from the source of Time Management thus, indicating that it had a negative association.

Stepwise multiple regression analysis entered the independent variables of Teacher Gender, SAT9 3rd Grade Total Reading Scores, and Coordinated Compliance Review which explained $12 \%$ of the variance in the dependent variable of Time Management. The percentage of variance explained in the dependent variable of Time Management was $12 \%$ with SAT9 3rd Grade Reading Scores appearing to increase stress Levels. Furthermore, of the three correlations with the Time Management variable, the SAT9 3rd grade reading score displayed the strongest direct relationship. Interestingly, this finding coincides with the Process for Accountability Review (PAR) which began in SDUSD back in October of 1997.

PAR was designed to help schools improve academic achievement by a process of self-study (evaluation) and academic program improvement based on the self-study findings. First, how is a school identified as a PAR school? The answer: quite simply by its report card grades, literacy portfolios, and Abbreviated Stanford Achievement Test (ASAT) scores (and after May 1998 by Stanford Achievement Test, Ninth Edition SAT9). These three criteria for becoming a PAR school are not weighted. However, the perception, by teachers and the public at large, is that test scores are a stronger indicator of a school's chance of being identified as a PAR school. In part, this belief is held due to the fact the ASAT and SAT9 scores are norm referenced tests with hard numbers.

With this said, test scores that show a pattern of decline or have been historically low and show no signs of improving could be a strong indicator that a school will be 
PARed. And once PARed, the school will begin an arduous process to develop new programs and strategies to improve student achievement. At several schools which participated in this study, SAT9 scores were very high. Two schools in particular, that were very proud of their high scores, commented on the hard work and many hours they put into maintaining them. Furthermore, in order to have high SAT9 scores, teachers must also be working diligently to keep report grades high and literacy portfolios at or above the district standard. These three criteria are not separated, nor isolated; they work in tandem. If students do well on report cards and literacy portfolios, it is only logical that their chances of scoring higher on the SAT9 are greater.

Teacher Stress as a Function of School-Site Conditions: Stratum II $(n=212)$

The predominant source of stress for stratum $I$ came from Student Discipline \& Motivation and Work-Related Stressors (see Table 26, chapter 4). The school-site condition variables ranged from negligible to low strength, direct, and inverse, relationships with the teacher stress variables of Student Discipline \& Motivation and Work-Related Stressors. More specifically, the school-site conditions of Class Size, Number of Instructional Minutes per Year for Kindergarten, Number of Instructional Minutes per Year for Grades 4-6, Grade Level Taught, and African-American Students had direct relationships with stress from the source of Student Discipline \& Motivation, thus indicating that they had a positive association. The only inverse relationship was between Percentage of Asian Students at the School-Site and Student Discipline \& Motivation, thus indicating that the Asian Student populations at school-sites had a 
negative association. Stepwise multiple regression analysis entered the independent variables of Class Size, Number of Instructional Minutes per Year Grades 1-3, and Unexcused Student Absences which explained $11 \%$ of the variance in the dependent variable of Student Discipline \& Motivation.

Finally, Work-Related Stressors were not the dominant sources of stress, but did have two direct relationships with SAT9 3rd Grade Reading Scores and with SAT9 3rd Grade Math Scores, thus indicating that these two measures of student achievement had a positive association with teacher stress levels at schools with staff sizes of 25 to 37 . Furthermore, stepwise multiple regression analysis entered the independent variables of SAT9 3rd Grade Total Math Score, SAT9 5th Grade Total Math Score, Class Size, Number of Instructional Minutes per Year for Kindergarten, and Staff Size which explained $9 \%$ of the variance in the dependent variable of Work-Related Stressors. In the last section, SAT9 scores were discussed and correlated with Time Management, and in this section with Work-Related Stressors. SAT9 scores were predictors of stress in both strata I and II.

Class Size, Instructional Minutes per Year, Unexcused Student Absences, and Grade Level Taught all treated a very similar area of school-site conditions -- the classroom environment. The situation with class size has already been discussed in detail in the section on the overall sample. However, Instructional Minutes per Year by SchoolSite added more predictors to teacher stress levels. In SDUSD, as in all school districts across the state of California, there are minimum instructional minutes required per year. For kindergarten, that minimum is 36,000 minutes; for grades $1-3$ that minimum is 50,400 
and for grades $4-6$, that minimum is 54,000 minutes. Schools may exceed the minimum, but not fall below it. The number of instructional minutes per year for kindergarten can be less than 14,400 per year than its counterpart in grades $1-3$, and 18,000 less per year than its counterpart in grades 4-6. In stratum II instructional minutes for kindergarten ranged from 36,000 to 49,205 a year, in grades $1-3$ from 54,195 to 59,140 a year, and grades 4-6 from 54,195 to 59,550 .

First, kindergarten maintains a class size of 20 or less while grades 4-6 have up to 36 students. Second, a kindergarten class of 36,000 minutes per year is a half-day program (approximately 3 hours) as opposed to grades 4-6s' full day programs (approximately 6 hours). However, kindergarten teachers with classes which extend toward the higher end of minutes per year, 49, 205 as opposed to 36,000 , are in many instances conducting split-session kindergarten classes. Split-session means a group of children arrive in the morning and remain until lunch, and a second group arrives around lunch time and stays until the final bell rings marking the end of the school day.

This situation of split-sessions can be very difficult for many kindergarten teachers. First, it can be comparable to having interaction with approximately 40 students during part of the schoolday. There are instances, when the kindergarten teacher is sharing one classroom with another kindergarten teacher. Additionally, at school-sites with limited space there are moments when both a.m. and p.m. groups are in the same classroom for about an hour. A classroom with 40 students in their first year of school, learning not only academic lessons, but also socialization skills, can be a "real handful" for teachers. It was not surprising that the school-site condition of Instructional Minutes per Year for 
Kindergarten had a direct relationship with Student Discipline \& Motivation. These findings, associated with instructional minutes (length of the day), supported teacher stress research dating from the 1940s to the present (Coates \& Thoresen, 1976; Swick \& Hanley, 1985; Wisniewski \& Gargiulo, 1997). A long day, many students, and challenging situations have been problematic for teachers for many decades.

\section{Teacher Stress as a Function of School-Site Conditions: Stratum III $(n=217)$}

The two predominant sources of stress for Stratum III came from Work-Related Stressors and Student Discipline \& Motivation (see Table 27, chapter 4). The School-Site Condition variables ranged from negligible to low strength, direct, and inverse relationships with the teacher stress variables. More specifically, the school-site conditions of Coordinated Compliance Review and Teacher Race had direct correlations with stress from the source of Work-Related Stressors thus indicating that they had a positive association. Additionally, the school-site conditions of Dollars Spent per Pupil by the School-Site and Principal Gender had inverse relationships with Work-Related Stressors thus indicating that they had a negative association. Stepwise multiple regression analysis entered the independent variables of Percentage of Other Student Ethnicities at School-Site and Class Size which explained $6 \%$ of the variance in the dependent variable of Work-Related Stressors.

Furthermore, the school-site conditions of Percentage of African-American Students, Asian Students, and Caucasian Students at the school-sites ranged from negligible to low strength, direct and inverse relationships with stress from the source of 
Student Discipline \& Motivation. Asian student and Caucasian student populations had inverse relationships thus indicating that they had a negative association; while AfricanAmerican student populations at school-sites had direct relationships thus indicating that they had a positive association. Stepwise multiple regression analysis entered the independent variable of Percentage of African-American Students at School-Site which explained $3 \%$ of the variance in the dependent variable of Student Discipline \& Motivation. The percentage of variance explained in the dependent variables of Student Discipline \& Motivation and Work-Related Stressors was minimal at best, but the schoolsite condition of Percentage of Other Student Ethnicities and African-American Students appeared to increase stress. Furthermore, the issue of minorities in California is substantial and merits discussion. The Census Bureau predicts that sometime in the early 21 st century, there will be no majority population in the state.

The association of special needs students or at-risk students with teacher stress levels has historically been one of the top stressors for teachers (NEA, 1939; Susskind et. al, 1969; Turk, Meeks, \& Turk, 1982). The San Diego Unified School District recognizes the special needs of minorities such as African-Americans and Latinos. At the district's Central Office, the Integration Programs and School Choice Office sponsors "Improving the Academic Achievement of African-American Students (IAAAAS) Program." It offers school-sites with Role Model Resource Projects which emphasize respect, responsibility, and cultural appreciation. African-American students are given opportunities to accomplish more academically, to understand social responsibility, to say "no" to gangs and drugs, and explore future educational and career possibilities. Latinos and Latinas 
have a similar program -- The Latinos/Latinas Achieving More Academically (LLAMA) Advocacy Office.

These programs' existence are indicative that both African-American and Latino students are considered populations at risk. In strata II and III of this study, AfricanAmerican students had a positive association with teacher stress leveis from the source of Student Discipline \& Motivation. More specifically, under the stress subscale of Student Discipline \& Motivation two of the six items asked teachers, "I feel frustrated because some students would do better if they tried" and " $T$ feel frustrated attempting to teach students who are poorly motivated." These items, depicted below, were the two highest rated stress producing items within the Student Discipline \& Motivation.

TSI Item 62 (Student Discipline \& Motivation Subscale) Stratum II I feel frustrated because some students would do better if they tried.

Value Label

No Strength-Not Noticeable

Mild Strength-Barely Noticeable

Medium Strength-Moderately Noticeable

Great Strength-Very Noticeable

Major Strength-Extremely Noticeable
Frequency

37

57

57

38

23

Total 212
Percent

17.5

26.9

26.9

17.9

10.8

100.0

$\begin{array}{lclrll}\text { Mean } & 2.778 & \text { Std err } & .085 & \text { Median } & 3.000 \\ \text { Mode } & 2.000 & \text { Std dev } & 1.240 & \text { Variance } & 1.538 \\ \text { Kurtosis } & -.908 & \text { S E Kurt } & .333 & \text { Skewness } & .219 \\ \text { S E Skew } & .167 & \text { Range } & 4.000 & \text { Minimum } & 1.000 \\ \text { Maximum } & 5.000 & \text { Sum } & 589.000 & & \end{array}$


TSI Item 62 (Student Discipline \& Motivation Subscale) Stratum III

I feel frustrated because some students would do better if they tried.

Value Label

Frequency

Percent

No Strength-Not Noticeable

36

16.6

Mild Strength-Barely Noticeable

54

24.9

Medium Strength-Moderately Noticeable

63

29.0

Great Strength-Very Noticeable

40

18.4

Major Strength-Extremely Noticeable

24

11.1

Total 217

100.0

$\begin{array}{lclrll}\text { Mean } & 2.825 & \text { Std err } & .084 & \text { Median } & 3.000 \\ \text { Mode } & 3.000 & \text { Std dev } & 1.231 & \text { Variance } & 1.515 \\ \text { Kurtosis } & -.891 & \text { S E Kurt } & .329 & \text { Skewness } & .158 \\ \text { S E Skew } & .165 & \text { Range } & 4.000 & \text { Minimum } & 1.000 \\ \text { Maximum } & 5.000 & \text { Sum } & 613.000 & & \end{array}$

TSI Item 63 (Student Discipline \& Motivation Subscale) Stratum II I feel frustrated attempting to teach students who are poorly motivated.

Value Label Frequency

Percent

No Strength-Not Noticeable

37

17.5

Mild Strength-Barely Noticeable

57

26.9

Medium Strength-Moderately Noticeable

Great Strength-Very Noticeable

47

22.2

Major Strength-Extremely Noticeable

42

19.8

29

13.7

Total 212

100.0

$\begin{array}{lclrlc}\text { Mean } & 2.854 & \text { Std err } & .090 & \text { Median } & 3.000 \\ \text { Mode } & 2.000 & \text { Std dev } & 1.303 & \text { Variance } & 1.699 \\ \text { Kurtosis } & -1.092 & \text { S E Kurt } & .333 & \text { Skewness } & .171 \\ \text { S E Skew } & .167 & \text { Range } & 4.000 & \text { Minimum } & 1.000 \\ \text { Maximum } & 5.000 & \text { Sum } & 605.000 & & \end{array}$


TSI Item 63 (Student Discipline \& Motivation Subscale) Stratum III

I feel frustrated attempting to teach students who are poorly motivated.

Value Label

No Strength-Not Noticeable

Mild Strength-Barely Noticeable

Medium Strength-Moderately Noticeable

Great Strength-Very Noticeable

Major Strength-Extremely Noticeable
Frequency

34

46

57

38

42

Total 217
Percent

15.7

21.2

26.3

17.5

19.4

100.0

$\begin{array}{lclrlc}\text { Mean } & 3.037 & \text { Std err } & .091 & \text { Median } & 3.000 \\ \text { Mode } & 3.000 & \text { Std dev } & 1.340 & \text { Variance } & 1.795 \\ \text { Kurtosis } & -1.129 & \text { S E Kurt } & .329 & \text { Skewness } & .025 \\ \text { S E Skew } & .165 & \text { Range } & 4.000 & \text { Minimum } & 1.000 \\ \text { Maximum } & 5.000 & \text { Sum } & 659.000 & & \end{array}$

With findings such as these, it would appear that the many of the strategies currently employed by teachers among all ethnicities are not as effective as they should be, and slightly less effective with African-American students. The "Tmproving the Academic Achievement of African-American Students (IAAAAS) Program" has only existed for ten years. Over the course of the years it has continued to develop and to grow in its scope of interventions. It is hoped that with more time and continued funding its interventions will enable more African-American students to reach student achievement parity with other ethnicities.

\section{Policy and Leadership Implications}

Almost two decades ago one set of researchers, Meléndez and De Guzmán (1983), purported that one of the biggest challenges facing teachers was literally staying in the 
profession. Each year thousands of competent teachers in increasing numbers were departing the profession. The loss of teachers was attributed to a variety of reasons. However, occupational stress was considered to be the strongest. Not much has changed since Meléndez and De Guzmán's research revealed the impact of stress upon teachers. In 1997, the U.S. Department of Education reported that many teachers were still departing the profession for the same reasons.

These attrition rates are cause for alarm. Coupled with the departure of thousands of teachers each year is a teach shortage. The NEA projects that hundreds of thousands of new teachers will be needed over the next couple of decades. Some school districts, in an effort to recruit not only new teachers but also experienced ones, have begun to give teachers a signing bonus to lure them to their district. Supply and demand has begun to invade the teaching profession. Efforts must be made to lower occupational stress levels in public schools so that the exodus can be stemmed and work conditions improved. In order to accomplish this change better policy and leadership implications are needed.

Throughout the course of this discussion section, results have been compared to actual events in the San Diego Unified School District. Much of that discussion centered on the impact of either state or district policy. The Class Size Reduction Initiative and Coordinated Compliance Review (CCR) both originated from the state of California; and the Process for Accountability Review (PAR) originated from the district. These policies were put in place with the intent to improve student academic achievement. However, policy-makers never adequately took into account the impact upon teachers. 
The Class Size Reduction Initiative was enacted in June of 1996. It allocated millions of dollars to public schools in California to lower kindergarten through third grades to twenty students or less. This legislation was monumental -- it was no less visionary than the G.I. Bill enacted by President Truman at the close of World War II. Classes which once had up to 36 students were now lowered almost 50\%. The theory behind the legislation was sound; lower class sizes, increase teacher contact with students, and improve student achievement. However, the implementation of this policy was poorly orchestrated. Schools were notified about the Class Size Reduction policy in late June of 1996 and expected to implement it by September 1996. Schools lacked adequate facilities and materials. The San Diego Unified School District had a limited number of portable rooms which it could give to its 115 elementary schools. Additionally, the district was only promising school-sites basic materials such as desks, chairs and books -- the site had to find the paper, the pencils, photocopy supplies, monies for teaching aides, etc. Besides the tangible items, there was also the reorganizing and planning. Teachers were reassigned students and classrooms, and new teachers had to be interviewed and hired. These activities coupled with a new school year substantially increased stress levels.

The Coordinated Compliance Review (CCR) is a form of program quality review required by the State and Federal Governments every three years for all those schools which choose to accept Title I monies. It is a process that helps schools evaluate the effectiveness of their current educational programs and then recommend changes to improve current programs or propose new ones. When a school is required to participate in the CCR, the process "usually" begins in October and culminates in May or June. The 
process is long and arduous, and includes the entire teaching staff. However, during the 1998-1999 school year, eighty-one schools in San Diego Unified were informed in January of 1999 that they were to participate in the CCR. Additionally, the process had to be completed by the end of March, 1999. Instead of eight or nine months to complete the $\mathrm{CCR}$, schools were given a little less than three months. As can be expected, teachers at schools undergoing the CCR process experienced more stress.

Lastly, the district accountability system -- Process for Accountability Review (PAR) -- was put into place in August of 1997. Twenty of the district's 172 schools, with low student performance were identified by the Accountability Task Force comprised of 10 teachers, 10 parents and 10 administrators. These twenty schools were required to participate in the PAR; an in-depth self-study process that allowed each school community to bring forward additional data to analyze their students academic achievement. As stated earlier, schools were identified by report card grades, literacy portfolios and ASAT/SAT9 scores. This process was similar to the CCR in that it helped a school evaluate its approach to student academic achievement. Additionally, like the CCR and Class Size Reduction policy, it consumed a great deal of a teacher's time and energy.

The implemented policies discussed in the above paragraphs caused a great deal of stress for teachers in the area of workload and the amount of time to complete that workload. Policy Makers did not think in terms of implementation and time constraints when enacting these policies. The Teacher Stress Inventory had 49 items. The seven items with the highest means of stress levels and registering more responses of "Great Strength; Very Noticeable" and "Major Strength/Extremely Noticeable" stress in my 
current position were under the subscales of Work-Related Stress and Time Management. Elementary teachers in San Diego Unified had too much work to do and insufficient time to complete it. Those seven items are shown below.

TSI Item 44 (Time Management Subscale) I have littie time to relax/enjoy the time of day.

Value Label Frequency

Percent

No Strength-Not Noticeable 22

3.8

Mild Strength-Barely Noticeable

82

14.0

Medium Strength-Moderately Noticeable 136

23.2

Great Strength-Very Noticeable

147

25.1

Major Strength-Extremely Noticeable

198

33.8

$\begin{array}{lll}\text { Total } & 585 & 100.0\end{array}$

$\begin{array}{lclrll}\text { Mean } & 3.713 & \text { Std err } & .049 & \text { Median } & 4.000 \\ \text { Mode } & 5.000 & \text { Std dev } & 1.179 & \text { Variance } & 1.390 \\ \text { Kurtosis } & -.798 & \text { S E Kurt } & .202 & \text { Skewness } & -.498 \\ \text { S E Skew } & .101 & \text { Range } & 4.000 & \text { Minimum } & 1.000 \\ \text { Maximum } & 5.000 & \text { Sum } & 2172.000 & & \end{array}$

TSI Item 46 (Time Management Subscale)

I feel uncomfortable wasting time.

Value Label

Frequency

Percent

No Strength-Not Noticeable

28

63

4.8

Mild Strength-Barely Noticeable

128

10.8

Medium Strength-Moderately Noticeable

156

21.9

Great Strength-Very Noticeable

210

26.7

Major Strength-Extremely Noticeable

$$
\begin{array}{lll} 
& \text { Total } 585 & -100.0
\end{array}
$$

$\begin{array}{lclrll}\text { Mean } & 3.781 & \text { Std err } & .049 & \text { Median } & 4.000 \\ \text { Mode } & 5.000 & \text { Std dev } & 1.181 & \text { Variance } & 1.394 \\ \text { Kurtosis } & -.504 & \text { S E Kurt } & .202 & \text { Skewness } & -.666 \\ \text { S E Skew } & .101 & \text { Range } & 4.000 & \text { Minimum } & 1.000 \\ \text { Maximum } & 5.000 & \text { Sum } & 2212.000 & & \end{array}$


TSI Item 47 (Time Management)

There is not enough time to get things done.

Value Label

Frequency

Percent

No Strength-Not Noticeable

Mild Strength-Barely Noticeable

8

1.4

Medium Strength-Moderately Noticeable

36

6.2

Great Strength-Very Noticeable

83

14.2

153

26.2

Major Strength-Extremely Noticeable

305

52.1

Total

585

100.0

$\begin{array}{lclclc}\text { Mean } & 4.215 & \text { Std err } & .041 & \text { Median } & 5.000 \\ \text { Mode } & 5.000 & \text { Std dev } & .994 & \text { Variance } & .988 \\ \text { Kurtosis } & .565 & \text { S E Kurt } & .202 & \text { Skewness } & -1.156 \\ \text { S E Skew } & .101 & \text { Range } & 4.000 & \text { Minimum } & 1.000 \\ \text { Maximum } & 5.000 & \text { Sum } & 2466.000 & & \end{array}$

TSI Item 49 (Work-Related Stressors Subscale)

There is little time to prepare for my lessons/responsibilities.

Value Label

Frequency

Percent

No Strength-Not Noticeable

Mild Strength-Barely Noticeable

22

99

3.8

Medium Strength-Moderately Noticeable $\quad 142$

16.9

Great Strength-Very Noticeable

162

24.3

Major Strength-Extremely Noticeable

160

27.7

27.4

Total 585

100.0

$\begin{array}{lclclc}\text { Mean } & 3.579 & \text { Std err } & .048 & \text { Median } & 4.000 \\ \text { Mode } & 4.000 & \text { Std dev } & 1.165 & \text { Variance } & 1.357 \\ \text { Kurtosis } & -.890 & \text { S E Kurt } & .202 & \text { Skewness } & -.353 \\ \text { S E Skew } & .101 & \text { Range } & 4.000 & \text { Minimum } & 1.000 \\ \text { Maximum } & 5.000 & \text { Sum } & 2094.000 & & \end{array}$


TSI Item 50 (Work-Related Subscale)

There is too much work to do.

Value Label

No Strength-Not Noticeable

Mild Strength-Barely Noticeable

Medium Strength-Moderately Noticeable

Great Strength-Very Noticeable

Major Strength-Extremely Noticeable
Frequency

13

48

96

158

270
Percent

2.2

8.2

16.4

27.0

46.2

Total 585

100.0

$\begin{array}{lclrll}\text { Mean } & 4.067 & \text { Std err } & .044 & \text { Median } & 4.000 \\ \text { Mode } & 5.000 & \text { Std dev } & 1.073 & \text { Variance } & 1.151 \\ \text { Kurtosis } & .057 & \text { S E Kurt } & .202 & \text { Skewness } & -.967 \\ \text { S E Skew } & .101 & \text { Range } & 4.000 & \text { Minimum } & 1.000 \\ \text { Maximum } & 5.000 & \text { Sum } & 2379.000 & & \end{array}$

TSI Item 53 (Work-Related Stressors Subscale)

My personal priorities are being shortchanged due to time demands.

Value Label

No Strength-Not Noticeable

Mild Strength-Barely Noticeable

Medium Strength-Moderately Noticeable

Great Strength-Very Noticeable

Major Strength-Extremely Noticeable
Frequency

22

84

144

158

177

Total 585

$\begin{array}{lclclc}\text { Mean } & 3.656 & \text { Std err } & .048 & \text { Median } & 4.000 \\ \text { Mode } & 5.000 & \text { Std dev } & 1.160 & \text { Variance } & 1.346 \\ \text { Kurtosis } & -.786 & \text { S E Kurt } & .202 & \text { Skewness } & -.439 \\ \text { S E Skew } & .101 & \text { Range } & 4.000 & \text { Minimum } & 1.000 \\ \text { Maximum } & 5.000 & \text { Sum } & 2139.000 & & \end{array}$

Percent

3.8

14.4

24.6

27.0

30.3 
TSI Item 54 (Work-Related Stressors Subscale)

There is too much administrative paperwork in my job.

Value Label

Frequency

Percent

No Strength-Not Noticeable

Mild Strength-Barely Noticeable

48

84

124

150

Medium Strength-Moderately Noticeable

Great Strength-Very Noticeable

179

21.2

Major Strength-Extremely Noticeable

Total 585

25.6

30.6

$\begin{array}{lclclc}\text { Mean } & 3.561 & \text { Std err } & .053 & \text { Median } & 4.000 \\ \text { Mode } & 5.000 & \text { Std dev } & 1.281 & \text { Variance } & 1.641 \\ \text { Kurtosis } & -.863 & \text { S E Kurt } & .202 & \text { Skewness } & -.491 \\ \text { S E Skew } & .101 & \text { Range } & 4.000 & \text { Minimum } & 1.000 \\ \text { Maximum } & 5.000 & \text { Sum } & 2083.000 & & \end{array}$

Policy Makers need to rethink their approach to implementation. First, resources must be made available to adequately enact policy. The Class Size Reduction Initiative required less students per class, but did not fully fund construction of more classrooms, supplies, and support personnel. Second, the impact upon teachers needs to be studied prior to enacting a policy. Teachers in the classroom -- those members most familiar with the organizational environment at the school-site -- must have more of a voice and be greater stakeholders in the development of policy. The CCR and PAR were designed to improve student achievement, but at the same time they robbed teachers of precious time to prepare lessons and interact with students -- the most vital part of helping students achieve academically.

Third, Policy Makers must remember why a teacher is called a "teacher." Their primary function is to teach students; they should not be encumbered by the duties of an 
administrator. Lastly, the Board of Education should consider putting more administrators at the school-sites. Every school-site, regardless of size, should be allocated a vice principal. This administrator's primary function should be to assist the principal in his/her administrative duties. This would relieve more of the workload burden and time constraints placed upon teachers. However, the possibility of acquiring more administrative positions in the district at this time is not likely. In late March, 1999, Alan Bersin, the Superintendent of SDUSD, eliminated over 100 administrative and clerical positions at the central office, a clear sign that more administrators are not forthcoming.

\section{Study Limitations}

No study is without limitations. The following comprised the five most profound areas of limitation for this study. There were five limitations associated with this investigation. First, the current study was limited to research in twenty-eight elementary schools in the San Diego Unified School District, San Diego, California. These elementary schools were selected by stratified random sampling. Since only elementary schools in SDUSD were part of the study, it would be difficult to generalize findings to other districts or regions of the country. Nevertheless, the study treated 28 of the 115 elementary schools (24\%) in SDUSD, the eighth largest school district in the United States. Hence generalizations could be drawn between it and other large urban school districts in the country with similar demographics.

Second, schools which participated in this study were on a volunteer basis. In order to administer the survey, permission from the principal at each site was necessary. 
Sixty-three sites were asked to participate and only 31 granted permission. Additionally, three of the 31 schools were unable to schedule time for the survey prior to the April 9, 1999 San Diego Unified School District deadline for gathering data in the district. Lastly, reasons given by the principals at the 32 schools, who chose not to participate, included: not enough time to complete required job responsibilities, no available staff meetings, either new or probationary principal, poor administrative/teacher relations, or the staff was already involved in a research project. In several cases schools never returned e-mails or phone calls. Since over $50 \%$ of all schools approached opted not to participate this might have been a factor limiting the range of leadership styles and teacher-stress levels surveyed. Furthermore, teacher participation was voluntary. This factor was not as limiting as that of principal permission because 585 teachers out of a total possible participating population of 813 chose to participate in the study. The overall response rate was $72 \%$.

Third, this study provided a cross-sectional examination of principal leadership styles and school-site conditions association with teacher stress levels. This study was not based upon longitudinal research. Comparisons of future years in SDUSD would render more conclusive results and stronger predictors of teacher-stress levels. Furthermore, research in other large urban districts with similar school staff sizes, student populations, and academic programs would also be beneficial.

Fourth, methods for reducing or coping with teacher stress were not directly addressed by this study. However, findings might aid SDUSD in the development of stress management/coping workshops for teachers and principals. 
Finally, the limitation of using only quantitative research methodology to study such a complex and multifaceted topic as Leadership and Teacher Stress was apparent. This research, coupled with a qualitative component, could have rendered additional data about leadership styles, and the causes and manifestations of teacher stress.

\section{$\underline{\text { Recommendations for Future Research }}$}

There were two principal contributions from this study. First, it contributed to the research literature in the area of Leadership Styles and School-Site Conditions relationship to teacher stress levels in a large urban school district. Second, it contributed to a better understanding of the current organizational environment in the San Diego Unified School

District. Because of the large sample size and number of variables investigated, this study obtained a "pulse" of the district during its first year with the new superintendent, Alan D. Bersin. This data could be a stepping-stone for future research in SDUSD and other school districts throughout the country.

There are several areas of inquiry that the researcher recommends in light of the findings and limitations of this study. First, more research needs to be conducted in not only elementary schools, but also middle schools (junior highs), and high schools. This would enable a district to better understand not only the relationship between leadership styles and teacher stress levels in elementary schools, but also in schools with students in grades 7 through 12 . Additionally, the "pulse" obtained from this study is from only part of the entire organization. Research conducted from kindergarten through twelfth grade would delve deeper into the entire organizational environment. 
Second, this study would render better predictor variables if a longitudinal study were conducted every year or every other year over a five to ten year period. Data would not only predict teacher stress levels with more accuracy, but trends and patterns could be compared to federal, state, and district policies. Cause and effect results might be possible, thus affording policy makers more insights into the impact of implemented policy and its effect upon principals and teachers.

Third, results from future studies should be presented with recommendations to help principals reduce teacher-stress levels and help those teachers suffering from stress find ways to cope, reduce, or eliminate those sources or manifestations of occupational stress. Furthermore, future results should also be presented to Teacher Credentialing and Administrative Credentialing Programs in order to expand the curriculum to include stress management and coping techniques.

Finally, future research needs to incorporate a qualitative research methodology component with the quantitative in order to study other areas of Leadership and Teacher Stress. This research, coupled with a qualitative component, could have rendered additional data about leadership styles, and the causes and manifestations of teacher stress that were constrained by the use of a survey. Quantitative and qualitative research methodologies are highly complementary while serving different data collection purposes. 


\section{REFERENCES}

Albrecht, K. (1979) Stress and the manager: Making it work for you. Englewood Cliffs: Prentice-Hall, Inc.

Argyris, C. (1957). Personality and organization. New York: Harper.

Argyris, C. (1964). Integrating the individual and the organization. New York: John Wiley and Sons.

Assouline, M. \& Meir, E. (1987). Meta-analysis of the relationship between congruence and well-being measures. Journal of Vocational Behavior, 31, 319-332.

Barnette, J. E. The relationship between leadership styles of school principals and teacher stress as perceived by teachers (Doctoral dissertation, West Virginia University 1990). Dissertation Abstracts International 51 (10A), 3278.

Bass, B. M. (1990). Bass \& Stogdill's Handbook of Leadership: Theory, Research and Managerial Applications. (3th ed.). London: Collier Macmillan Publishers.

Bernard, L. L. (1926). Leadership and propaganda. In J. Davis \& H. E. Barnes (Eds.), An introduction to sociology. New York: Health.

Best, J. W., \& Kahn, J. V. (1986) Research in education. (5th ed.). Englewood Cliffs, NJ: Prentice-Hall.

Bhella, S. K. (1982). Principal's leadership style: Does it affect teacher morale? Education 102(4), 369-376.

Bingham, W. V. (1927). Leadership. In H. C. Metcalf, The psychological foundations of management. New York: Shaw.

Blake, R. R., \& McCanse, A. A. (1991). Leadership dilemmas - Grid solutions. Houston, TX: Gulf Publishing. Publishing.

Blake, R. R., \& Mouton, J. S. (1964). The managerial grid. Houston, TX: Gulf

Blake, R. R., \& Mouton, J. S. (1978). The new managerial grid. Houston, TX: Gulf Publishing.

Blake, R. R., \& Mouton, J. S. (1985). The managerial grid III. Houston, TX: Gulf Publishing. 
Blase, J.J., Dedrick, C. \& Strathe, M. (1986). Leadership behavior of school principals in relation to teacher stress, satisfaction, and performance. Journal of Humanistic Education and Development, 24, (4), 159-171.

Blase, J.J. (1984). School principals and teacher stress: A qualitative analysis. National Forum of Educational Administration and Supervision, 1, 35-43.

Bogardus, E. S. (1934). Leaders and leadership. New York: Appleton-Century.

Borg, W. R. \& Gall, M. D. (1989). Educational research: An introduction, (5th Ed.).New York: Longman Press.

Brightwell, M. A. (1985). Dissertation: Factors involved in burnout among West Virginia teachers of exceptional children. West Virginia University.

Brissie, J. S., Hoover-Dempsey, K. V. \& Bassler, O. C. (1988). Individual, situational contributors to teacher burnout. Journal of Educational Research, 82(2), 106112.

Burchfield, S. R. (1979). The stress response: A new perspective. Psychometric Medicine, 41, 661-672.

Burns, J. M. (1978). Leadership. New York: Harper \& Row.

Buros, O., K. (Ed.). (1978). Leaders Behavior Description Questionnaire. The Eighth Mental Measurements Yearbook, 2, 1742-1747.

Carnegie Forum on Education and the Economy. (1986). A nation prepared: Teachers for the 21st century. Hyattsville, MD. (ERIC Document Reproduction Service No. ED 268 120)

Cartwright, D., \& Zander, A. (1960). Group dynamics research and theory. Evanston, IL: Row, Peterson.

Case, C. M. (1933). Leadership and conjecture. Sociology and Social Research 17, 510-513.

Cedoline, A. J. (1982). Job burnout in public education: Symptoms, causes, and survival skills. New York: Teachers College Press.

Chen, M., \& Miller, G. (1997). Teacher stress: A review of the international literature. East Lansing, MI. (ERIC Document Reproduction Service No. ED 410 187)

Coates, T. J., \& Thoresen, C. E. (1976). Teacher anxiety: A review with recommendations. Review of Educational Research, 46(2), 159-184. 
Cole, M., \& Walker, S. (1989). Teaching and stress. Philadelphia: Open University Press.

Cook, K. E. (1979). Teacher morale: Symptoms, diagnosis and prescription. The Clearing House, 52, 355-359.

Cook, K. E. (1983). The relationship between teacher perceptions of supervisory behavioral style and perceived teacher burnout. (Doctoral dissertation. The University of Connecticut, 1983). Dissertation Abstracts International 44. 925-A.

Cox T. A. \& Harquail, C.V. (1991). Career paths and career success in the early career of male and female MBA's. Journal of Vocational Behavior, 39, 54-75.

D'Arienzo, R. V., Moracco, J. C. \& Krajewski, R. J. (1982). Stress in teaching: A comparison of perceived occupational stress factors between special education and regular classroom teachers. Washington, D.C.: University Press.

Drummond, R. J. (1996). Appraisal procedures for counselors and helping professionals. (3rd Ed.). Englewood Cliffs: Prentice-Hall, Inc.

Dunham, J. (1984). Stress in teaching. New York: Nichols Publishing Co.

Dworkin, A. G. (1987). Teacher burnout in the public schools. Albany: State University of New York Press.

Evans, V. \& Johnson, D. (1990). The relationship of principals' leadership behavior and teachers' job satisfaction and job-related stress. Journal of Instructional Psychology, 17(1), 11-18.

Farber, B. A. (1991). Crisis in education: Stress and burnout in the American teacher. San Francisco: Jossey-Bass.

Fiedler, F. E. (1958). Leader attitudes and group effectiveness. Urbana: University of Illinois Press.

Fimian, M. J. (1982). What is teacher stress? The Clearing House, 56, 101-105.

Fimian, M. J. (1985). The development of an instrument to measure occupational stress in teachers of exceptional students. Techniques: A journal for Remedial Education and Counseling, 270-285.

Fimian, M. J. (1986). Note on reliability of the Teacher Stress Inventory. Psychological Reports 59(1), 275-278.

Fimian, M. J. (1988). Teacher Concerns Inventory Test Booklet. Austin: PROED Publishers. 
Fimian, M. J., Lieberman, R. J., \& Fastenau, P.J. (1991). Development and validation of an instrument to measure organizational stress in speech-language pathologists. American Speech-Language-Hearing Association, 34, 439-448.

Fimian, M. J., \& Santoro, T. M. (1983). Sources and manifestations of occupational stress as reported by full-time special education teachers. Exceptional Children, 49, 540-543.

Fleishman, E. A., Harris, E. F., \& Burtt, H. E. (1956). Leadership and supervision in industry. Columbus, Ohio: Bureau of Educational Research, Ohio State University.

Frederick of Prussia. (1981). The refutation of Machiavelli's Prince or AntiMachiavel. Columbus: Ohio University Press

Fried, Y. \& Tiegs, R. (1995). Supervisors' role conflict and role ambiguity differential relations with performance ratings of subordinates and the moderating effect of screening ability. Journal of Applied Psychology, 80 (2), 282-291.

Fuller, F. F. (1969). A developmental conceptualization. American Educational Research Journal, 6, 207-226.

Gattiker, W. H. \& Durrick, M. (1990). Prediction of career achievement in the corporate hierarchy. Human Relation, 42, 703-726.

Ginsberg, M. B. et al. (1981). Roosevelt University College of Education and Research and Development Center. Working Conditions as Antecedents of Teacher Stress. Chicago: Roosevelt University.

Gmelch, W. H. (1982a). A bird's eye view of stress in school. Thrust for Educational Leadership, 11(4), 8-11.

Gmelch, W. H. (1982b). Beyond stress to effective management. New York: John Wiley and Sons.

Gold, Y. \& Roth, R. A. (1993). Teachers managing stress and preventing burnout: The professional health solution. London: The Falmer Press.

Good vs. bad stress. (1978). G. E. Monogram, September-October, 38-39.

Halpin, A. W. (1953). Studies in air crew composition. X. The combat leader behavior of B-29 aircraft commanders. Columbus: Ohio State University, Personnel Research Board. 
Halpin, A. W. (1958). Manual for the Leader Behavior Description Questionnaire. Mimeo. Columbus: The Ohio State University, Bureau of Business Research.

Hanchey, S. G. \& Brown, R. (1989). The relationship of teacher burnout to primary and secondary appraisal, coping systems, role strain and teacher/principal behavior. Paper presented at the meeting of the American Educational Research Association, San Francisco.

Hanson, E. M. (1979). Educational administration and organizational behavior. Boston: Allyn and Bacon, Inc.

Harlin, V. K., \& Jerrick, S. J. (1976). Is teaching hazardous to your health? Instructor, 86, 55-58; 212-214.

Heifetz, R. A. (1994). Leadership without easy answers. Cambridge: The Belknap Press of Harvard University Press.

Hemphill, J. K. (1949). The leader and his group. Joumal of Educational Research, 28, 225-229, 245-246.

Hersey, P. \& Blanchard, K. (1977). Management of organizational behavior: Utilizing human resources. ( $3 \mathrm{rd}$ ed.). Englewood Cliffs, N. J.: Prentice-Hall, Inc.

Hersey, P. \& Blanchard, K. (1981). So you want to know your leadership style? Training and Development Journal, 35.

Hicks, F. P. (1933). The mental health of teachers. New York: Cullman and Ghertner.

Hinkle, D. E., Wiersma, W., Jurs, S. G. (1998). Applied statistics for the behavioral sciences. (4th ed.). New York: Houghton Mifflin Co.

Hoover-Dempsey, K. \& Kendall, E. (1982). Stress and coping among teachers: Experience in search of theory and science. Washington, D.C.: National Institute of Education. (ERIC ED 241-503).

Huck, S. W. \& Cormier, W. H. (1996). Reading statistics and research. (2nd ed.). New York: Harper Collins Publishers Inc.

Hunter, M. (1977). Countering irritants to teaching. Paper presented at the annual meeting of the American Association of School Administrators, Las Vegas. 
Johnson, J. L. A study of the relationship between the leadership styles of suburban secondary principals and the stress levels of their teachers (Doctoral dissertation, University of Minnesota, 1990). Dissertation Abstracts International 51 (11A), AAG9107433.

Judge, T., Boudreau, J. \& Bretz, R. (1994). Job and life attitudes of male executives. Journal of Applied Psychology, 79 (5), 767-782.

Kahn, R. L. (1956). The production of productivity. The Journal of Social Issues, $12,41-49$.

Kahn, R. \& Byosiere, P. (1992). Stress in organizations. In M. Dunnette \& L. Hough (eds.) Handbook of industrial and organizational psychology, 3. 571-650. Palo Alto, CA: Consulting Psychologists Press.

Kaiser, J. S., \& Polczynski, J. J. (1982). Educational stress: sources, reactions, preventions. Peabody Journal of Education, 59, 127-136.

Katz, D., \& Kahn, R. L. (1951). Human organization and worker motivation. In L.R. Tripp (Ed.), Industrial productivity (pp. 146-177). Madison, WI: Industrial Relations Research Association.

Kilbourne, C. E. (1935). The elements of leadership. Journal of Coast Artillery, $78,437-439$.

Klanderman, S. J. A study of teacher stress and principal leadership styles in private urban schools (Doctoral dissertation, Teachers College, Columbia University, 1985).

Kramer, J., J. \& Conoley, J. C. (Eds.). (1992). Teachers Stress Inventory. The Eleventh Mental Measurements Yearbook, 1, 917-919.

Kremer-Hayon, L. \& Kurtz, H. (1985). The relation of personal and environmental variables to teacher burnout. Teaching \& Teacher Education, 1, 243-249.

Kunz, D. M., \& Hoy, W. K. (1976). Leadership style of principals and the professional zone of acceptance of teachers. Educational Administrative Quarterly, 12, 49-64.

Kyriacou, C., \& Sutcliffe, J. (1978). A model of teacher stress. Educational Studies, 4, 1-6.

Knezevich, S. J. (1975). Administration of public education (3rd ed.). New York: Harper and Row. 
Landsmann, L. (1978). Warning to principals: You may be hazardous to your teachers' health. The National Elementary Principal, 57(3), 69-73. Springer.

Lazarus, R., \& Folkman, S. (1984). Stress, appraisal, and coping. New York:

Likert, R. (1947). A program of research on the fundamental problems of organizational human behavior. Ann Arbor, MI: Survey Research Center, Institute for Social Research. Co.

Likert, R. (1961). New patterns of management. New York: McGraw-Hill Book

Likert, R. (1967). The human organization. New York: McGraw-Hill Book Co.

Louis Harris \& Associates. (1988). The Metropolitan Life survey of American teachers: Strengthening the relationships between teachers and students. New York: Metropolitan Life.

Maslach, C. \& Leiter, M. P. (1997). The truth about burnout. San Francisco: Josey Bass, Inc., Publishers.

Maslow, A. H. (1954). Motivation and personality. New York: Harper.

Mayo, E., \& Lombard, G. F. F. (1944). Teamwork and labor turnover in the aircraft industry of Southern California (Report No. 32). Cambridge, MA: Harvard Business School.

McGrath, J.R. (1976). Stress and behavior in organizations. In M. Dunnette (Eds.), Handbook of Industrial and Organizational Psychology. Chicago: Rand McNally, 1351-1395.

McGregor, D. (1944). Conditions of effective leadership in the industrial organization. Journal of Consulting Psychology, 8, 55-63.

McGregor, D. (1966). Leadership and motivation. Cambridge, MA.: MTT Press.

Melendez, W. and De Guzman, R. (1983). Burnout: The new academic disease. Washington, D.C.: Association for the Study of Higher Education.

Metropolitan Milwaukee Chamber of Commerce (1990). Hotline, Fall.

Misumi, J. (1985). The behavioral science of leadership. An interdisciplinary Japanese research program. Ann Arbor: University of Michigan Press. 
Moracco, J., \& McFadden, H. (1980). Counselor's role in reducing teacher stress. Unpublished research report, Auburn University.

Murphy, A. J. (1941). A study of the leadership process. American Sociological Review, 6, 674-687.

National Education Association. (1939). The teacher looks at teacher load. Research Bulletin, 17(5).

National Education Association. (1951). Teaching load in 1950. Research Bulletin, 29(1), 3-50.

National Education Association. (1967). Teachers' problems. Research Bulletin. 45, 116-117.

National Education Association. (1974). Teacher supply and demand in public schools, 1973. Washington, D.C.: National Education Association-Research.

National Education Association. (1979). Nationwide teacher opinion poll. Washington, D.C.: National Education Association-Research.

National Education Association. (1982). Status of the American public school teacher, 1980-81. Washington, D.C.: National Education Association-Research.

National Education Association. (1983). Teacher supply and demand in public schools, 1981-82. Washington, D.C.: National Education Association-Research.

National Education Association, Department of Classroom Teachers. (1938). Fit to teach: A study of the health problems of teachers. Washington, D. C.: NEA, Department of Classroom Teachers.

Needle, R. H., Griffin, T., Svendsen, R., \& Barney, C. (1980). Teacher stress: Sources and consequences. The Journal of School Health, 50, 96-99.

Northouse, P. G. (1997). Leadership: Theory and practice. Thousand Islands, CA: Sage Publications, Inc.

Olander, H. T., \& Farrell, M. E. (1970). Professional problems of elementary teachers. Journal of Teacher Education, 21, 276-280. June, $27-33$.

Olson, L. \& Rodman, B. (1988). In the urban crucible. Education Week, 22

Page, D. P. (1935). Measurement and prediction of leadership. American Journal of Sociology, 41, 31-43. 
Paré, P. Prolonged teacher stress as a function of teachers' perceptions of principal leadership style adaptability and teachers' belief systems (Doctoral dissertation, The Colleḡe of William and Mary, 1995). Dissertation Abstracts International 56 (6A), 2119.

Parsons, J. S., \& Fuller, F. F. (1972). Concerns of teachers: Reliability, bipolarity, and relationship to teaching experience. Paper presented at the meeting of the American Educational Research Association, Chicago. (ERIC Document Reproduction Service No. ED 063 257) Publishing.

Patten, M. L. (1997). Understanding research methods. Los Angeles: Pyrczak

Peck, L. (1933). A study of the adjustment difficulties of a group of women teachers. Journal of Educational Psychology, 27, 401-416.

Randall, H. B. (1951). Health is for teachers too. National Education Association Joumal, 40, 467-468.

Reber, A. S. (1985). Dictionary of Psychology. New York: Penguin Group.

Roberts, K. L. (1983). An analysis of the relationship of principals' leadership style to teacher stress and job related outcome (Doctoral Dissertation, Washington State University, 1983). Dissertation Abstracts International, 44, 2002A.

Rost, J. C. (1993). Leadership for the twenty-first century. New York: Praeger.

Rudd, W. G., \& Wiseman, S. (1962). Sources of dissatisfaction among a group of teachers. British Journal of Educational Psychology, 32, 275-291.

San Diego Unified School District. (1998). San Diego City Schools: School Accountability Report Cards (9th Ed.). (Available from SDUSD, 4100 Normal Street, San Diege, CA 92103-2682)

Schlechty, P. C. \& Vance, V. S. (1983). Recruitment, selection and retention: The shape of the teaching force. The Elementary School Journal, 83(4) $470-487$.

Schneider, J. (1937). The cultural situation as a condition for the achievement of fame. American Sociology Review, $2,480-491$.

Schwab, R. L., Jackson, S.E. \& Schuler, R.S. (1986). Educator burnout: Sources and consequences. Educational Research Quarterly, 10 (3), 14-30.

Selye, H. (1974). Stress without distress. Philadelphia: J. B. Lippincott Co. 
Senge, P. M. (1990). Fifth discipline: Mastering the five practices of the Learning Organization. New York: Doubleday.

Shartle, C. L. (1951). Leader behavior in jobs. Occupations, 30, 164-166.

Smith A. (1985). The wealth of nations. New York: McGraw.

Smith, M., \& Bourke, S. (1992). Teacher stress: Examining a model based on context, workload, and satisfaction. Teaching and Teacher Education, 8, 31-46.

Sparks, D. and Hammond, J. (1981). Managing teacher stress and burnout. Washington, D. C.: AAHPERD, (ERIC Document Reproduction Service No. ED 200 522). 232.

Spiller, G. (1929). The dynamics of greatness. Sociological Review $21,218-$

Stogdill, R. M. (1974). Handbook of leadership: A survey of theory and research. New York: Free Press.

Stogdill, R. M. (1957). Manual for the Leader Behavior Description Questionnaire. Columbus: The Ohio State University, Bureau of Business Research.

Stogdill, R. M. (1963). Manual for the Leader Behavior Description Questionnaire-Form XII. Columbus: The Ohio State University, Bureau of Business Research.

Stogdill, R. M. (1948). Personal factors associated with leadership: A survey of the literature. Journal of Psychology, $25,35-71$.

Susskind, D. J., Franks, C. M., \& Lonoff, R. (1969, September). Desensitization program with third and fourth-grade teachers: A new application and a controlled study. Paper presented at the meeting of the Association for the Advancement of Behavior Therapy, Washington, D. C.

Sutherland, V.J. \& Cooper, C.J. (1988). Sources of work stress. In J.J. Hurrell, Jr., L.R. Murphy \& S.L. Souter (eds.) Occupational stress: Issues and development in research. New York: Taylor \& Francis, 3-40.

Swick, K. J., \& Hanley, P. E. (1985). Stress and the classroom teacher. Washington, DC: National Education Association.

Taylor, F. W. (1911). The principles of scientific management. New York: Harper and Brothers. 
Tead, O. (1929). The art of leadership. New York: McGraw-Hill.

Tharenou, P., Latimer, S. \& Conway, D. (1984). How do you make it to the top? An examination of influence on women's and men's managerial advancement. Advancement of Management Journal, 37 (4), 899-931.

Thoresen, C. E. (1973). The healthy personality as a sick trait. The Counseling Psychologist, 4(2), 51-55.

Turk, D. C., Meeks, S. \& Turk, L. M. (1982). Factors contributing to teacher stress: Implications for research. Behavioral Counseling Quarterly, 2(1), 3-25.

Tawari, O. C. (1986). Principals' leadership behavior and teacher morale: A perceptual study of secondary school teachers in Bendel State (Nigeria). Nigeria Journal of Guidance and Counseling. 12-22.

U.S. Department of Education, National Center for Education Statistics. (1997). America's Teachers: Profile of a profession, 1993-94. NCES 97-460. Washington, D.C.: U.S. Government Printing Office.

Walsh, D. (1979). Classroom stress and teacher burnout. Kappan, 61, 253.

Weber, M. (1921/1947). The theory of social and economic organizations. Translated by A M. Henderson and T. Parsons (Eds.). New York: The Free Press. (originally published in 1921).

Weisbord, M. R. (1992). Discovering Common Ground. San Francisco: BerrettKoehler Publishers.

Williams, D. (1982). Dissertation: The relationship between teacher stress and the leader behavior of principals, teacher self-concept and the degree level of teachers. Western California University.

Wisniewski, L., \& Gargiulo, R. M. (1997). Occupational stress and burnout among special educators: A review of the literature. The Joumal of Special Education, 31(3), 325-346.

Wright, D. B. (1997). Understanding statistics: An introduction for the social sciences. London: Sage Publications. 
APPENDICES

Reproduced with permission of the copyright owner. Further reproduction prohibited without permission. 
APPENDIX A

\section{LEADER BEHAVIOR DESCRIPTION QUESTIONNAIRE}

Developed by Staff Members of

The Ohio State Leadership Studies

College of Administrative Science

The Ohio State University

Columbus, Ohio

Copyright 1957 
Appendix A

\section{LEADER BEHAVIOR DESCRIPTION QUESTIONNAIRE}

Below is a list of items that may be used to describe the behavior of your principal. Each item describes a specific kind of behavior but does not ask you to judge whether the behavior is desirable or undesirable. This is not a test of ability. It simply asks you to describe, as accurately as you can, the behavior of your principal.

The term "group" refers to the elementary school staff.

The term "members" refers to the teachers.

Directions: Read each item carefully. Think about how frequently the principal engages in the behavior described by the item. Decide whether s/he always, often, occasionally, seldom or never acts as described by the item. Fill in the circle on the scantron sheet for one of the five letters to show the answer you have selected.

$$
\begin{array}{lllll}
\text { A = Always } & \text { B }=\text { 0ften } & \text { C }=\text { 0ccasionally } & \mathbf{D}=\text { Seldom } & E=\text { Never }
\end{array}
$$

1. Does personal favors for group members.

2. Makes his/her attitudes clear to the group.

3. Does little things to make it pleasant to be a member of the group.

4. Tries out his/her new ideas with the group.

5. Acts as the real leader of the group.

6. Is easy to understand.

7. Rules with an iron hand.

8. Finds time to listen to group members.

9. Criticizes poor work.

10. Gives advance notice of changes.

11. Speaks in a manner not to be questioned.

12. Keeps to himself/herself.

13. Looks out for the personal welfare of individual group members.

14. Assigns group members to particular tasks.

15. Is the spokesperson of the group.

16. Schedules the work to be done.

17. Maintains definite standards of performance.

18. Refuses to explain his/her actions.

19. Keeps the group informed.

20. Acts without consulting the group.

21. Backs up the members in their actions.

22. Emphasizes the meeting of deadlines.

23. Treats all group members as his/her equals.

24. Encourages the use of uniform procedures.

25. Gets what he/she asks for from his/her superiors. 
Appendix A
A = Always
B $=$ 0ften
C $=$ Occasionally
D $=$ Seldom
$E=$ Never

26. Is willing to make changes.

27. Makes sure that his/her part in the organization is understood by group members.

28. Is friendly and approachable.

29. Asks that group members follow standards and regulations.

30. Fails to take necessary action.

31. Makes group members feel at ease when talking with them.

32. Lets group members know what is expected of them.

33. Speaks as the representative of the group.

34. Puts suggestions made by the group into operation.

35 . Sees to it that group members are working up to capacity.

36. Lets other people take away his/her leadership in the group.

37. Gets his/her superiors to act for the welfare of the group members.

38. Gets group approval in important matters before going ahead.

39. Sees to it that the work of group members is coordinated.

40. Keeps the group working together as a team. 
APPENDIX B

TEACHER CONCERNS INVENTORY

$\mathbf{A} / \mathbf{K} / \mathbf{A}$

TEACHER STRESS INVENTORY

Developed by Dr. Michael J. Fimian

Copyright 1988 
Appendix B

\section{TEACHER CONCERNS INVENTORY ITEMS 41-89}

\section{Directions: The following are a number of teacher concerns.}

1) Please identify those factors which cause you stress in your present position.

2) Read each statement carefully and decide if you ever feel this way about your job.

3) Then, indicate how strong the feeling is when you experience it by selecting the appropriate letter on the 5-point scale.

If you have not experienced this feeling, or if the item is inappropriate for your position, fill in "A" on the scantron sheet (no strength; not noticeable). The rating scale is shown at the top of each page.

\section{Examples:}

No

Strength

How Strong?

Strength

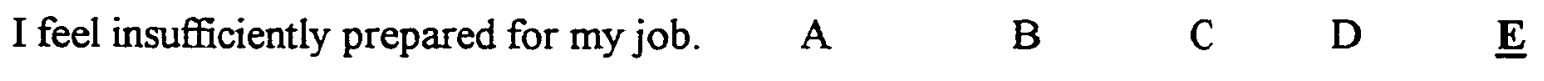

If you feel very strongly that you are insufficiently prepared for your job, you would select letter "E."

I feel that if I decrease either effort or commitment, I may be seen as less competent.

\section{How Strong?}

No
Strength
A $\quad$ B
C
D
E

If you never feel this way, and the feeling does not have noticeable strength, you would select letter "A." 
Appendix B

\begin{tabular}{llllll}
\hline & A & B & C & D & E \\
HOW & no & mild & medium & great & major \\
STRONG? & strength; & strength; & strength; & strength; & strength; \\
& not & barely & moderately & very & extremely \\
& noticeable & noticeable & noticeable & noticeable & noticeable \\
\hline
\end{tabular}

42. I become impatient if others do things too slowly.

43. I have to try doing more than one thing at a time.

44. I have little time to relax/enjoy the time of day.

45. I think about unrelated matters during conversations.

46. I feel uncomfortable wasting time.

47. There isn't enough time to get things done.

48. I rush in my speech.

49. There is little time to prepare for my lessons/responsibilities.

50. There is too much work to do.

51. The pace of the schoolday is too fast.

52. My caseload/class is too big.

53. My personal priorities are being shortchanged due to time demands.

54. There is too much administrative paperwork in my job.

55. I lack promotion and/or advancement opportunities.

56. I am not progressing in my job as rapidly as I would like.

57. I need more status and respect on my job.

58. I receive an inadequate salary for the work I do.

59. I lack recognition for the extra work and/or good teaching I do. 
Appendix B

\begin{tabular}{llllll}
\hline & A & B & C & D & E \\
HOW & no & mild & medium & great & major \\
STRONG? & strength; & strength; & strength; & strength; & strength; \\
& not & barely & moderately & very & extremely \\
& noticeable & noticeable & noticeable & noticeable & noticeable \\
\hline
\end{tabular}

\section{I feel frustrated...}

60. ...because of discipline problems in my classroom.

61. ...having to monitor pupil behavior.

62. ...because some students would do better if they tried.

63. ...attempting to teach students who are poorly motivated.

64. ...because of inadequate/poorly defined discipline problems.

65. ...when my authority is rejected by pupils/administration.

66. My personal opinions are not sufficiently aired.

67. I lack control over decisions made about classroom/school matters.

68. I am not emotionally/intellectually stimulated on the job.

69. I lack opportunities for professional improvement. 
Appendix B

\begin{tabular}{llllll}
\hline & A & B & C & D & E \\
HOW & no & mild & medium & great & major \\
STRONG? & strength; & strength; & strength; & strength; & strength; \\
& not & barely & moderately & very & extremely \\
& noticeable & noticeable & noticeable & noticeable & noticeable \\
\hline
\end{tabular}

\section{I respond to stress...}

70. ...by feeling insecure.

71. ...by feeling vulnerable.

72. ...by feeling unable to cope.

73. ...by feeling depressed.

74. ...by feeling anxious.

75. ...by sleeping more than usual.

76. ...by procrastinating.

77. ...by becoming fatigued in a very short time.

78. ...with physical exhaustion.

79. ... with physical weakness.

80. ...with feelings of increased blood pressure.

81....with feeling of heart pounding or racing.

82. ...with rapid and/or shallow breath.

83. ...with stomach pain of extended duration.

84. ... with stomach cramps.

85. ...with stomach acid.

86. ...by using over-the-counter drugs. 
Appendix B

\begin{tabular}{llllll}
\hline & A & B & C & D & E \\
HOW & no & mild & medium & great & major \\
STRONG? & strength; & strength; & strength; & strength; & strength; \\
& not & barely & moderately & very & extremely \\
& noticeable & noticeable & noticeable & noticeable & noticeable \\
\hline
\end{tabular}

I respond to stress...

87. ...by using prescription drugs.

88. ...by using alcohol.

89. ...by calling in sick. 


\section{APPENDIX C \\ DEMOGRAPHIC INFORMATION SHEET}


Appendix C

\section{DEMOGRAPHIC INFORMATION SHEET}

Please fill in the circle on your scantron sheet which indicates your answer to each of the following items:
90. Gender:
(a) Female
(b) Male

91. Years teaching at current site:
(a) $0-5$
(b) $6-10$
(c) $11-20$
(d) 21-29
(e) 30 or more

92. Years of teaching experience:
(a) $0-5$
(b) 6-10
(c) $11-20$
(d) $21-29$
(e) 30 or more

93. Highest degree earned: $\begin{array}{ll}\text { (a) B.S. or B.A. } & \text { (b) Masters }\end{array}$

(c) Ph. D. or Ed. D.

94. Type of credential held:

(a) Prelim. or Clear Professional Multiple Subject - CLAD

(b) Prelim. or Clear Professional Multiple Subject - BCLAD

(c) Emergency Credential

(d) Single Subject Credential

(e) Any other credential issued by the Commission for Teacher Credentialing

95. Type of class taught:

(a) Regular English

(b) Bilingual, Sheltered or Transition

(c) G.A.T.E./Seminar

(d) Res Spec/Spec Ed.

(e) Other
96. Class size:
(a) $1-10$
(b) $11-20$
(c) $21-30$
(d) 31 or more
97. Age:
(a) 20-29
(b) $30-39$
(c) $40-49$
(d) $50-59$
(e) 60 or older 
Appendix C

DEMOGRAPHIC INFORMATION SHEET
98. Race:
(a) African American
(b) Asian
(d) Latino/a
(e) Other
(c) Caucasian

99. Grade level taught: \begin{tabular}{llll|} 
(a) 1 & (b) $1-2$ & (c) 2 & (d) $2-3$ \\
(e) 3 & (a) & OR &
\end{tabular}
100. Grade level taught: $\begin{array}{llll}\text { (a) } 4 & \text { (b) } 4-5 & \text { (c) } 5 & \text { (d) } 5-6 \\
\text { (e) } 6 & & \end{array}$
*** Kindergarten Teachers Leave 99 and 100 Blank ***




\section{APPENDLX D \\ PRINCIPAL INFORMED CONSENT FORM}

Reproduced with permission of the copyright owner. Further reproduction prohibited without permission. 
Appendix D

Date:

Dear

To complete the requirements for an Ed. D. at the University of San Diego (USD), I am conducting research about teacher stress levels and principal leadership styles in randomly selected elementary schools in the San Diego Unified School District (SDUSD). Your site is one of thirty that I have randomly selected to participate. Your teachers will be asked to complete three surveys which will take approximately 30 minutes. No client identifiers will be requested on any of the surveys. Confidentiality and anonymity will be maintained. All surveys will be secured away from the school district facilities and after five years of study completion, all data will be destroyed. Additionally, as an added measure to preserve anonymity only group data will be used in any publication of the results of this study.

SDUSD's Research and Reporting Unit and USD's Committee on the Protection of Human Subjects have approved my research. However, I am still required to request permission formally from each principal. By signing this letter, you acknowledge that the study has been explained to you, all questions were answered, and you give Mark $N$.

Remy permission to conduct research at your site. The actual meeting date will be agreed upon by you and the researcher. Additionally, I have received a copy of this informedconsent form and there are no other agreements, written or verbal, related to this study beyond that expressed in this document.

If you should have any additional questions, please feel free to contact Mark N. Remy at 619-298-6717 (e-mail: mremy@students.acusd.edu) or Dr. Ronn Johnson, dissertation director at 619-260-4702.

Thank you for your assistance with my research.

Sincerely,

Mark N. Remy

Doctoral Student

Signature of Principal

Location, Date and Time of Survey Administration 


\section{Appendix E \\ University of San Diego \\ CONSENT TO ACT AS A RESEARCH SUBJECT}

Mark N. Remy is conducting a research study on the relationship between teacher stress levels and principal leadership behavior styles in San Diego Unified School District. Since I have been selected to participate in this study, I understand that I will be a research subject.

I understand that the data collection will involve three questionnaires which will take approximately thirty minutes to complete all three. Participation in the study should not involve any added risks or discomforts to me except for possible minor fatigue.

My participation in this study is entirely voluntary. I understand I may refuse to participate or withdraw at any time without jeopardy to me or my position in the school district.

I understand my research records will be kept completely confidential. My identity will not be disclosed without consent unless required by law. I further understand that to preserve my anonymity only group data will be used in any publication of the results of this study.

Mark N. Remy has explained this study to me and answered my questions. If I have other questions or research-related problems, I can reach Mark N. Remy at 619-298-6717. I understand that I may also contact the dissertation director, Dr. Ronn Johnson, Associate Professor at the University of San Diego, at 619-260-4702. Additionally, if I should suffer from psychological effects, during or after participation in this study, I may contact the Employee Assistance Services for Education (EASE) at 619-277-0063 and receive six free office visits per calendar year.

There are no other agreements, written or verbal, related to this study beyond that expressed on this consent form. I have received a copy of this informed consent document.

I, the undersigned, understand the above explanations and, on that basis, I give consent to my voluntary participation in this research.

Signature of Subject

Date

Location

Signature of Witness

Date

Signature of Researcher

Date 


\section{APPENDLX F \\ LETTER FROM THE OHIO STATE UNIVERSITY: \\ PERMISSION TO USE THE LEADER BEHAVIOR DESCRIPTION QUESTIONNAIRE}




\section{FISHER \\ COLLEGE OF BUSINESS \\ THE OHIO STATE LNIVERSITY}

BLSTIESS RESEARCH

January, 4, 1999

\section{Mark Remy}

5744 Mildred Street

San Diego, CA 92110

Dear Mr Remy,

In response to your request, we grant you permission to use the Leader Behavior Description Questionnaire Form XM(1962) - We understand that you will not use the instrument for promotional activities or for producing income.

Here are your 100 copies of the LBDQ Form XII (1962) -along with Statement of Policy and Manual. If you have any further questions, please do not hesitate to write or call.

Sincerely,

Marianne E Shetler

(614) 292-5031

100 FISHER HALL - 2100 VEIL AVENLE - COLLMBLS, OH $+3210-114+$

TELEPHONE: $61+-292-5031$ - FAX: 61+-292-1651 - HTTP:IWWW.COB.OHIO-STATE.EDL

Reproduced with permission of the copyright owner. Further reproduction prohibited without permission. 


\section{APPENDLX G \\ LETTER FROM DR. MICHAEL J. FIMIAN: \\ PERMISSION TO USE THE TEACHER STRESS INVENTORY}


To: Mark Nicholas Remy <mremy@students.acusd.edu>

From: Michael Fimian <Fimian@oscn.com>

Subject Re: TSI

Cc:

Bcc:

Attached: G:ITSI_Docsitsicorr.coc; G:ITSi_Docsich1.doc; G:ITSI_Docsich2.doc; G:ITSI_Docslch3.doc; G:ITSI_Docsicn̈.coc; G:ITSI_Docslch5.doc; G:ITSI_Docsitsi.txt; G:ITSI_Docsbibman.dcc;

\section{Good Morning Mark...}

Welcome to the club; I only recendly found out myself that ProEd had dropped the TSI - a year ago... Just last week I received tre legai cocumentation fro them, and am waiting the documentation that you wolla ne=s. In liej of this, I am trying to find some of the older master copies that I submitted in trie first place. it may take a while to find these, but I can pass on the permissions to you now, as unat is irnat ycu'il need most for your committee. In the interim, lam emailing you copies of some of the files tnat I used to develop the TSI manual; a number of the tables were damaged at one point ur anotner, so. I'll have to zerox and send you these when the Docs amive from ProEd. On nili in paricular (TS!.Ext) includes all the items and the Likert-type strength rating scale; this should be enough to cut and paste a copy using the format that you want.

Please email me your snail mail adiress...

This memo is to inform you thizi y u a d have my permission to use the Teacher Stress Inventory in your research work. Tine clly lirhitelion is unat you do not change the item wording in any way, and that you use the sarrie ratii is scaic. Also, you agreed to send me a copy of the data in raw form with a "variable biole" at $\omega_{i}$ e en la or your work, as well as a copy of your results chapter. These data would be added to a growing pool from other researchers and students, and would be used in future upgrade work or thie TSI. Of course, your work would be cited appropriately in the lit review section of the manual, and your contribution cited in the Samples and Reference section of the work... These data would be used only, and exclusively, for this purpose.

There is no cost to use the TSI., and you can make as many copies as you want. You can add or alter the demographic questions any way you see fit, as long as you keep the items themselves intact Ke€p in mind inat if you do alter the demographic questions, doing so may make it difficult to make airect group-by-group comparisons to the findings of eartier studies (e.g.,

trying to compare teachers aged $30-35$ in one study with teachers aged $30-39$ in your study. To this extent, you are advised to maintain the current set of demographic questions. Feel free to add any others that you need for your study, or to use the TSI in combination with any other scale that measures other constructs.

Please note my email adaress below; even if I move next year, I will arrange to bounce my email to where ever... If you have any questions or concerns, please feel free to contact me. I wish you luck with your project, and if I can be of any assistance, please let me know...

I remain

Dr. Michael J. Fimian 


\section{APPENDIX H}

LETTER FROM DR. MARIAM L. TRUE:

ENDORSEMENT AND SPONSORSHIP FROM SDUSD'S

INSTITUTE FOR LEARNING - TEACHER DEVELOPMENT AND INDUCTION 


\begin{tabular}{|c|c|c|}
\hline \multirow{2}{*}{\begin{tabular}{|l|l|}
$S$ & $D$ \\
$C$ & $S$ \\
\end{tabular}} & \multicolumn{2}{|c|}{ SAN DIEGO CITY SCHOOLS } \\
\hline & $\begin{array}{l}\text { IMC, } 2441 \text { Cardinal Lane } \\
\text { San Diego, CA 92123-3798 }\end{array}$ & $\begin{array}{c}\text { Phone: }(619) 496-1880 \\
\text { F.AX: }(619) 496-1860\end{array}$ \\
\hline
\end{tabular}

November 12,1998

Dr. Peter D. Bell, Department Head

San Diego Unified School District

Department of Research and Reporting Unit

4100 Normal Street, Room 3110

San Diego, CA 92103

Dear Dr. Bell:

On November 5, 1998, I met with Mr. Remy and reviewed his research proposal. The proposed study will provide the district with valuable information about teacher stress and principal leadership styles. I an willing to endorse and sponsor his research. Furthermore, I understand that I will: attend the review of the proposal by district staff on December 14, 1998; provide necessary help and guidance to the researcher following approval of the research; and ensure that researci is done as proposed.

If you have any questions, please feel free to contact me at 496-1880.

Sincerely,

Mariam True

Program Manager

Teacher Development and Induction

$\mathrm{MT}: \mathrm{nb}$ 


\begin{abstract}
APPENDIX I
LETTER FROM DR. PETER D. BELL, DIRECTOR DEPARTMENT OF RESEARCH AND REPORTING UNIT: PERMISSION TO CONDUCT RESEARCH IN SDUSD
\end{abstract}


December 15, 1998

Mr. Mark N. Remy

5744 Mildred St.

San Diego, CA 92110

Dear Mr. Remy:

Our Research Proposal Review Panel was happy to review your application to conduct research in San Diego City Schools on "Principal Leadership Styles' Impact on Teacher Stress Levels in Elementary Schools in San Diego Unified School District." The committee has decided to approve your request.

We do, however, suggest that you consider modifying your approach to selecting participating teachers at schools. Rather than have teachers at a school volunteer to participate (either by choosing to attend a meeting whose subject they know in advance or by volunteering to fill out a questionnaire) and thus introducing considerable (self-)selection bias, you might somehow select participating teachers more randomly. This might be done by randomly selecting teachers from schools which meet various criteria and mailing or otherwise distributing questionnaires to them. Alternatively, you could select participants from those attending the meeting, perhaps before telling them what the subject is. Other methods might also be possible. Naturally, the teachers can choose to participate or not, but self-selection and its possible bias might be reduced.

I hope that your research experience in the district is valuable. Mariam True of the district's Teacher Development and Induction Program can assist in the logistics of your study. Our office and hers would greatly appreciate a copy each of the final report on your findings.

If you have any questions or if I can be helpful to you, please contact me at (619) 293-8629.

Sincerely.

Pete; D. Bell

Supsrvising Educational Researche! 


\section{APPENDIX J \\ SCRIPT TO ADMINISTER THE SURVEY TO TEACHERS AT \\ PARTICIPATING SCHOOL SITES}




\section{SCRIPT TO ADMINISTER SURVEY}

1. Good moming / afternoon, my name is Mark Remy. I am a teacher in SDUSD and a doctoral student at USD. This is Carmen. She will be helping me today. Thank you for agreeing to participate in my study.

2. Since time is precious and I know you have other things to do, I am going to get started. Carmen and I will hand out the Survey packets and pencils now. Please do not start; I want to go over them first. (HAND-OUT SURVEY PACKETS \& PENCILS)

3. The first form is an informed-consent form and it is required by USD.

A. It acknowledges that I am conducting research and you are participating.

B. The research records will be kept confidential. Your name, your principal's name or school name are never requested nor ever included in my findings.

C. Data is looked at only as a group. I am surveying 30 schools.

D. If you have any questions or concerns you may call me or my dissertation chair. All numbers are on the form and you'll receive a copy for your records.

E. You sign on the first line "Signature of Subject" and date it. (ANY QUESTIONS?)

4. Before you fill out the survey, I am going to read the directions. 
5. First of all, please remove the informed-consent form and the scantron sheet from the survey packet. All answers will be recorded on the scantron and please use the pencil provided.

\section{(HOLD-UP SCANTRON SHEET)}

6. There are three sections to the survey.

7. The first is on leadership styles. Please go to page 1. I am going to start reading from the top paragraph. You may follow as I read or just listen.

Below is a list of items that may be used to describe the behavior of your principal. Each item describes a specific kind of behavior but does not ask you to judge whether the behavior is desirable or undesirable. This is not a test of ability. It simply asks you to describe, as accurately as you can, the behavior of your principal.

The term "group" refers to the elementary school staff.

The term "members" refers to the teachers.

Directions: Read each item carefully. Think about how frequently your principal engages in the behavior described by the item. Decide whether s/he always, often, occasionally, seldom or never acts as described by the item. Fill in the space on the scantron sheet for one of the five letters to show the answer you have selected. The rating scale is shown at the top of each page.

\section{(ANY QUESTIONS?)}

8. The second section is on teacher concerns. Please go to page 3. I am going to start reading from where it says "Directions." You may follow as I read or just listen.

Directions: The following are a number of teacher concerns.

1) Please identify those factors which cause you stress in your present position.

2) Read each statement carefully and decide if you ever feel this way about your job.

3) Then, indicate how strong the feeling is when you experience it by selecting the appropriate letter on the 5-point scale. 
If you have not experienced this feeling, or if the item is inappropriate for your position, fill in "A" on the scantron sheet (no strength; not noticeable). The rating scale is shown at the top of each page.

Please remember that you are stating HOW STRONGLY YOU FEEL about each statement on the 2nd section of the survey. Choice " $A$ " is not having experienced that feeling, and choice 'E" would be the opposite end of the scale feeling very strongly about that statement.

9. The last part is a demographic information sheet and is self explanatory.

10. When you complete the survey please, bring the signed informed-consent form, the survey and the scantron sheet to this table. We'll collect them and give you a copy of the informed-consent form for your records. Once again, thank you for helping me complete my doctorate.

11. If there are no questions... Please begin 
APPENDIX K

SUBSCALES SCORES OF TEACHER STRESS INVENTORY AND LEADER BEFAVIOR DESCRIPTION QUESTIONNAIRE IN TABULAR FORM FOR OVERALL SAMPLE OF 28 SCHOOLS, STRATUM I, STRATUM $\Pi$, STRATUM II, AND INDIVIDUAL SCHOOLS 
Teacher Stress Inventory: Overall Subscale Means from Least Stress Producing Subscale to Greatest Stress Producing Subscale for the Overall Sample - 28 Schools - (n=585) with LBDQ Scores for Comparison

\begin{tabular}{lllll}
\hline Variable & Mean & Std Dev & Minimum & Maximum \\
\hline & & & & \\
Behavioral Manifestations & 1.47 & .62 & 1.00 & 4.75 \\
Gastronomical Manifestations & 1.62 & .94 & 1.00 & 5.00 \\
Cardiovascular Manifestations & 1.88 & .96 & 1.00 & 5.00 \\
Professional Investment & 2.14 & .85 & 1.00 & 5.00 \\
TSI Total Stress Score & $\mathbf{2 . 4 1}$ & .56 & 1.27 & 4.46 \\
Fatigue Manifestations & 2.45 & .97 & 1.00 & 5.00 \\
Professional Distress & 2.52 & 1.01 & 1.00 & 5.00 \\
Emotional Manifestations & 2.60 & 1.01 & 1.00 & 5.00 \\
Discipline \& Motivation & 2.64 & 1.03 & 1.00 & 5.00 \\
Time Management & 3.35 & .70 & 1.25 & 5.00 \\
Work-related Stressors & 3.44 & .87 & 1.00 & 5.00 \\
Initiating Structure & 39.22 & 7.56 & 10.00 & 60.00 \\
Consideration & 42.05 & 8.81 & 14.00 & 58.00
\end{tabular}

Teacher Stress Inventory: Overall Subscale Means from Least Stress Producing Subscale to Greatest Stress Producing Subscale for the 12 Schools in Stratum I $(n=156)$ with LBDQ Scores for Comparison

\begin{tabular}{lllll}
\hline Variable & Mean & Std Dev & Minimum & Maximum \\
\hline Behavioral Manifestations & 1.52 & .69 & & \\
Gastronomical Manifestations & 1.63 & .98 & 1.00 & 4.00 \\
Cardiovascular Manifestations & 1.95 & .98 & 1.00 & 5.00 \\
Professional Investment & 2.26 & .94 & 1.00 & 5.00 \\
TSI Total Stress Score & $\mathbf{2 . 4 7}$ & $\mathbf{. 5 8}$ & 1.29 & 5.00 \\
Fatigue Manifestations & 2.50 & 1.02 & 1.00 & $\mathbf{4 . 4 5}$ \\
Emotional Manifestations & 2.64 & .97 & 1.00 & 5.00 \\
Professional Distress & 2.65 & 1.08 & 1.00 & 5.00 \\
Discipline \& Motivation & 2.69 & 1.02 & 1.00 & 5.00 \\
Time Management & 3.36 & .73 & 1.25 & 5.00 \\
Work-related Stressors & 3.46 & .88 & 1.00 & 5.00 \\
Initiating Structure & 37.85 & 8.95 & 10.00 & 5.00 \\
Consideration & 40.12 & 9.84 & 14.00 & 50.00 \\
\end{tabular}


Teacher Stress Inventory: Overall Subscale Means from Least Stress Producing Subscale to Greatest Stress Producing Subscale for the 9 Schools in Stratum II $(n=212)$ with LBDQ Scores for Comparison

\begin{tabular}{lllll}
\hline Variable & Mean & Std Dev & Minimum & Maximum \\
\hline Behavioral Manifestations & 1.42 & .55 & 1.00 & 4.75 \\
Gastronomical Manifestations & 1.57 & .84 & 1.00 & 5.00 \\
Cardiovascular Manifestations & 1.80 & .91 & 1.00 & 5.00 \\
Professional Investment & 2.01 & .77 & 1.00 & 4.50 \\
TSI Total Stress Score & $\mathbf{2 . 3 5}$ & $\mathbf{. 5 2}$ & $\mathbf{1 . 2 8}$ & $\mathbf{3 . 7 2}$ \\
Fatigue Manifestations & 2.38 & .89 & 1.00 & 5.00 \\
Professional Distress & 2.47 & .96 & 1.00 & 5.00 \\
Emotional Manifestations & 2.51 & 1.00 & 1.00 & 5.00 \\
Discipline \& Motivation & 2.58 & 1.04 & 1.00 & 5.00 \\
Time Management & 3.33 & .69 & 1.25 & 5.00 \\
Work-related Stressors & 3.42 & .88 & 1.17 & 5.00 \\
Initiating Structure & 39.83 & 6.71 & 22.00 & 56.00 \\
Consideration & 43.33 & 8.64 & 20.00 & 58.00
\end{tabular}

Teacher Stress Inventory: Overall Subscale Means from Least Stress Producing Subscale to Greatest Stress Producing Subscale for the 7 Schools in Stratum III ( $r=217$ ) with LBDQ Scores for Comparison

\begin{tabular}{lllll}
\hline Variable & Mean & Std Dev & Minimum & Maximum \\
\hline Behavioral Manifestations & 1.47 & .63 & & \\
Gastronomical Manifestations & 1.66 & 1.00 & 1.00 & 4.50 \\
Cardiovascular Manifestations & 1.90 & .99 & 1.00 & 5.00 \\
Professional Investment & 2.18 & .85 & 1.00 & 5.00 \\
TSI Total Stress Score & $\mathbf{2 . 4 3}$ & $\mathbf{. 5 9}$ & $\mathbf{1 . 2 7}$ & 4.50 \\
Professional Distress & 2.47 & .99 & 1.00 & 5.00 \\
Fatigue Manifestations & 2.48 & 1.00 & 1.00 & 5.00 \\
Emotional Manifestations & 2.64 & 1.06 & 1.00 & 5.00 \\
Discipline \& Motivation & 2.66 & 1.03 & 1.00 & 5.00 \\
Time Management & 3.35 & .69 & 1.63 & 4.88 \\
Work-related Stressors & 3.45 & .85 & 1.17 & 5.00 \\
Initiating Structure & 39.60 & 7.16 & 15.00 & 57.00 \\
Consideration & 42.07 & 7.94 & 21.00 & 58.00
\end{tabular}


Teacher Stress Inventory: Subscale Means from Least Stress Producing Subscale to Greatest Stress Producing Subscale for All 12 Schools in Stratum I ( $n=156)$ with LBDQ Scores for Comparison (All Schools Listed Individually by Randomly Assigned Identification Numbers)

\begin{tabular}{|c|c|c|c|c|}
\hline Variable & Mean & Std Dev & Minimum & Maxin \\
\hline \multicolumn{5}{|l|}{ School 1: $(n=16)$} \\
\hline Behavioral Manifestations & 1.25 & .27 & 1.00 & 1.75 \\
\hline Gastronomical Manifestations & 1.38 & .83 & 1.00 & 4.33 \\
\hline Cardiovascular Manifestations & 2.15 & 1.15 & 1.00 & 5.00 \\
\hline Professional Investment & 2.16 & .97 & 1.00 & 4.50 \\
\hline Professional Distress & 2.16 & .95 & 1.00 & 4.20 \\
\hline TSI Total Stress Score & 2.33 & .50 & 1.54 & 3.33 \\
\hline Fatigue Manifestations & 2.46 & 1.06 & 1.20 & 4.60 \\
\hline Emotional Manifestations & 2.56 & .99 & 1.40 & 4.40 \\
\hline Discipline \& Motivation & 2.70 & .75 & 1.33 & 3.50 \\
\hline Work-related Stressors & 3.24 & .66 & 2.00 & 4.00 \\
\hline Time Management & 3.27 & .66 & 1.75 & 4.25 \\
\hline Consideration & 43.25 & 6.13 & 34.00 & 56.00 \\
\hline Initiating Structure & 44.25 & 5.79 & 31.00 & 53.00 \\
\hline \multicolumn{5}{|l|}{ School 4: $(n=12)$} \\
\hline Behavioral Manifestations & 1.94 & .86 & 1.00 & 4.00 \\
\hline Gastronomical Manifestations & 1.97 & 1.11 & 1.00 & 4.67 \\
\hline Cardiovascular Manifestations & 2.19 & 1.12 & 1.00 & 4.00 \\
\hline Professional Investment & 2.23 & .69 & 1.50 & 3.50 \\
\hline Professional Distress & 2.33 & .84 & 1.00 & 3.80 \\
\hline TSI Total Stress Score & 2.52 & .36 & 1.92 & 3.06 \\
\hline Discipline \& Motivation & 2.60 & 1.05 & 1.00 & 4.33 \\
\hline Fatigue Manifestations & 2.65 & .56 & 1.60 & 3.60 \\
\hline Emotional Manifestations & 2.88 & .89 & 1.00 & 4.00 \\
\hline Time Management & 2.97 & .67 & 1.25 & 4.00 \\
\hline Work-related Stressors & 3.42 & .60 & 2.50 & 4.33 \\
\hline Initiating Structure & 28.58 & 9.89 & 15.00 & 45.00 \\
\hline Consideration & 37.58 & 10.08 & 26.00 & 57.00 \\
\hline
\end{tabular}


Teacher Stress Inventory: Subscale Means from Least Stress Producing Subscale to Greatest Stress Producing Subscale for All 12 Schools in Stratum I ( $n=156)$ with LBDQ Scores for Comparison (All Schools Listed Individually by Randomly Assigned Identification Numbers)

\begin{tabular}{|c|c|c|c|c|}
\hline Variable & Mean & Std Dev & Minimum & Maxim \\
\hline \multicolumn{5}{|l|}{ School 12: $(n=16)$} \\
\hline Behavioral Manifestations & 1.77 & .89 & 1.00 & 4.00 \\
\hline Cardiovascular Manifestations & 1.92 & 1.11 & 1.00 & 5.00 \\
\hline Professional Investment & 2.05 & .61 & 1.00 & 3.25 \\
\hline Gastronomical Manifestations & 2.15 & 1.49 & 1.00 & 5.00 \\
\hline Fatigue Manifestations & 2.36 & 1.11 & 1.20 & 5.00 \\
\hline TSI Total Stress Score & 2.60 & .77 & 1.51 & 4.45 \\
\hline Emotional Manifestations & 2.81 & 1.02 & 1.60 & 5.00 \\
\hline Professional Distress & 2.91 & 1.21 & 1.00 & 5.00 \\
\hline Discipline \& Motivation & 3.06 & 1.15 & 1.17 & 5.00 \\
\hline Time Management & 3.48 & .58 & 2.50 & 4.63 \\
\hline Work-related Stressors & 3.49 & 1.05 & 1.50 & 4.83 \\
\hline Initiating Structure & 40.81 & 5.97 & 27.00 & 52.00 \\
\hline Consideration & 43.69 & 10.28 & 18.00 & 55.00 \\
\hline \multicolumn{5}{|l|}{ School 13: $(n=8)$} \\
\hline Behavioral Manifestations & 1.25 & .44 & 1.00 & 2.25 \\
\hline Cardiovascular Manifestations & 1.58 & .81 & 1.00 & 3.00 \\
\hline Gastronomical Manifestations & 1.83 & 1.17 & 1.00 & 4.00 \\
\hline Professional Investment & 2.16 & 1.06 & 1.00 & 3.75 \\
\hline Fatigue Manifestations & 2.25 & .74 & 1.00 & 3.40 \\
\hline TSI Total Stress Score & 2.48 & .57 & 1.59 & 3.23 \\
\hline Emotional Manifestations & 2.58 & 1.09 & 1.00 & 4.00 \\
\hline Discipline \& Motivation & 2.81 & 1.29 & 1.33 & 4.83 \\
\hline Professional Distress & 3.18 & 1.24 & 1.80 & 5.00 \\
\hline Work-related Stressors & 3.38 & .93 & 1.50 & 4.33 \\
\hline Time Management & 3.81 & .52 & 2.63 & 4.25 \\
\hline Initiating Structure & 26.75 & 9.07 & 10.00 & 38.00 \\
\hline Consideration & 29.13 & 8.66 & 20.00 & 48.00 \\
\hline
\end{tabular}


Teacher Stress Inventory: Subscale Means from Least Stress Producing Subscale to Greatest Stress Producing Subscale for All 12 Schools in Stratum I ( $n=156)$ with LBDQ Scores for Comparison (All Schools Listed Individually by Randomly Assigned Identification Numbers)

\begin{tabular}{lllll}
\hline Variable & Mean & Std Dev & Minimum & Maximun \\
\hline & & & & \\
School 15: ( $\boldsymbol{n}=$ ) & & & & \\
Behavioral Manifestations & 1.39 & .73 & 1.00 & 3.00 \\
Gastronomical Manifestations & 1.71 & .89 & 1.00 & 3.33 \\
Cardiovascular Manifestations & 1.86 & 1.05 & 1.00 & 3.33 \\
Professional Investment & 2.36 & 1.12 & 1.00 & 4.00 \\
Professional Distress & 2.37 & .92 & 1.40 & 4.00 \\
TSI Total Stress Score & $\mathbf{2 . 4 0}$ & .77 & 1.50 & 3.47 \\
Fatigue Manifestations & 2.43 & .86 & 1.40 & 4.00 \\
Emotional Manifestations & 2.51 & .72 & 1.60 & 3.60 \\
Discipline \& Motivation & 2.69 & .94 & 1.50 & 4.17 \\
Work-related Stressors & 3.33 & 1.29 & 1.33 & 4.83 \\
Time Management & 3.34 & .95 & 2.13 & 4.50 \\
Initiating Structure & 37.57 & 5.44 & 29.00 & 44.00 \\
Consideration & 45.29 & 4.23 & 39.00 & 51.00 \\
& & & & \\
School 16: (n=19) & & & & \\
Behavioral Manifestations & 1.36 & .47 & 1.00 & 2.50 \\
Gastronomical Manifestations & 1.42 & .74 & 1.00 & 3.33 \\
Cardiovascular Manifestations & 1.96 & .90 & 1.00 & 3.67 \\
Professional Investment & 2.16 & .87 & 1.25 & 4.25 \\
Fatigue Manifestations & 2.34 & 1.04 & 1.00 & 4.60 \\
Discipline \& Motivation & 2.35 & 1.15 & 1.00 & 4.83 \\
TSI Total Stress Score & $\mathbf{2 . 3 6}$ & .64 & 1.51 & 3.74 \\
Professional Distress & 2.37 & 1.06 & 1.00 & 4.60 \\
Emotional Manifestations & 2.59 & .92 & 1.20 & 4.20 \\
Time Management & 3.49 & .79 & 2.25 & 5.00 \\
Work-related Stressors & 3.54 & .96 & 2.00 & 5.00 \\
Consideration & 41.21 & 8.77 & 26.00 & 53.00 \\
Initiating Structure & 47.58 & 6.27 & 34.00 & 60.00
\end{tabular}


Teacher Stress Irventory: Subscale Means from Least Stress Producing Subscale to Greatest Stress Producing Subscale for All 12 Schools in Stratum I ( $n=156)$ with LBDQ Scores for Comparison (All Schools Listed Individually by Randomly Assigned Identification Numbers)

\begin{tabular}{lllll}
\hline Variable & Mean & Std Dev & Minimum & Maxim \\
\hline & & & & \\
School 20: (n=14) & & & & \\
Behavioral Manifestations & 1.61 & .84 & 1.00 & 3.75 \\
Gastronomical Manifestations & 1.71 & .98 & 1.00 & 3.67 \\
Cardiovascular Manifestations & 2.12 & .98 & 1.00 & 4.00 \\
Professional Investment & 2.59 & .85 & 1.00 & 4.25 \\
Emotional Manifestations & 2.63 & .78 & 1.00 & 3.80 \\
Fatigue Manifestations & 2.67 & 1.12 & 1.20 & 5.00 \\
TSI Total Stress Score & $\mathbf{2 . 7 7}$ & .52 & 1.59 & 3.50 \\
Discipline \& Motivation & 3.24 & .88 & 1.50 & 4.67 \\
Professional Distress & 3.59 & 1.05 & 1.40 & 5.00 \\
Work-related Stressors & 3.76 & 1.12 & 1.00 & 5.00 \\
Time Management & 3.81 & 1.03 & 1.63 & 5.00 \\
Consideration & 33.79 & 9.54 & 15.00 & 50.00 \\
Initiating Structure & 34.29 & 4.83 & 26.00 & 42.00 \\
& & & & \\
& & & & \\
School 21: (n=13) & & & & \\
Gastronomical Manifestations & 1.33 & .49 & 1.00 & 2.33 \\
Behavioral Manifestations & 1.77 & .91 & 1.00 & 3.50 \\
Cardiovascular Manifestations & 1.82 & 1.00 & 1.00 & 4.33 \\
TSI Total Stress Score & $\mathbf{2 . 4 3}$ &. $\mathbf{4 1}$ & $\mathbf{1 . 7 4}$ & $\mathbf{3 . 0 1}$ \\
Professional Investment & 2.46 & 1.01 & 1.00 & 4.00 \\
Emotional Manifestations & 2.46 & .92 & 1.00 & 4.20 \\
Fatigue Manifestations & 2.48 & 1.10 & 1.00 & 4.20 \\
Professional Distress & 2.62 & .74 & 1.60 & 4.60 \\
Discipline \& Motivation & 2.64 & 1.03 & 1.50 & 4.50 \\
Time Management & 3.13 & .63 & 1.88 & 4.00 \\
Work-related Stressors & 3.55 & .55 & 3.00 & 4.83 \\
Initiating Structure & 31.08 & 6.59 & 22.00 & 44.00 \\
Consideration & 35.00 & 10.29 & 14.00 & 49.00
\end{tabular}


Teacher Stress Inventory: Subscale Means from Least Stress Producing Subscale to Greatest Stress Producing Subscale for All 12 Schools in Stratum I ( $n=150)$ with LBDQ Scores for Comparison (All Schools Listed Individually by Randomly Assigned Identification Numbers)

\begin{tabular}{|c|c|c|c|c|}
\hline Variable & Mean & Std Dev & Minimum & Maximum \\
\hline \multicolumn{5}{|l|}{ School 22: $(n=12)$} \\
\hline Gastronomical Manifestations & 1.28 & .53 & 1.00 & 2.67 \\
\hline Behavioral Manifestations & 1.54 & .44 & 1.00 & 2.00 \\
\hline Cardiovascular Manifestations & 1.81 & 1.09 & 1.00 & 4.67 \\
\hline Professional Investment & 1.85 & .74 & 1.00 & 3.75 \\
\hline Discipline \& Motivation & 2.22 & .98 & 1.17 & 4.00 \\
\hline TSI Total Stress Score & 2.30 & .56 & 1.29 & 3.06 \\
\hline Fatigue Manifestations & 2.45 & 1.11 & 1.20 & 4.60 \\
\hline Professional Distress & 2.48 & 1.31 & 1.00 & 5.00 \\
\hline Emotional Manifestations & 2.55 & 1.19 & 1.00 & 4.40 \\
\hline Work-related Stressors & 3.35 & .72 & 2.00 & 4.33 \\
\hline Time Management & 3.43 & .78 & 1.75 & 4.50 \\
\hline Initiating Structure & 35.75 & 8.08 & 18.00 & 47.00 \\
\hline Consideration & 44.75 & 6.93 & 33.00 & 54.00 \\
\hline \multicolumn{5}{|l|}{ School 24: $(n=14)$} \\
\hline Gastronomical Manifestations & 1.55 & 1.11 & 1.00 & 5.00 \\
\hline Behavioral Manifestations & 1.55 & .85 & 1.00 & 3.50 \\
\hline Professional Investment & 1.80 & .84 & 1.00 & 3.25 \\
\hline Cardiovascular Manifestations & 1.88 & .81 & 1.00 & 3.33 \\
\hline Professional Distress & 2.19 & .91 & 1.00 & 4.00 \\
\hline Discipline \& Motivation & 2.30 & .69 & 1.33 & 3.50 \\
\hline TSI Total Stress Score & 2.32 & .71 & 1.50 & 3.58 \\
\hline Fatigue Manifestations & 2.64 & 1.33 & 1.20 & 5.00 \\
\hline Emotional Manifestations & 2.73 & 1.27 & 1.00 & 5.00 \\
\hline Time Management & 3.12 & .66 & 2.13 & 4.50 \\
\hline Work-related Stressors & 3.40 & 1.08 & 1.00 & 5.00 \\
\hline Initiating Structure & 42.43 & 5.03 & 31.00 & 53.00 \\
\hline Consideration & 45.71 & 7.92 & 31.00 & 55.00 \\
\hline
\end{tabular}


Teacher Stress Inventory: Subscale Means from Least Stress Producing Subscale to Greatest Stress Producing Subscale for All 12 Schools in Stratum I $(n=156$ ) with LBDQ Scores for Comparison (All Schools Listed Individually by Randomly Assigned Identification Numbers)

\begin{tabular}{lllll}
\hline Variable & Mean & Std Dev & Minimum & Maxim \\
\hline & & & & \\
School 26: ( $\boldsymbol{n}=\mathbf{1 2})$ & & & & \\
Behavioral Manifestations & 1.15 & .25 & 1.00 & 1.75 \\
Gastronomical Manifestations & 1.64 & .87 & 1.00 & 3.00 \\
Cardiovascular Manifestations & 1.78 & .88 & 1.00 & 4.00 \\
Emotional Manifestations & 2.20 & .69 & 1.60 & 3.80 \\
Fatigue Manifestations & 2.28 & 1.04 & 1.00 & 4.60 \\
TSI Total Stress Score & $\mathbf{2 . 4 2}$ & $\mathbf{. 4 8}$ & $\mathbf{1 . 5 8}$ & $\mathbf{3 . 2 1}$ \\
Professional Investment & 2.77 & 1.40 & 1.00 & 5.00 \\
Professional Distress & 2.88 & .83 & 1.40 & 4.20 \\
Discipline \& Motivation & 3.04 & 1.13 & 1.50 & 5.00 \\
Time Management & 3.08 & .71 & 2.25 & 4.13 \\
Work-related Stressors & 3.40 & 1.00 & 1.17 & 4.67 \\
Initiating Structure & 35.83 & 9.19 & 20.00 & 49.00 \\
Consideration & 37.75 & 12.77 & 15.00 & 52.00
\end{tabular}

School 27: $(n=13)$

Behavioral Manifestations $\quad 1.54$

Gastronomical Manifestations 1.79

.79
2.08

.65

1.00

2.75

Cardiovascular Manifestations 2.08

1.07

1.00

3.67

Professional Investment

2.63

.94

1.00

3.67

TSI Total Stress Score

2.67

Discipline \& Motivation

2.72

.96

1.00

4.00

Fatigue Manifestations

2.95

.54

1.83

3.52

Professional Distress

2.97

.99

1.00

3.83

.96

1.20

4.60

Emotional Manifestations

1.11

1.40

5.00

Time Management

3.11

Work-related Stressors

3.39

1.03

1.60

5.00

Initiating Structure

3.51

.44

2.50

4.00

.67

37.15

4.58

2.83

4.50

Consideration

40.38

8.43

33.00

48.00

24.00

54.00 
Teacher Stress Inventory: Subscale Means from Least Stress Producing Subscale to Greatest Stress Producing Subscale for All 9 Schools in Stratum II ( $n=212)$ with LBDQ Scores for Comparison (All Schools Listed Individually by Randomly Assigned Identification Numbers)

\begin{tabular}{lllll}
\hline Variable & Mean & Std Dev & Minimum & Maxim \\
\hline & & & & \\
School 3: (n=18) & & & & \\
Gastronomical Manifestations & 1.69 & .84 & 1.00 & 3.67 \\
Behavioral Manifestations & 1.86 & 1.04 & 1.00 & 4.75 \\
Cardiovascular Manifestations & 2.09 & 1.35 & 1.00 & 5.00 \\
Professional Investment & 2.14 & .83 & 1.00 & 3.50 \\
TSI Total Stress Score & $\mathbf{2 . 6 4}$ & $\mathbf{. 7 0}$ & $\mathbf{1 . 7 2}$ & $\mathbf{3 . 7 1}$ \\
Emotional Manifestations & 2.71 & 1.09 & 1.20 & 4.80 \\
Fatigue Manifestations & 2.72 & 1.25 & 1.00 & 5.00 \\
Professional Distress & 2.82 & .88 & 1.40 & 4.40 \\
Discipline \& Motivation & 3.01 & 1.18 & 1.17 & 5.00 \\
Time Management & 3.42 & .71 & 2.13 & 4.38 \\
Work-related Stressors & 3.97 & .99 & 1.17 & 5.00 \\
Initiating Structure & 38.50 & 5.85 & 29.00 & 52.00 \\
Consideration & 45.67 & 7.10 & 31.00 & 58.00 \\
& & & & \\
School 8: (n=27) & & & & \\
Behavioral Manifestations & 1.39 & .55 & 1.00 & 3.00 \\
Professional Investment & 1.76 & .79 & 1.00 & 3.50 \\
Gastronomical Manifestations & 1.78 & 1.00 & 1.00 & 4.33 \\
Cardiovascular Manifestations & 1.89 & .82 & 1.00 & 3.67 \\
Fatigue Manifestations & 2.07 & .63 & 1.00 & 3.60 \\
TSI Total Stress Score & $\mathbf{2 . 3 0}$ & $\mathbf{. 5 7}$ & $\mathbf{1 . 2 8}$ & $\mathbf{3 . 4 8}$ \\
Discipline \& Motivation & 2.33 & 1.15 & 1.00 & 4.50 \\
Emotional Manifestations & 2.36 & .83 & 1.00 & 4.20 \\
Professional Distress & 2.59 & 1.16 & 1.20 & 4.80 \\
Time Management & 3.23 & .82 & 1.25 & 4.75 \\
Work-related Stressors & 3.56 & .96 & 1.67 & 5.00 \\
Initiating Structure & 44.04 & 5.55 & 34.00 & 54.00 \\
Consideration & 45.11 & 8.23 & 26.00 & 58.00
\end{tabular}


Teacher Stress Inventory: Subscale Means from Least Stress Producing Subscale to Greatest Stress Producing Subscale for All 9 Schools in Stratum $\amalg(n=212)$ with LBDQ Scores for Comparison (All Schools Listed Individually by Randomly Assigned Identification Numbers)

\begin{tabular}{lllll}
\hline Variable & Mean & Std Dev & Minimum & Maximur \\
\hline & & & & \\
School 10: (n=24) & & & & \\
Behavioral Manifestations & 1.30 & .41 & 1.00 & 2.50 \\
Gastronomical Manifestations & 1.64 & 1.19 & 1.00 & 5.00 \\
Professional Investment & 1.84 & .61 & 1.00 & 2.75 \\
Cardiovascuiar Manifestations & 1.94 & 1.19 & 1.00 & 4.33 \\
Fatigue Manifestations & 2.24 & .83 & 1.00 & 4.20 \\
TSI Total Stress Score & $\mathbf{2 . 2 9}$ & .51 & 1.58 & 3.30 \\
Emotional Manifestations & 2.29 & 1.11 & 1.00 & 4.60 \\
Professional Distress & 2.38 & 1.07 & 1.00 & 5.00 \\
Discipline \& Motivation & 2.92 & 1.08 & 1.17 & 5.00 \\
Time Management & 3.12 & .65 & 2.25 & 4.75 \\
Work-related Stressors & 3.23 & .90 & 1.83 & 5.00 \\
Consideration & 36.92 & 9.29 & 21.00 & 53.00 \\
Initiating Structure & 37.88 & 8.45 & 24.00 & 51.00 \\
& & & & \\
School 11: (n=25) & & & & \\
Behavioral Manifestations & 1.50 & .56 & 1.00 & 3.25 \\
Gastronomical Manifestations & 1.84 & 1.00 & 1.00 & 5.00 \\
Cardiovascular Manifestations & 1.96 & .98 & 1.00 & 5.00 \\
Professional Investment & 2.33 & .87 & 1.00 & 4.50 \\
TSI Total Stress Score & $\mathbf{2 . 6 2}$ & .56 & 1.64 & 3.72 \\
Professional Distress & 2.68 & 1.12 & 1.00 & 5.00 \\
Fatigue Manifestations & 2.69 & 1.04 & 1.20 & 5.00 \\
Discipline \& Motivation & 2.89 & 1.10 & 1.00 & 5.00 \\
Emotional Manifestations & 2.93 & 1.24 & 1.00 & 5.00 \\
Time Management & 3.55 & .74 & 2.50 & 5.00 \\
Work-related Stressors & 3.84 & .82 & 2.00 & 5.00 \\
Consideration & 42.32 & 8.01 & 25.00 & 58.00 \\
Initiating Structure & 44.24 & 6.48 & 29.00 & 55.00
\end{tabular}


Teacher Stress Inventory: Subscale Means from Least Stress Producing Subscale to Greatest Stress Producing Subscale for All 9 Schools in Stratum II ( $n=212)$ with LBDQ Scores for Comparison (All Schools Listed Individually by Randomly Assigned Identification Numbers)

\begin{tabular}{|c|c|c|c|c|}
\hline Variable & Mean & Std Dev & Minimum & Maximum \\
\hline \multicolumn{5}{|l|}{ School 14: $(n=25)$} \\
\hline Behavioral Manifestations & 1.46 & .49 & 1.00 & 2.50 \\
\hline Gastronomical Manifestations & 1.51 & .61 & 1.00 & 3.00 \\
\hline Professional Investment & 1.74 & .62 & 1.00 & 2.75 \\
\hline Cardiovascular Manifestations & 1.81 & .65 & 1.00 & 3.00 \\
\hline Professional Distress & 2.24 & .89 & 1.00 & 4.20 \\
\hline TSI Total Stress Score & 2.24 & .43 & 1.50 & 3.06 \\
\hline Fatigue Manifestations & 2.28 & .59 & 1.00 & 3.40 \\
\hline Discipline \& Motivation & 2.33 & .81 & 1.00 & 4.17 \\
\hline Emotional Manifestations & 2.51 & .75 & 1.20 & 4.00 \\
\hline Work-related Stressors & 3.17 & .90 & 1.33 & 4.67 \\
\hline Time Management & 3.39 & .63 & 1.88 & 4.38 \\
\hline Initiating Structure & 39.80 & 5.94 & 31.00 & 54.00 \\
\hline Consideration & 45.92 & 5.90 & 32.00 & 55.00 \\
\hline \multicolumn{5}{|l|}{ School 18: $(n=26)$} \\
\hline Behavioral Manifestations & 1.26 & .32 & 1.00 & 2.00 \\
\hline Cardiovascular Manifestations & 1.36 & .60 & 1.00 & 3.33 \\
\hline Gastronomical Manifestations & 1.49 & .71 & 1.00 & 3.33 \\
\hline Professional Investment & 2.04 & .77 & 1.00 & 3.50 \\
\hline TSI Total Stress Score & 2.20 & .41 & 1.48 & 2.97 \\
\hline Professional Distress & 2.31 & .90 & 1.00 & 4.20 \\
\hline Emotional Manifestations & 2.32 & .99 & 1.00 & 5.00 \\
\hline Fatigue Manifestations & 2.32 & .93 & 1.00 & 4.20 \\
\hline Discipline \& Motivation & 2.64 & .80 & 1.00 & 4.33 \\
\hline Work-related Stressors & 3.04 & .86 & 1.67 & 4.67 \\
\hline Time Management & 3.21 & .72 & 1.75 & 4.50 \\
\hline Initiating Structure & 35.42 & 5.71 & 29.00 & 49.00 \\
\hline Consideration & 41.65 & 9.70 & 24.00 & 56.00 \\
\hline
\end{tabular}


Teacher Stress Inventory: Subscale Means from Least Stress Producing Subscale to Greatest Stress Producing Subscale for All 9 Schools in Stratum I ( $n=212)$ with LBDQ Scores for Comparison (All Schools Listed Individually by Randomly Assigned Identification Numbers)

\begin{tabular}{lllll}
\hline Variable & Mean & Std Dev & Minimum & Maximur \\
\hline & & & & \\
School 23: (n=21) & & & & \\
Gastronomical Manifestations & 1.17 & .36 & 1.00 & 2.00 \\
Behavioral Manifestations & 1.54 & .48 & 1.00 & 3.25 \\
Cardiovascular Manifestations & 1.75 & .84 & 1.00 & 3.67 \\
Professional Investment & 2.11 & .81 & 1.00 & 3.75 \\
TSI Total Stress Score & $\mathbf{2 . 3 1}$ & .51 & 1.39 & $\mathbf{3 . 2 1}$ \\
Professional Distress & 2.39 & .91 & 1.00 & 3.80 \\
Emotional Manifestations & 2.41 & .97 & 1.00 & 4.00 \\
Fatigue Manifestations & 2.55 & .90 & 1.00 & 4.40 \\
Discipline \& Motivation & 2.72 & 1.22 & 1.00 & 4.83 \\
Work-related Stressors & 3.23 & .88 & 1.50 & 5.00 \\
Time Management & 3.27 & .66 & 1.38 & 4.13 \\
Initiating Structure & 38.76 & 3.60 & 33.00 & 48.00 \\
Consideration & 47.14 & 6.16 & 33.00 & 57.00
\end{tabular}

School 25: $(n=21)$

$\begin{array}{lllll}\text { Behavioral Manifestations } & 1.13 & .25 & 1.00 & 2.00 \\ \text { Gastronomical Manifestations } & 1.19 & .37 & 1.00 & 2.33 \\ \text { Cardiovascular Manifestations } & 1.52 & .71 & 1.00 & 3.67 \\ \text { Discipline \& Motivation } & 1.83 & .70 & 1.00 & 3.17 \\ \text { Professional Investment } & 1.90 & .70 & 1.00 & 3.75 \\ \text { TSI Total Stress Score } & \mathbf{2 . 1 8} & .39 & 1.46 & \mathbf{2 . 8 6} \\ \text { Fatigue Manifestations } & 2.31 & 1.01 & 1.00 & 4.40 \\ \text { Professional Distress } & 2.40 & .81 & 1.20 & 4.00 \\ \text { Emotional Manifestations } & 2.70 & 1.16 & 1.00 & 5.00 \\ \text { Work-related Stressors } & 3.33 & .61 & 2.33 & 4.83 \\ \text { Time Management } & 3.49 & .75 & 2.25 & 4.63 \\ \text { Initiating Structure } & 36.24 & 6.59 & 22.00 & 48.00 \\ \text { Consideration } & 48.29 & 6.17 & 34.00 & 58.00\end{array}$


Teacher Stress Inventory: Subscale Means from Least Stress Producing Subscale to Greatest Stress Producing Subscale for All 9 Schools in Stratum II $(n=212)$ with LBDQ Scores for Comparison (All Schools Listed Individually by Randomly Assigned Identification Numbers)

\begin{tabular}{lllll}
\hline Variable & Mean & Std Dev & Minimum & Maxim \\
\hline & & & & \\
School 28: $(\boldsymbol{n}=\mathbf{2 5})$ & & & & \\
Behavioral Manifestations & 1.48 & .48 & 1.00 & 2.50 \\
Gastronomical Manifestations & 1.71 & .86 & 1.00 & 4.33 \\
Cardiovascular Manifestations & 1.88 & .89 & 1.00 & 4.33 \\
Professional Investment & 2.25 & .77 & 1.00 & 4.00 \\
Fatigue Manifestations & 2.35 & .76 & 1.00 & 4.60 \\
TSI Total Stress Score & 2.40 & .40 & 1.78 & 3.39 \\
Professional Distress & 2.46 & .79 & 1.00 & 3.60 \\
Emotional Manifestations & 2.46 & .75 & 1.00 & 3.60 \\
Discipline \& Motivation & 2.60 & .89 & 1.00 & 4.67 \\
Time Management & 3.38 & .48 & 2.63 & 4.25 \\
Work-related Stressors & 3.48 & .61 & 2.33 & 4.83 \\
Consideration & 38.64 & 9.30 & 20.00 & 58.00 \\
Initiating Structure & 42.28 & 5.14 & 30.00 & 56.00
\end{tabular}


Teacher Stress Inventory: Subscale Means from Least Stress Producing Subscale to Greatest Stress Producing Subscale for All 12 Schools in Stratum III ( $n=217)$ with LBDQ Scores for Comparison (All Schools Listed Individually by Randomly Assigned Identification Numbers)

\begin{tabular}{lllll}
\hline Variable & Mean & Std Dev & Minimum & Maxim \\
\hline & & & & \\
School 2: ( $\boldsymbol{n}=\mathbf{3 6}$ ) & & & & \\
Behavioral Manifestations & 1.65 & .75 & 1.00 & 3.75 \\
Gastronomical Manifestations & 1.89 & 1.15 & 1.00 & 5.00 \\
Cardiovascular Manifestations & 1.94 & .86 & 1.00 & 4.00 \\
Fatigue Manifestations & 2.26 & .98 & 1.00 & 4.60 \\
Professional Investment & 2.28 & .87 & 1.00 & 4.50 \\
TSI Total Stress Score & $\mathbf{2 . 4 2}$ & .57 & 1.27 & 3.67 \\
Professional Distress & 2.43 & .91 & 1.00 & 4.80 \\
Discipline \& Motivation & 2.63 & 1.12 & 1.00 & 5.00 \\
Emotional Manifestations & 2.67 & 1.02 & 1.00 & 4.80 \\
Work-related Stressors & 3.06 & .70 & 1.50 & 4.33 \\
Time Management & 3.39 & .56 & 2.25 & 4.38 \\
Initiating Structure & 32.97 & 8.35 & 15.00 & 47.00 \\
Consideration & 37.72 & 7.87 & 21.00 & 53.00 \\
& & & & \\
School 5: (n=32) & & & & \\
Behavioral Manifestations & 1.38 & .48 & 1.00 & 2.75 \\
Gastronomical Manifestations & 1.84 & 1.08 & 1.00 & 4.00 \\
Cardiovascular Manifestations & 1.90 & .91 & 1.00 & 4.00 \\
Professional Investment & 2.05 & .86 & 1.00 & 4.00 \\
TSI Total Stress Score & $\mathbf{2 . 4 0}$ & .57 & $\mathbf{1 . 4 8}$ & $\mathbf{3 . 7 5}$ \\
Professional Distress & 2.44 & 1.02 & 1.00 & 5.00 \\
Fatigue Manifestations & 2.53 & .93 & 1.00 & 4.60 \\
Discipline \& Motivation & 2.60 & .85 & 1.00 & 5.00 \\
Emotional Manifestations & 2.61 & 1.06 & 1.00 & 4.40 \\
Time Management & 3.27 & .59 & 2.25 & 4.75 \\
Work-related Stressors & 3.39 & .85 & 2.00 & 5.00 \\
Initiating Structure & 39.91 & 6.85 & 24.00 & 56.00 \\
Consideration & 45.00 & 7.91 & 21.00 & 58.00
\end{tabular}


Teacher Stress Inventory: Subscale Means from Least Stress Producing Subscale to Greatest Stress Producing Subscale for All 12 Schools in Stratum III ( $n=217$ ) with LBDQ Scores for Comparison (All Schools Listed Individually by Randomly Assigned Identification Numbers)

\begin{tabular}{lllll}
\hline Variable & Mean & Std Dev & Minimum & Maxinum \\
\hline School 6: $(\boldsymbol{n}=\mathbf{2 2})$ & & & & \\
Behavioral Manifestations & 1.56 & .65 & 1.00 & 3.00 \\
Gastronomical Manifestations & 1.62 & 1.07 & 1.00 & 5.00 \\
Cardiovascular Manifestations & 1.88 & 1.07 & 1.00 & 4.67 \\
Professional Investment & 2.15 & .73 & 1.00 & 3.50 \\
TSI Total Stress Score & $\mathbf{2 . 4 0}$ & $\mathbf{. 6 2}$ & $\mathbf{1 . 3 6}$ & $\mathbf{4 . 0 6}$ \\
Fatigue Manifestations & 2.46 & .93 & 1.00 & 4.20 \\
Professional Distress & 2.50 & 1.01 & 1.00 & 4.60 \\
Emotional Manifestations & 2.54 & 1.12 & 1.00 & 4.20 \\
Discipline \& Motivation & 2.73 & .91 & 1.00 & 4.67 \\
Time Management & 3.21 & .85 & 1.63 & 4.63 \\
Work-related Stressors & 3.39 & .95 & 1.17 & 5.00 \\
Initiating Structure & 41.00 & 5.49 & 30.00 & 52.00 \\
Consideration & 46.45 & 6.16 & 33.00 & 56.00
\end{tabular}

$\begin{array}{lllll}\text { School 7: }(\boldsymbol{n}=\mathbf{4 8}) & & & & \\ \text { Behavioral Manifestations } & 1.29 & .52 & 1.00 & 3.25 \\ \text { Gastronomical Manifestations } & 1.57 & 1.01 & 1.00 & 5.00 \\ \text { Cardiovascular Manifestations } & 1.90 & 1.09 & 1.00 & 5.00 \\ \text { Professional Investment } & 2.10 & .85 & 1.00 & 4.00 \\ \text { Fatigue Manifestations } & 2.28 & .99 & 1.00 & 4.80 \\ \text { TSI Total Stress Score } & \mathbf{2 . 3 7} & \mathbf{6 0} & 1.31 & \mathbf{4 . 0 4} \\ \text { Professional Distress } & 2.41 & 1.04 & 1.00 & 5.00 \\ \text { Emotional Manifestations } & 2.53 & 1.08 & 1.00 & 5.00 \\ \text { Discipline \& Motivation } & 2.70 & 1.05 & 1.00 & 4.83 \\ \text { Time Management } & 3.40 & .69 & 1.75 & 4.50 \\ \text { Work-related Stressors } & 3.56 & .90 & 1.33 & 5.00 \\ \text { Initiating Structure } & 41.15 & 5.32 & 29.00 & 52.00 \\ \text { Consideration } & 42.71 & 7.30 & 22.00 & 58.00\end{array}$


Teacher Stress Inventory: Subscale Means from Least Stress Producing Subscale to Greatest Stress Producing Subscale for All 12 Schools in Stratum III $(n=217)$ with LBDQ Scores for Comparison (All Schools Listed Individually by Randomly Assigned Identification Numbers)

\begin{tabular}{lllll}
\hline Variable & Mean & Std Dev & Minimum & Maxim \\
\hline School 9: $(\boldsymbol{n}=\mathbf{2 0})$ & & & & \\
Gastronomical Manifestations & 1.40 & .58 & 1.00 & 3.00 \\
Behavioral Manifestations & 1.56 & .67 & 1.00 & 3.50 \\
Cardiovascular Manifestations & 1.78 & .77 & 1.00 & 3.33 \\
Professional Investment & 2.06 & .84 & 1.00 & 4.25 \\
Discipline \& Motivation & 2.27 & .64 & 1.00 & 3.67 \\
Professional Distress & 2.31 & 1.05 & 1.00 & 4.20 \\
TSI Total Stress Score & $\mathbf{2 . 3 9}$ & $\mathbf{. 4 4}$ & $\mathbf{1 . 4 9}$ & $\mathbf{3 . 1 5}$ \\
Emotional Manifestations & 2.66 & .88 & 1.40 & 5.00 \\
Fatigue Manifestations & 2.69 & .80 & 1.40 & 4.00 \\
Time Management & 3.40 & .70 & 1.63 & 4.63 \\
Work-related Stressors & 3.73 & .76 & 1.83 & 5.00 \\
Consideration & 37.40 & 7.11 & 28.00 & 53.00 \\
Initiating Structure & 39.75 & 5.37 & 29.00 & 50.00
\end{tabular}

School 17: $(n=30)$

$\begin{array}{lllll}\text { Gastronomical Manifestations } & 1.52 & .98 & 1.00 & 5.00 \\ \text { Behavioral Manifestations } & 1.53 & .76 & 1.00 & 4.50 \\ \text { Cardiovascular Manifestations } & 1.89 & 1.08 & 1.00 & 5.00 \\ \text { Professional Investment } & 2.16 & .90 & 1.00 & 4.25 \\ \text { TSI Total Stress Score } & \mathbf{2 . 4 2} & .73 & 1.30 & \mathbf{4 . 4 6} \\ \text { Fatigue Manifestations } & 2.47 & 1.00 & 1.00 & 4.60 \\ \text { Discipline \& Motivation } & 2.48 & 1.01 & 1.00 & 4.33 \\ \text { Professional Distress } & 2.49 & 1.05 & 1.00 & 5.00 \\ \text { Emotional Manifestations } & 2.55 & 1.16 & 1.00 & 5.00 \\ \text { Time Management } & 3.45 & .85 & 1.88 & 4.88 \\ \text { Work-related Stressors } & 3.69 & .90 & 1.67 & 5.00 \\ \text { Consideration } & 41.67 & 8.15 & 25.00 & 54.00 \\ \text { Initiating Structure } & 43.10 & 6.26 & 29.00 & 57.00\end{array}$


Teacher Stress Inventory: Subscale Means from Least Stress Producing Subscale to Greatest Stress Producing Subscale for All 12 Schools in Stratum III ( $n=217$ ) with LBDQ Scores for Comparison (All Schools Listed Individually by Randomly Assigned Identification Numbers)

\begin{tabular}{lllll}
\hline Variable & Mean & Std Dev & Minimum & Maximun \\
\hline School 19: $(\boldsymbol{n}=\mathbf{2 9}$ ) & & & & \\
Behavioral Manifestations & 1.49 & .54 & 1.00 & 3.00 \\
Gastronomical Manifestations & 1.67 & .86 & 1.00 & 4.33 \\
Cardiovascular Manifestations & 2.00 & 1.12 & 1.00 & 4.67 \\
Professional Investment & 2.47 & .91 & 1.00 & 4.50 \\
TSI Total Stress Score & $\mathbf{2 . 6 2}$ & .56 & $\mathbf{1 . 8 2}$ & $\mathbf{4 . 1 3}$ \\
Professional Distress & 2.73 & .96 & 1.00 & 4.60 \\
Fatigue Manifestations & 2.93 & 1.17 & 1.00 & 5.00 \\
Emotional Manifestations & 2.99 & 1.06 & 1.20 & 5.00 \\
Discipline \& Motivation & 3.12 & 1.25 & 1.00 & 5.00 \\
Time Management & 3.31 & .64 & 2.00 & 4.38 \\
Work-related Stressors & 3.46 & .76 & 1.50 & 4.50 \\
Initiating Structure & 40.14 & 7.11 & 24.00 & 57.00 \\
Consideration & 43.52 & 7.11 & 25.00 & 56.00
\end{tabular}

